\title{
Single-Step Ironmaking from Ore to Improve Energy Efficiency
}

\section{Final Technical Report}

Report Period Start Date:

Report Period End Date:

Authors:

Date of Issue:

DOE Award Number:

Submitting Organization:
October 10, 2003

September 30, 2005
S. K. Kawatra - Principal Investigator

B. Anameric

T. C. Eisele

October 2005

DE-FG26-03NT41930

Department of Chemical Engineering

Michigan Technological University 1400 Townsend Drive Houghton, MI 49931 - 1295 


\section{DISCLAIMER:}

This report was prepared as an account of work sponsored by an agency of the United States Government. Neither the United States Government nor any agency thereof, nor any of their employees, makes any warranty, express or implied, or assumes any legal liability or responsibility for the accuracy, completeness, or usefulness of any information, apparatus, product, or process disclosed, or represents that its use would not infringe privately owned rights. Reference herein to any specific commercial product, process, or service by trade name, trademark, manufacturer, or otherwise does not necessarily constitute or imply its endorsement, recommendation, or favoring by the United States Government or any agency thereof. The views and opinions of authors expressed herein do not necessarily state or reflect those of the United States Government or any agency thereof. 


\begin{abstract}
The pig iron nugget process was developed as an alternative to the traditional blast furnace process by Kobe Steel. The process aimed to produce pig iron nuggets, which have similar chemical and physical properties to blast furnace pig iron, in a single step. The pig iron nugget process utilizes coal instead of coke and self reducing and fluxing dried green balls instead of pellets and sinters. In this process the environmental emissions caused by coke and sinter production, and energy lost between pellet induration (heat hardening) and transportation to the blast furnace can be eliminated. The objectives of this research were to (i) produce pig iron nuggets in the laboratory, (ii) characterize the pig iron nugget produced and compare them with blast furnace pig iron, (iii) investigate the furnace temperature and residence time effects on the pig iron nugget production, and (iv) optimize the operational furnace temperatures and residence times. The experiments involved heat treatment of self reducing and fluxing dried green balls at various furnace temperatures and residence times. Three chemically and physically different products were produced after the compete reduction of iron oxides to iron depending on the operational furnace temperatures and/ or residence times. These products were direct reduced iron (DRI), transition direct reduced iron (TDRI), and pig iron nuggets. The increase in the carbon content of the system as a function of furnace temperature and/ or residence time dictated the formation of these products. The direct reduced iron, transition direct reduced iron, and pig iron nuggets produced were analyzed for their chemical composition, degree of metallization, apparent density, microstructure and microhardness. In addition, the change in the carbon content of the system with the changing furnace temperature and/ or residence time was detected by optical microscopy and Microhardness measurements. The sufficient carbon dissolution required for the production of pig iron nuggets was determined. It was determined that pig iron nuggets produced had a high apparent density $(6.7-7.2 \mathrm{gr} / \mathrm{cm} 3)$, highly metallized, slag free structure, high iron content (95 - 97\%), high microhardness values (> $325 \mathrm{HVN}$ ) and microstructure similar to white cast iron. These properties made them a competitive alternative to blast furnace pig iron.
\end{abstract}




\title{
Table of Contents
}

\author{
Abstract \\ Table of Contents \\ List of Figures \\ List of Tables
}

Chapter 1 Introduction

Executive Summary

$-13-$

Chapter 2 Theoretical Background -15-

2.1 Pig Iron Nugget Process

2.1.1 Slag Separation Requirements and Iron - Iron Carbide Metastable System

2.2 White Cast Inon 
Chapter 3 Experimental -30-

3.1 Raw Materials -30-

3.2 Procedures -35-

3.2.1 Apparent D ensity Measurements -39-

3.2.2 O ptical Microscopy, Scanning Electron Microscopy, and X-ray Diffraction $\quad-40$ -

3.2.3 Chemical Analysis -41-

3.2.4 Microhardness Measurements -42-

Chapter 4 Results and Discussions

4.1 Products

4.1.1 Direct Reduced Iron (D RI) - -48-

4.1.2 Transition Direct Reduced Iron (TD RI) -49-

4.1.3 Pig Iron Nuggets $\quad$-50-

4.1.3.1 Chemical Analysis and D egree of Metallization -52-

4.1.4 Summary -Pig Iron Nuggets versus

Blast Furnace Pig Iron - 53- 


\subsection{Fumace Residence Time Effects on Pig Iron}

Nugget Production

4.2.1 O ptical Microscopy and Scanning Electron Microscopy - -58-

4.2.1.1 Direct Reduced Iron -58-

4.2.1.2 Pig Iron Nuggets

4.2.2 Microhardness Measurements -64-

4.2.3 Apparent D ensity Measurements -67-

4.3 Fumace Temperature Effects on

Pig Iron Nugget Production $\quad$-70-

4.3.1 Optical Microscopy - -70-

4.3.1.1 Direct Reduced Iron -70-

4.3.1.2 Pig Iron Nuggets

4.3.1.3 Interpretation of Pig Iron Nugget Microstructures

4.3.2 Microhardness Measurements -80- 


\subsection{Optimization of Operating Furnace Temperature and Residence Time for Pig iron}

Nugget Production

4.4.1 Identification of Phases and Micro constituents -83-

4.4.2 Microhardness Measurements -88-

4.4.3 Apparent D ensity Measurements -92-

4.4.4 Pig Iron Nugget Production Furnace Temperature and Residence Time Predictions $\quad$-94-

4.4.5 Summary of the Experimental Results -103-

Chapter 5 Conclusions

References 


\section{LIST OF FIGURES}

Figure 1.1The schematic process flow-sheet and requirements of blast furnace process.

Figure 1.2 The schematic process flow-sheet and requirements of iron nugget process

Figure 1.3 The major cost components of the traditional blast furnace iron making process.

Figure 1.4 Simplified schematic diagrams for integration of mining with blast furnace iron making and steel making

Figure 1.5 Simplified schematic diagram for integration of mining with pig iron nugget making and steel making

Figure 2.1The schematic of single step pig iron nugget process.

Figure 2.2 The schematic diagram showing the slag separation requirements for pig iron nugget process

Figure 2.3 The portion of the iron - iron carbide metastable phase diagram (Krauss, 1990). The occurrence regions of $\alpha$ ferrite + Pearlite, and cementite + Pearlite microsconstituents are shown under equilibrium cooling conditions.

Figure 2.4. The schematic representation of the white cast iron microstructure at room temeprature. The dark grey areas represents the former austenite dendrites which transformed to Pearlite (the eutectoid microstructure, 
alternating layers of $\mathrm{Fe}_{3} \mathrm{C}$ and $\alpha$ ferrite), and white areas represents the eutectic iron carbides (cementite). Cementite is hard, brittle and dominates the microstructure.

Figure 3.1 Laboratory scale pelletizing drum with overall diameter $40.6 \mathrm{~cm}$ (16 in), mouth diameter $25.4 \mathrm{~cm}$ (10 in) and depth $17.8 \mathrm{~cm}$ (7in) rotating in a counter-clock wise direction at $35 \mathrm{rpm}$.

Figure 3.2 The x-ray diffraction pattern of the magnetite concentrate utilized as an iron source.

Figure 3.3 The x-ray diffraction pattern of the limestone utilized as flux.

Figure 3.4 Schematic drawing of the experimental set-up used for production of dried green balls and pig iron nuggets.

Figure 3.5 (a) Schematic drawing of the experimental set up used for analyzing the pig iron nuggets produced (b) Schematic drawing of the experimental set up used for chemical analysis of the pig iron nuggets produced.

Figure 3.6 The schematic representation of Vickers hardness measurements Figure 4.1 A portion of the iron-carbon metastable phase diagram, where the operational regions investigated for D RI, TD RI, and pig iron nuggets is shown. Figure 4.2 An example of the direct reduced iron produced at furnace temperature $1200 \mathrm{C}$ and furnace residence times 3 hours.

Figure 4.3 An example of the direct reduced iron produced at furnace temperature $1350 \mathrm{C}$ and furnace residence times 2.5 hours. 
Figure 4.4 The direct reduced iron produced at furnace temperature $1425 \mathrm{C}$ and furnace residence time $16 \mathrm{~min}$. Its apparent density is lower than pig iron nuggets. This is due to porosity, and the intimate mixture of slag and metallic iron ( $\alpha$ ferrite).

Figure 4.5 The transition direct reduced iron produced at furnace temperature $1425 \mathrm{C}$ and furnace residence time $28 \mathrm{~min}$. Its apparent density is lower than pig iron nuggets, and higher than D RI. This is due to the reduced amount of porosity, and partial slag separation, and higher metallization.

Figure 4.6 Molten iron nugget and molten slag observed when the crucible was pulled out of the furnace. The molten nugget shown was made at furnace temperature $1450 \mathrm{C}$ and residence time $22 \mathrm{~min}$.

Figure 4.7 Pig iron nuggets made at furnace temperature $1450 \mathrm{C}$ and residence time $22 \mathrm{~min}$, accompanied with their slag. Slag can easily be separated by physical means.

Figure 4.8 The summary of the experimental work conducted for determining the residence times required for pig iron nugget making at $1425 \mathrm{C}$ furnace temperature. The pictures of the D RI, TD RI and pig iron nuggets produced are shown on the top of the figure. The scale bars shown are $1 \mathrm{~cm}$. 
Figure $4.9(\mathbf{a}, \mathbf{b}, \mathbf{c})$ The direct reduced iron (D RI) produced at residence times $10 \mathrm{~min}, 16 \mathrm{~min}$, and $22 \mathrm{~min}$ respectively. The metallized portion is a solid state product; slag was not separated from the metal. $(\mathbf{d}, \mathbf{e})$ The transition direct reduced iron (TD RI) produced at residence times $28 \mathrm{~min}$, and $32 \mathrm{~min}$ respectively. The metallized portion is a solid and liquid state product; slag was partially separated from the metal. (f, $\mathbf{g}, \mathbf{h}$ ) The pig iron nugget (PIN) and slag produced at residence times $40 \mathrm{~min}, 50 \mathrm{~min}$, and $60 \mathrm{~min}$. The metallized portion is a liquid state product, slag was completely separated from the metal.

Figure 4.10 (a-c) Optical micrograph of a cross section of a direct reduced iron produced at furnace temperature $1425 \mathrm{C}$ furnace residence time $16 \mathrm{~min}$, for various magnifications (Nital etch)

Figure 4.11 (a,b) SEM backscattered images for the D RI made at furnace temperature $1425 \mathrm{C}$ furnace residence time $16 \mathrm{~min}$ for varying magnifications.

Figure 4.12 (a-c) Optical micrograph of a cross section of a direct reduced iron produced at furnace temperature $1425 \mathrm{C}$ and furnace residence time $22 \mathrm{~min}$, for various magnifications (Nital etch).

Figure 4.13 (a-b) SEM secondary images for the D RI made at furnace temperature $1425 \mathrm{C}$ and furnace residence time $22 \mathrm{~min}$ for varying magnifications. 
Figure 4.14 (a-c) Optical micrograph of a cross section of a pig iron nugget produced at furnace temperature $1425 \mathrm{C}$ and furnace residence time $50 \mathrm{~min}$ for varying magnifications (Nital etch).

Figure 4.15 (a-c) Optical micrograph of a cross section of a pig iron nugget produced at furnace temperature $1425 \mathrm{C}$ and furnace residence time $60 \mathrm{~min}$ for varying magnifications (Nital etch).

Figure 4.16 The average Vickers hardness values of the D RI, TD RI, and pig iron nuggets representing the increase in the amount of carbon in the system with increasing furnace residence time at constant furnace temperature $1425 \mathrm{C}$. 16 or more measurements were taken from the metallized portion of each sample.

Figure 4.17 The average apparent density values of the D RI, TD RI, and pig iron nuggets representing the increase degree of metallization, slag separation, and decrease in degree of porosity with increasing furnace residence time at constant furnace temperature $1425 \mathrm{C}$.

Figure 4.18 (a-b) O ptical micrograph of a cross section of a direct reduced iron produced at furnace temperature $1415 \mathrm{C}$ and furnace residence time $10 \mathrm{~min}$ (Nital etch)

Figure 4.19 Optical micrograph of a cross section of a direct reduced iron produced at furnace temperature $1425 \mathrm{C}$ and furnace residence time $10 \mathrm{~min}$, (Nital etch) 
Figure 4.200 ptical micrograph of a cross section of a direct reduced iron produced at furnace temperature $1455 \mathrm{C}$ and furnace residence time $10 \mathrm{~min}$, (Nital etch)

Figure 4.21 Optical micrograph of a cross section of a direct reduced iron produced at furnace temperature $1465 \mathrm{C}$ and furnace residence time $10 \mathrm{~min}$, (Nital etch)

Figure 4.220 ptical micrograph of a cross section of a direct reduced iron produced at furnace temperature $1475 \mathrm{C}$ and furnace residence time $10 \mathrm{~min}$, (Nital etch)

Figure 4.230 ptical micrograph of a cross section of a direct reduced iron produced at furnace temperature $1485 \mathrm{C}$ and furnace residence time $10 \mathrm{~min}$, (Nital etch)

Figure 4.240 ptical micrograph of a cross section of a direct reduced iron produced at furnace temperature $1495 \mathrm{C}$ and furnace residence time $10 \mathrm{~min}$, (Nital etch)

Figure 4.25 Schematic figures describing the solidification of gig iron nuggets containing 3.3\% carbon, utilizing $\mathrm{Fe}-\mathrm{Fe}_{3} \mathrm{C}$ metastable phase diagram Figure 4.26 A scanning electron microscopy secondary image of the austenite dendrites present in the porosity of the pig iron nugget made at furnace temperature $1450 \mathrm{C}$ and residence time $22 \mathrm{~min}$. 
Figure 4.27 The average Vickers hardness values of the D RI, TD RI, and pig iron nuggets representing the increase in the amount of carbon in the system with increasing furnace temperature at constant furnace residence time $10 \mathrm{~min}$. 16 or more measurements were taken from the metallized portion of each sample.

Figure 4.28The summary of the experimental work conducted in order to be able to determine the optimum pig iron nugget making furnace temperatures and residence times.

Figure 4.29 Optical micrographs of a cross section of the pig iron nuggets made at furnace temperature $1450 \mathrm{C}$ and furnace residence $22 \mathrm{~min}$ time for varying magnifications.(Nital etch)

Figure 4.30 Optical micrographs of a cross section of the pig iron nuggets made at furnace temperature $1450 \mathrm{C}$ and furnace residence $28 \mathrm{~min}$ time.(Nital etch)

Figure 4.310ptical micrographs of a cross section of the pig iron nuggets made at furnace temperature $1475 \mathrm{C}$ and furnace residence $22 \mathrm{~min}$ time for varying magnifications.(Nital etch)

Figure 4.32 0 ptical micrographs of a cross section of the pig iron nuggets made at furnace temperature $1475 \mathrm{C}$ and furnace residence $28 \mathrm{~min}$ time for varying magnifications.(Nital etch) 
Figure 4.33 SEM secondary image of the pig iron nugget made at furnace residence time $22 \mathrm{~min}$.

Figure 4.34The $\mathrm{X}$-ray diffraction pattern of the pig iron nugget produced at furnace temperature $1450 \mathrm{C}$ and residence time $22 \mathrm{~min}$.

Figure 4.35The average Vickers hardness values of the D RI, TD RI, and pig iron nuggets made at furnace temperatures $1425 \mathrm{C}, 1450 \mathrm{C}$, and $1475 \mathrm{C}$ and residence times $16 \mathrm{~min}, 22 \mathrm{~min}, 28 \mathrm{~min}, 34 \mathrm{~min}, 40 \mathrm{~min}, 50 \mathrm{~min}$, and $60 \mathrm{~min} .16$ or more measurements were taken from each sample.

Figure 4.36 Apparent density values of the D RI, TD RI, and pig iron nuggets produced plotted against furnace residence time. Error bars indicate the standard deviation of 4 measurements. The initial dried green ball density before firing was $2.5 \mathrm{~g} / \mathrm{cm}^{3}$ (The density of the green balls was calculated by measuring the green ball diameter and mass).

Figure 4.37 The natural logarithm of the 1 / furnace residence time required for pig iron nugget production versus the required furnace temperatures.

Figure 4.38 The compatibility theoretical of the furnace residence time and temperature threshold values calculated with the equation 4.2 and the experimental data.

Figure 5.1 The plot representing the formation and production regions of DRI, TDRI and pig iron nuggets. 


\section{LIST OF TABLES}

Table 1.I Research motivation - The comparison of some of the basic process properties of the blast furnace and pig iron nugget process.

Table 2.I Chemical composition ranges for typical unalloyed cast irons and blast furnace pig iron.

Table 2.II Typical Vickers hardness values for certain iron-carbon alloys

Table 3.I The chemical analysis of the bentonite clay utilized as binder

Table 3.II The proximate and ultimate analysis of the coal utilized as reducing and carburizing agent.

Table 4.I A comparison of the chemical compositions of the blast furnace pig iron, white cast iron and pig iron nuggets.

Table 4.II The comparison of some of the properties of the pig iron nuggets and blast furnace pig iron.

Table 4.III The approximate local chemical analysis of the wustite, Fe rich slag phase, and $\alpha$-Fe present in the D RI (production furnace residence time $22 \mathrm{~min}$ ) microstructure.

Table 4.IV The average Vickers hardness values of the D RI, TD RI, and pig iron nuggets made at various furnace residence times (constant furnace temperature 1425 C). 16 or more measurements were taken for each sample. 
Table 4.V The average apparent density values of the D RI, TD RI, and pig iron nuggets made at various furnace residence times (constant furnace temperature 1425 C).

Table 4.VI The phases and constituents present in the pig iron nugget microstructures

Table 4.VII The average Vickers hardness values of the D RI, TD RI, and pig iron nuggets made at various furnace temperatures (constant furnace residence time $10 \mathrm{~min}) .16$ or more measurements were taken for each sample.

Table 4.VIII The approximate local chemical analysis of the phases present in the pig iron nugget produced at furnace temperature $1475 \mathrm{C}$ and residence time $22 \mathrm{~min}$.

Table 4.IX The average Vickers hardness values of the D RI, TD RI, and pig iron nuggets made at various furnace temperature and residence times. 16 or more measurements were taken for each sample.

Table 4.X Apparent density values of the D RI, TD RI and pig iron nuggets made at varying furnace temperatures and residence times.

Table 4.XI The density values of selected ferrous iron based materials

Table 4. XII The furnace temperature and residence time threshold values for pig iron nugget production

Table 4. XIII The comparison of the furnace residence times calculated by utilizing equation 4.2 and experimental results 
Table 4. XIV Comparison of some of the properties of direct reduced iron, transition direct reduced iron and pig iron nuggets produced 


\section{Chapter 1Introduction}

The blast furnace technology is still the primary method for pig iron production. The schematic process flow-sheet and requirements are shown in Figure 1.1. The success of this process is dependent on the quality of the raw materials used. Production or reliable supply of high quality raw materials such as sinter, pellets, and coke are the primary economical and environmental constraints of the process (Zervas, 1996). In addition the inflexibility of the process capacity, high capital and operation costs, and energy lost in between steps, leads to a search for alternatives, such as the iron nugget process (Anameric and Kawatra, 2004; Anameric et al., 2005). The comparison of some of the basic process properties for blast furnace process and pig iron nugget process is shown in Table 1.I.

The pig iron nugget process was developed by Kobe Steel as an environmentally friendly, economical alternative to traditional blast furnace process (Kobayashi et al., 2001; Tsuge et al.,2002). It aims to produce pig iron nuggets which have similar chemical and physical properties to blast furnace pig iron. Throughout this single step process, feed materials, self reducing and fluxing dried green balls were reduced, carburized and smelted. The self reducing and fluxing dried green balls were produced by agglomeration of iron ore concentrate (magnetite), flux (limestone), binder (bentonite), and reducingcarburizing agent (coal). The schematic pig iron nugget process flowsheet and requirements are shown in Figure 1.2. The comparison of the basic process properties of blast furnace process and pig iron nugget process is shown in Table 1.I. 


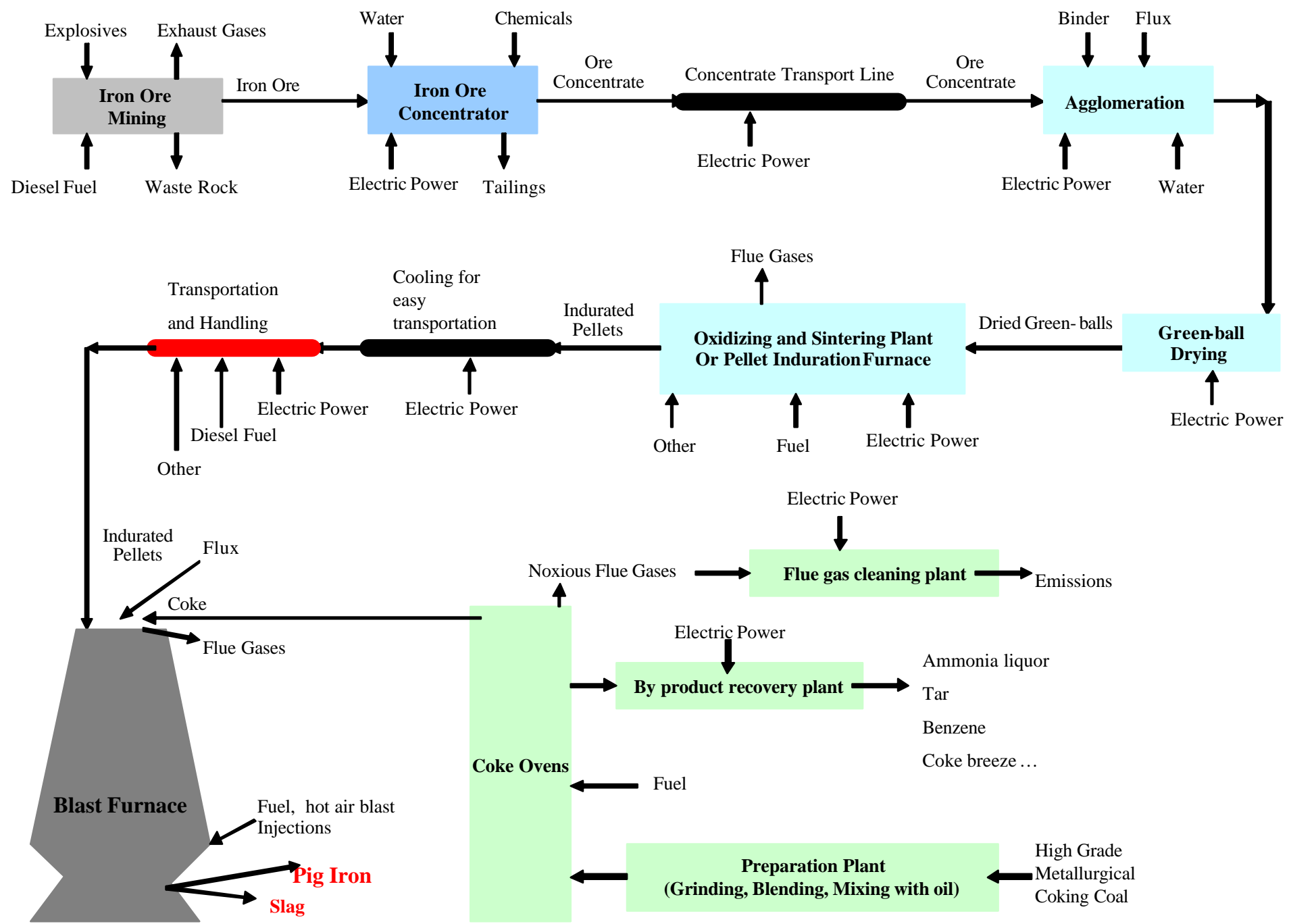

Figure 11The schematic process flow-sheet and requirements of blast furnace process. 


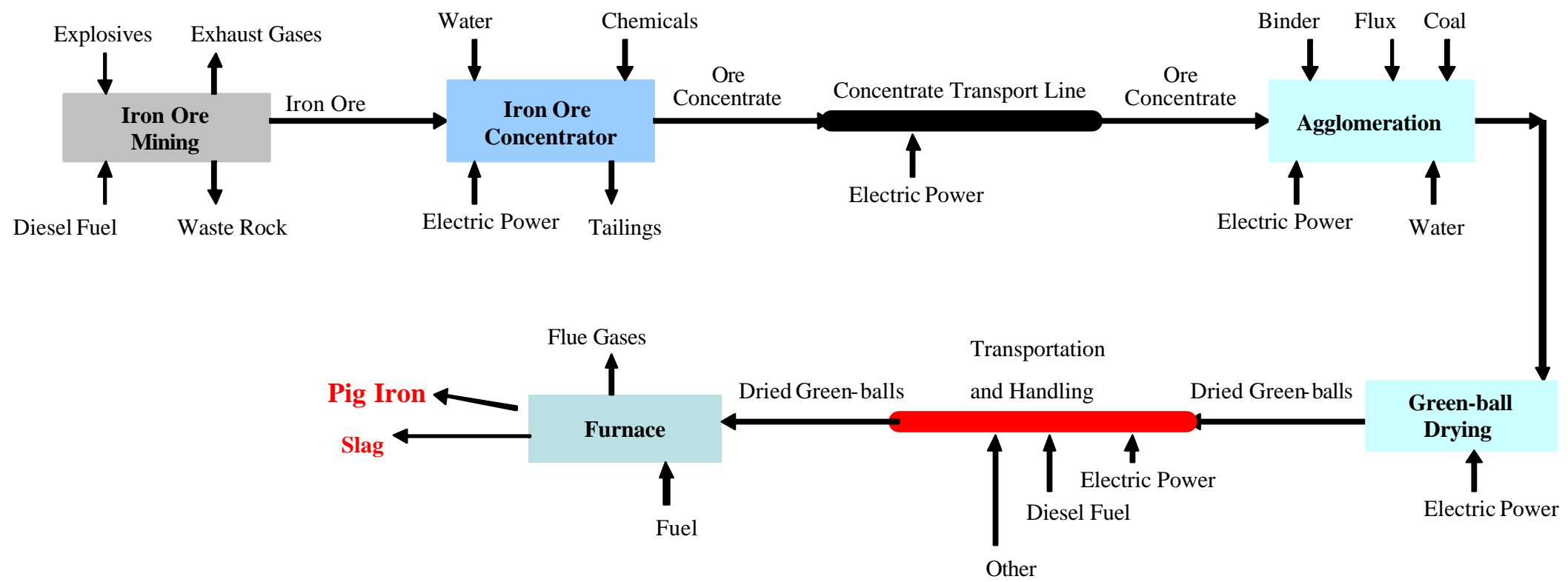

Figure 1.2 The schematic process flow-sheet and requirements of iron nugget proces 
Table 1.I Research motivation - The comparison of some of the basic process properties of the blast furnace and pig iron nugget process.

\section{Motivation Blast Fumace versus Iron N ugget Process}

\section{Blast Fumace}

- Requires considerable associated infrastructure and auxiliary plants.

- Energy lost in between steps.

- Requires metallurgical grade coke.

- Coke ovens are the primary contributors of the environmental emissions.

- Inflexible, hard to maintain and control operation.
Iron Nugget Process

- All reactions (reduction, melting, slag separation, and carburization) take place in a single reactor.

- Energy conservation.

- Does not require coke.

- Environmentally friendlier. (Does not require coke)

- Flexible, easy maintained and controlled operation.

The advantages and incentives behind the development of the pig iron nugget process can be summanized as follows (Mazurak, 2003; Zervas et al, 1996 (a); Steffen and Lungen, 2004, Basu et al, 1995; Anameric and Kawatra, 2004; Anameric et al, 2005): 
In the traditional blast furnace iron making route, as a first step, the run of mine ore is liberated from its gangue minerals by crushing and grinding operations. Then, this pulverized ore is concentrated utilizing desliming, magnetic separation and/ or flotation forming the iron ore concentrate (also called filter cake). Iron ore concentrate is mixed with binder bentonite clay and agglomerated in balling drums with the aid of water forming green balls which contain 60 - $65 \%$ iron. The green balls are then dried and heat hardened and oxidized in

rotary kilns forming pellets. These pellets are cooled prior to their transportation to blast furnace site. Finally, pellets are fed to the blast furnace along with limestone and coke for reduction and smelting purposes. On the other hand, the pig iron nugget process is designed to utilize self reducing and fluxing dried green balls which are produced by agglomerating iron ore concentrate with flux, binder and reducing- carburizing agent in balling drums and then drying them at $100{ }^{\circ} \mathrm{C}$. This eliminates (a) the energy loss by cooling and re-heating of the pellets and (b) extensive reducing agent consumption by oxidizing and rereducing of the pellets.

Cost competitive process, raw iron oxide and reducing carburizing agent utilization

The major cost components of the traditional blast furnace iron making process are shown in Figure 1.3 (True, 1983;Leckie et al, 1982). To make the processes more cost competitive the critical cost components: iron oxide feed, 
energy, and capital costs should be reduced. Blast furnace operation is a capital intensive operation due to ancillary plant and equipment requirements. The primary cost cuts can be made by eliminating high quality coke and pellet, briquette, lump ore and sinter requirements of the process. The pig iron nugget process utilizes dried green balls as iron oxide feed material. In addition, it utilizes widely available coal instead of metallurgical coke. This thereby eliminates coke ovens, sinter plants, and induration (heat hardening) kilns.

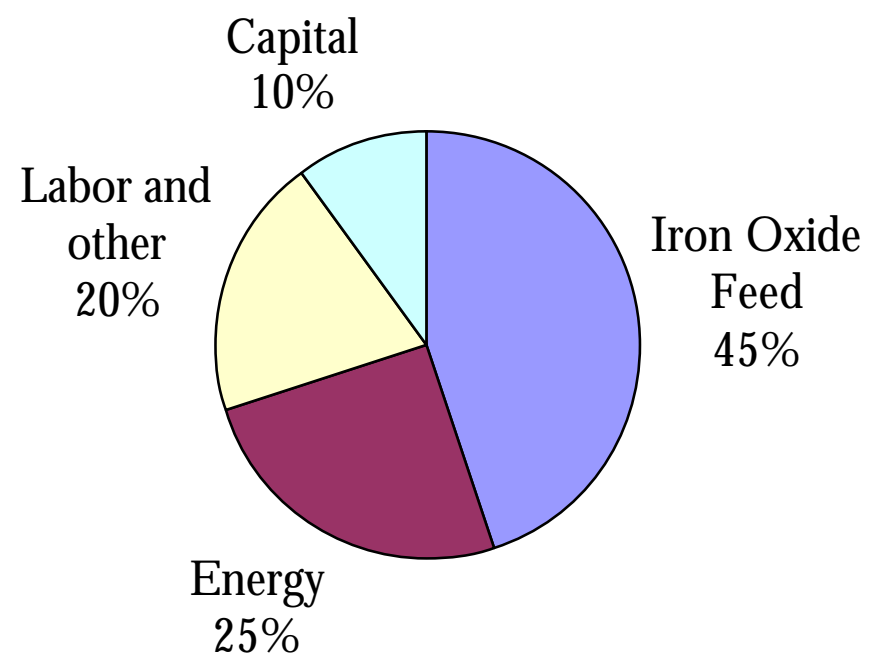

Figure 1.3 The major cost components of the traditional blast furnace iron making process. 
(iii) Reduced residence time in the reactor

For the pig iron nugget process the kinetics of the reduction and carburization reactions are enhanced by agglomeration of an iron ore source, flux, and reducing - carburizing agent together. The close contact of the reacting materials and availability of a large number of reacting sites enhances the solid- solid reduction and slag forming reactions. Also, the internal gas generation and small diffusion distances in the sample enhance the solid-gas reduction reactions, and reducing gas regeneration, slag forming and carburization reactions (Nascimento et al, 1998;Mourao and Capacchi, 1996;A grawal et al, 2000;G oksel ,1977;G oksel et al, 1991;G oksel et al, 1988). The goal was to reduce the eight hour residence time of the iron oxide feed materials in the blast furnace. Impurity (gangue) separation with formation of fusible slag at lower temperatures

The impurities are separated from the metal by the formation of slag. Flux materials such as limestone, dolomite, and magnesia are added to lower fusion temperatures to enable the slag formation. The slag can only be separated from the metal when metal and slag are in liquid state. This requires metal (pure iron fusion temperature $1535^{\circ} \mathrm{C}$ ) and slag (slag fusion temperature around 1200 $\left.{ }^{\circ} \mathrm{C}\right)$ to be heated above their fusion temperatures. The blast furnace process operates at temperatures above the fusion temperature of iron and produce liquid metal (pig iron) and slag. On the other hand, throughout the pig iron nugget process, it is intended to have carburization of pure iron, lowering its fusion temperature (this effect takes place until the eutectic carbon composition 
is reached). This should allow the pig iron nugget process to operate at lower temperatures than the fusion temperature of iron and still obtain slag separation. Environmentally friendlier process

The coking process is the major contributor of environmental emissions. The amount of coke required for the blast furnace process can be reduced by using pre-reduced sinters and pellets and higher temperatures in the furnace. However, the reduction of coke requirements is not enough due to increasing environmental regulations on coke making and increasing operation costs. On the other hand, the pig iron nugget process utilizes widely available coal as the reducing and carburizing agent. This eliminates the environmental emissions caused by coke ovens. Flexible process

O ptimum, economically viable high production rates and high degrees (85-90\%) of heat utilization can be achieved for a blast furnace operation when operating at high capacities (Zervas 1996 (a)). This requires a continuous supply of high quality raw materials such as iron ore pellets, lumps, briquettes, sinter and coke. Since blast furnaces cannot be shut down and restarted easily this continuous high capacity production takes place even under depressed market conditions. Conversely, since the pig iron nugget process is designed as a single step process it is easier to adjust and control its operation with the market conditions. It is designed in such a way that it can be shut down and restarted easier than the blast furnace process, and its operational capacity can also be incrementally increased. 
(vii) Decreased capital and operational costs by elimination of coke ovens and sinter plants

The pig iron nugget process utilizes non coking coal directly mixed in the dried green ball. This eliminates the need for coke ovens and sinter plants. The elimination of coke ovens and sinter plants reduces the total capital required for starting up a traditional blast furnace operation by $60 \%$ (Basu et al., 1995)

(viii) Easily controlled and maintained process

Unlike the blast furnace process, the pig iron nugget process does not require auxiliary plants such as coke ovens, sinter plants and induration kilns. And all the pig iron nugget producing reactions take place in a single reactor at constant furnace temperature. This enables easier process control and maintenance. Integration with existing steel works

The blast furnace pig iron can be used in the basic oxygen furnace and electric arc furnaces (in the granulated form) for steel production. On the other hand, the pig iron nuggets are aimed to be beneficiated in (i) the electric arc furnaces for steel production, (ii) the electric arc furnaces, foundry cupolas and basic oxygen furnaces to lower residuals, replace scrap and direct reduced iron, (iii) as a coolant in electric arc furnaces, foundry cupolas and basic oxygen furnaces, and (iv) in ferrous foundry operations as iron unit charge. 
Pig iron nugget process is a simple single step process. Therefore pig iron nugget furnaces can easily be incorporated with the processing plants as shown in Figure 1.5. Reduced shipping, transportation, and handling costs and efforts

It can be seen from Figure 1.4 that through out the traditional blast furnace process generally iron ore is mined, concentrated, agglomerated and heat hardened to pellets prior to their transportation to the blast furnace site. The pig iron produced from these pellets is then transported to the steel making operations. On the other hand, it can be seen from Figure 1.5 that with the utilization of pig iron nugget process instead of blast furnace process the iron ore mined can be directly be concentrated, agglomerated and smelted into pig iron at the mine site. This would eliminate the shipping, transportation and handling costs due elimination of one transportation step and avoidance of gangue transportation. 


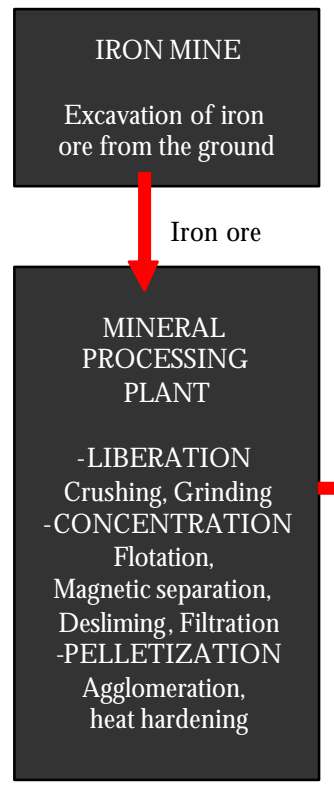

Iron ore

pellets

$60-65 \%$ iron rest gangue minerals

BLAST FURNAC

Pig Iron

Crushing, Grinding

NCENTRATION

(

ELLETIZATIO N

Agglomeration

heat hardening

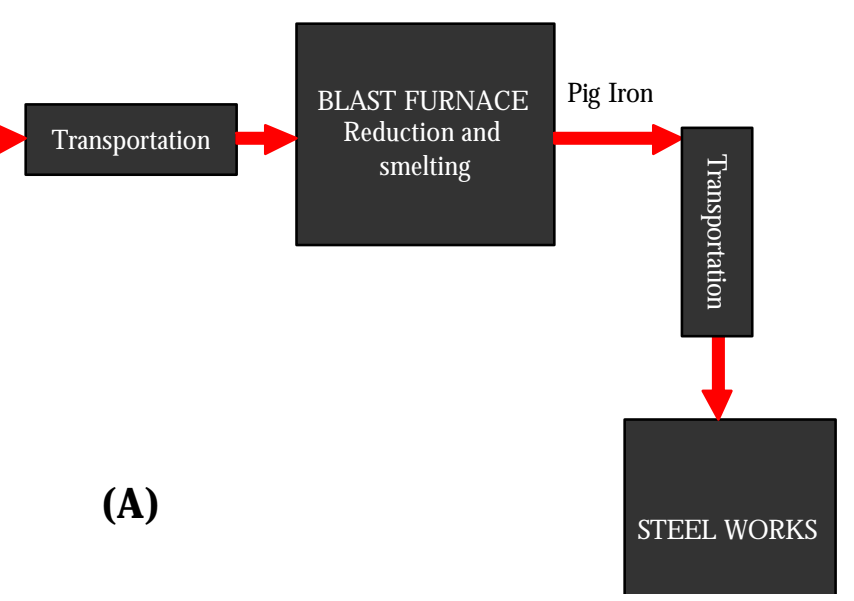

IRON MINE

Excavation of iron

ore from the ground
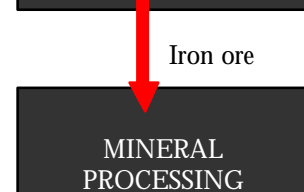

PROCESSING PLANT

-LIBERATION

Crushing, G rinding

-CONCENTRATION

Flotation,

Magnetic separation

Desliming, Filtration

-PELLETIZATION

Agglomeration,

heat hardening

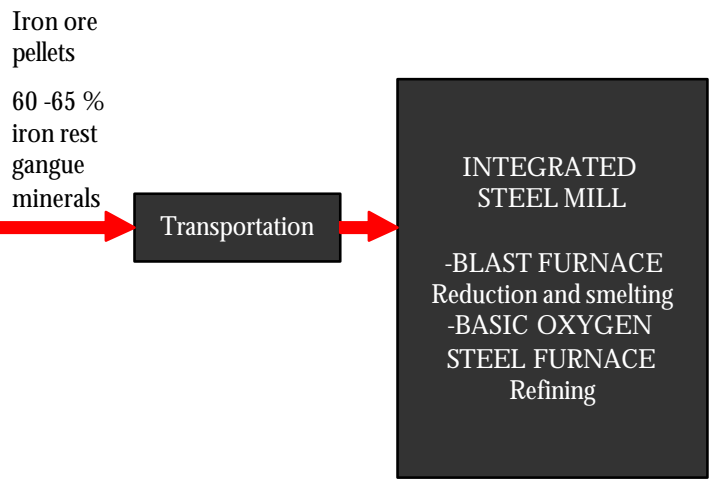

(B)

Figure 1.4 Simplified schematic diagrams for integration of mining with blast furnace iron making and steel making 


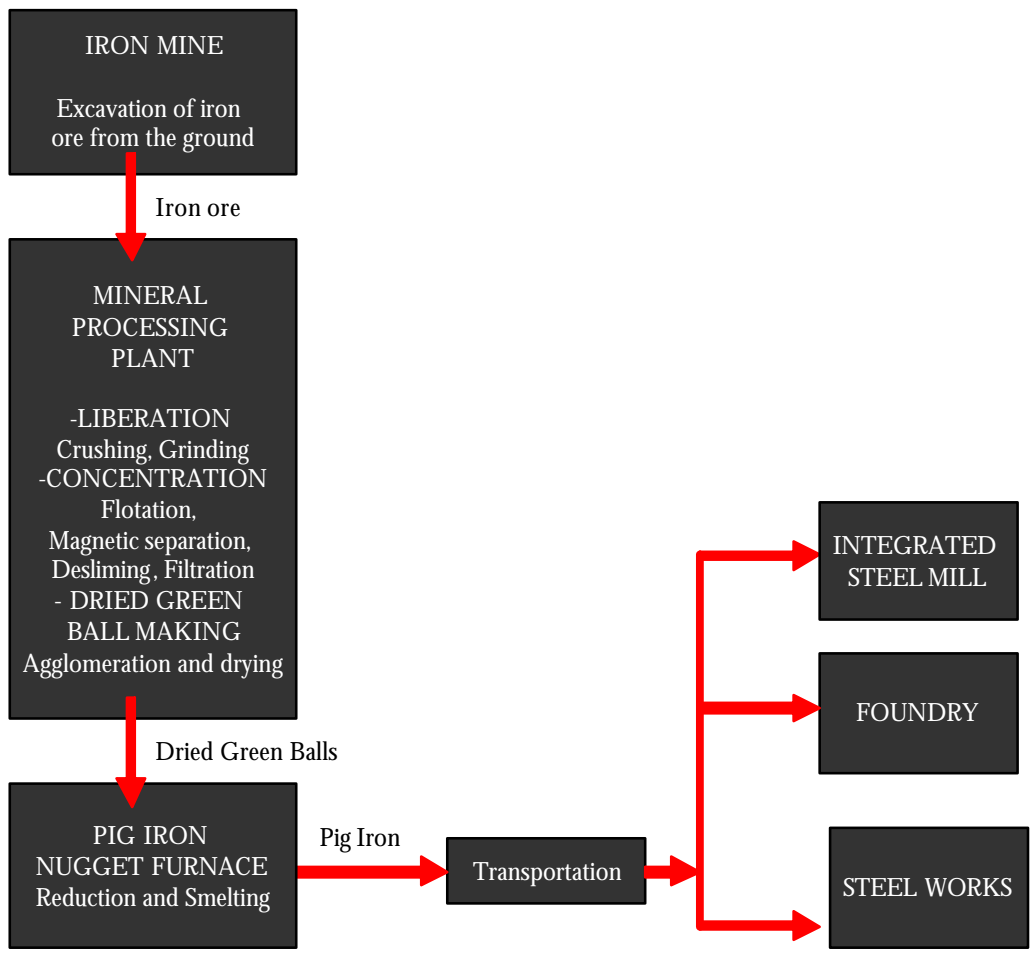

Figure 1.5 Simplified schematic diagram for integration of mining with pig iron nugget making and steel making 


\section{Executive Summary}

To date, the blast furnace technology is the primary method for producing metallic iron from ore. However, the industry is interested in moving away from the blast furnace because of its need to be run on a very large scale in order to be economical, its requirement for coke made from fossil fuel as the fuel and reducing agent, the great expense involved in shutting down and restarting, the need to run the furnace at nearly full capacity the entire time it is operating, and the inherent energy inefficiency involved in producing the iron ore pellets that are commonly used as blast furnace feed.

The pig iron nugget process is being developed by Kobe Steel as an environmentally friendly, economical alternative to traditional blast furnace process (Kobayashi et al., 2001; Tsuge et al.,2002). It aims to produce pig iron nuggets which have similar chemical and physical properties to blast furnace pig iron. Throughout this single step process, feed materials, self reducing and fluxing dried green balls were reduced, carburized and smelted. The self reducing and fluxing dried green balls were produced by agglomeration of iron ore concentrate (magnetite), flux (limestone), binder (bentonite), and reducing/ carburizing agent (coal). The advantages and incentives behind the development of the pig iron nugget process can be summarized as follows (Mazurak, 2003; Zervas et al, 1996 (a); Steffen and Lungen, 2004, Basu et al, 1995; Anameric and Kawatra, 2004; Anameric et al, 2005):

(i) Reduced energy losses in iron oxide feed preparation.

(ii) Cost competitive process, raw iron oxide and reducing - carburizing agent utilization.

(iii) Reduced residence time in the reactor

(iv) Impurity (gangue) separation with formation of fusible slag at lower temperatures

(v) Environmentally friendlier process

(vi) Increased process flexibility

(vii) D ecreased capital and operational costs by elimination of coke ovens and sinter plants

(viii) Easily controlled and maintained process

(ix) Easily integrated with existing steel works

(x) Improved process simplicity

(xi) Reduced shipping, transportation, and handling costs

Hence the objectives of this research were to:

(i) Investigate the technical soundness of the pig iron nugget process. This involved intensive investigation of all ironmaking routes and their comparison.

(ii) Produce pig iron nuggets and develop analysis techniques for determination of their physical and chemical properties. This portion of the study investigated the technical feasibility of the production of pig iron nuggets and compared the physical and chemical properties of the pig iron nuggets with blast furnace pig iron. The physical and chemical properties of the pig iron nuggets were investigated utilizing $\mathrm{X}$-ray fluorescence, $\mathrm{X}$-ray diffraction, Scanning electron microscopy, optical microscopy, Microhardness, and apparent density measurements.

(iii) Investigate the slag separation requirements. The necessary conditions for slag (impurity) separation from the metal were determined. The slag separation can only be achieved by the formation of two immiscible liquid phases, metal and slag. The slag formed during the reduction of the iron oxides to iron melts at lower temperatures than pure iron. 
Therefore carburization requirements of the pure iron to lower its melting temperature were investigated. The resulting products were characterized according to their: (a) state after heat treatment, (b) microstructure, and (c) microhardness.

(iv) Identification of the furnace temperature and residence time dependent process requirements on the carburization of the metal and subsequent pig iron nugget formation.

(v) Optimization of furnace temperature and residence time required for production of pig iron nuggets. This identified the threshold furnace temperatures and residence times for pig iron nugget making.

This project successfully produced solid, high density, slag free, pig iron nuggets in a laboratory scale resistance box furnace at varying furnace temperatures and residence times. The pig iron nugget produced had similar physical and chemical properties to blast furnace pig iron. For the first time, the furnace temperature and residence time threshold for pig iron nugget production was determined. It was found that the threshold temperature for producing iron nuggets was approximately $1410^{\circ} \mathrm{C}$, where nuggets formed after a time of approximately 1 hour. However, the necessary processing time could be reduced to less than 10 minutes by increasing the temperature to approximately $1475^{\circ} \mathrm{C}$. This is critical information for proper design of full-scale iron nugget production facilities, as before this project was conducted the time necessary to make nuggets as a function of temperature was not known.

D uring pig iron nugget production as the furnace temperature and residence time increased, (i) the degree of metallization was increased, (ii) porosity was reduced, and (iii) amount of bulk carbon dissolved in the metal was increased. The increased degree of metallization and reduced porosity was indicated by increased apparent density. The increased amount of carbon dissolved was indicated by increased Microhardness values. Increased metallization, increased carbon content, and reduced porosity are all desirable features in iron nuggets, as they improve the marketability for steelmaking processes.

This project has resulted in the determination of a great deal of basic information that is crucial for full-scale implementation of the iron nugget process. Once this process is adopted by the iron and steel industry, it is expected to save in excess of $3280 \mathrm{MJ}$ per metric ton of metal produced for the annual US production of 40 million metric tons of pig iron. 


\section{Chapter 2 Theoretical Background}

\subsection{Pig Iron Nugget Process}

The pig iron nugget process is a single step process where the self reducing and self fluxing dried green balls are converted into pig iron nugget. The schematic process steps are shown in Figure 2.1(Haque and Ray, 1995; Mourao and Capocchi, 1996; Nascimento et al, 1997, 1998 and 1999, Zervas et al, 1996, Chatterjee, 1994). It can be seen from Figure 2.1 that during the process, thermal decomposition of the coal takes place first. This supplies the additional energy and reducing and carburizing agents required for the reduction of iron oxide to iron and carburization of the iron. During the reduction of iron oxides, slag forming reactions also take place forming the slag phase, which melts at temperatures around $1200^{\circ} \mathrm{C}$. When the reduction of the iron oxides is completed the carburization of the metal formed takes place, lowering its melting temperature. Finally, when the melting of the metal phase is accomplished, the separation of the liquid metal and slag takes place due to the density difference and immiscibility of the two phases. 

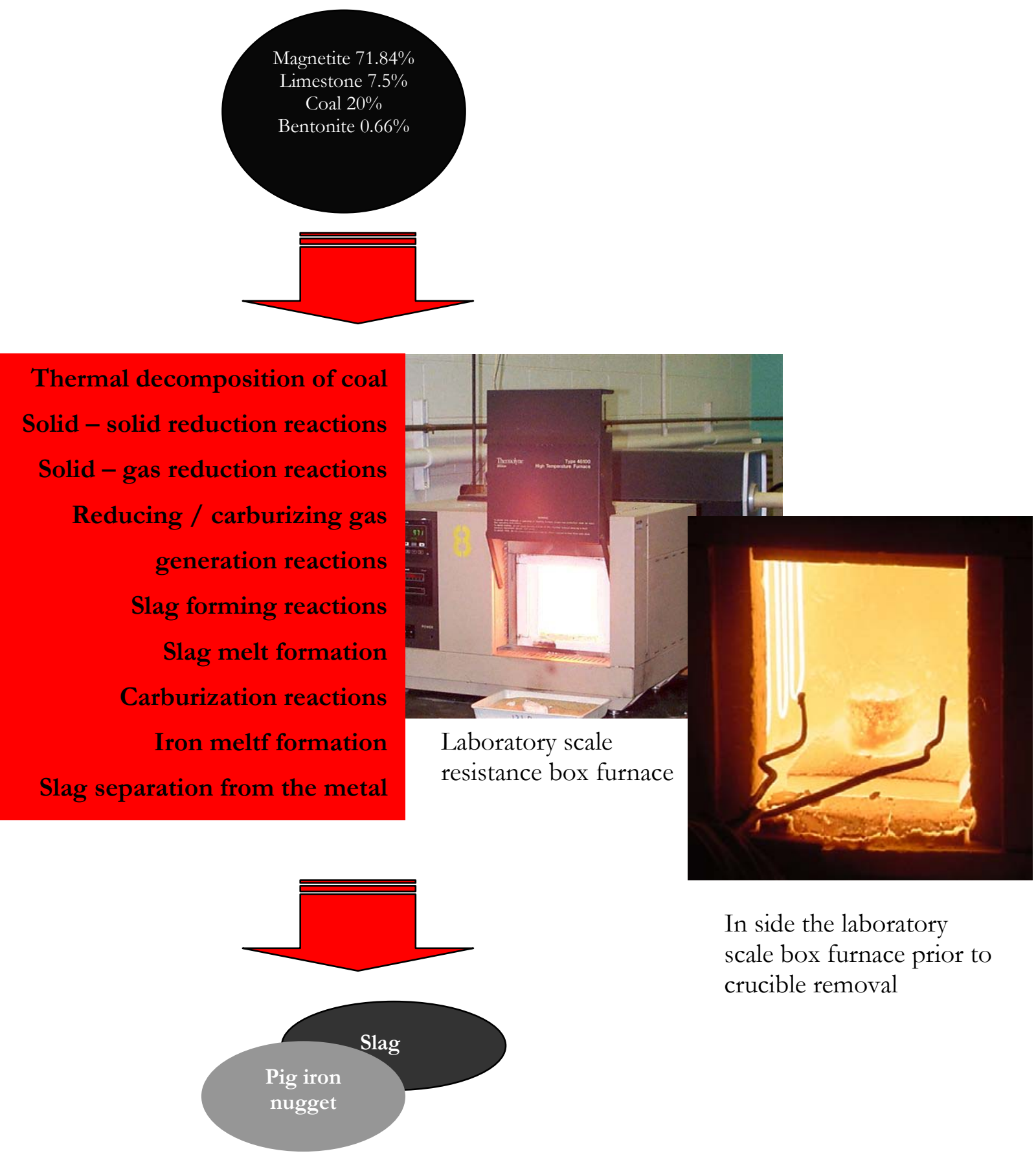

In side the laboratory scale box furnace prior to crucible removal

Figure 2.1 The schematic of single step pig iron nugget proces 
CHAPTER 2 THEORETICAL BACKGROUND -17-

Thermal decomposition of coal, reaction 1 and reducing gas regeneration reactions represented by reactions 2 through 6 , takes place in the same reactor in which the iron nuggets are produced. This eliminates the need for other reactors for the gasification, gas quenching, gas regeneration, and gas heating. Reaction 3 of the reducing gas regeneration reactions is an important reaction known as Boudouard reaction. This reaction was found to be the rate controlling step for iron ore reduction according to Rao (1971), Fruehan (1977), Seaton and co-workers, Srinivasan and Lahiri, Abraham and Ghosh (Mourao and Capocchi, 1996).
Coal $\rightarrow \mathrm{CO}, \mathrm{CO}_{2}, \mathrm{H}_{2}, \mathrm{~N}_{2}, \mathrm{C}_{\mathrm{n}} \mathrm{H}_{\mathrm{m}}, \mathrm{C}$
Reaction (1)
$\mathrm{C}+\mathrm{O}_{2} \leftrightarrow \mathrm{CO}_{2}$
Reaction (2)
$\mathrm{CO}_{2}+\mathrm{C} \leftrightarrow 2 \mathrm{CO}$
Reaction (3)
$\mathrm{C}+1 / 2 \mathrm{O}_{2} \leftrightarrow \mathrm{CO}$
Reaction (4)
$\mathrm{CH}_{4}+\mathrm{CO}_{2} \leftrightarrow 2 \mathrm{CO}+2 \mathrm{H}_{2}$
Reaction (5)
$\mathrm{C}+\mathrm{H}_{2} \mathrm{O} \leftrightarrow \mathrm{CO}+\mathrm{H}_{2}$
Reaction (6)

The endothermic, exergonic direct reduction reactions which through solid carbon react with solid magnetite $\left(\mathrm{Fe}_{3} \mathrm{O}_{4}\right)$ and wustite $(\mathrm{FeO})$ are represented by reactions 7 and 8 . The endothermic, exergonic indirect reduction reaction, where the gas product of direct reduction (reactions 7 and 8) or reducing gas forming reactions (reactions $1,3,4,5,6$ ), carbon monoxide, reacts 
CHAPTER 2 THEORETICAL BACKGROUND -18-

with solid magnetite, $\left(\mathrm{Fe}_{3} \mathrm{O}_{4}\right)$ is represented by reaction 9. The exothermic, endergonic indirect reduction reaction, where carbon monoxide reacts with wustite $(\mathrm{FeO})$, is represented by reaction 10. This reaction was found to be the rate controlling step for iron ore reduction according to Ghosh and Tiwari (1970), Srinivasan and Lahiri (1977), Mourao and Capocchi (1996).Other endothermic, endergonic reduction reactions, where hydrogen is the reducing agent are represented by reactions 11 and 12 .
$\mathrm{Fe}_{3} \mathrm{O}_{4}+\mathrm{C} \leftrightarrow 3 \mathrm{FeO}+\mathrm{CO}$
Reaction (7)
$\mathrm{FeO}+\mathrm{C} \leftrightarrow \mathrm{Fe}+\mathrm{CO}$
Reaction (8)
$\mathrm{Fe}_{3} \mathrm{O}_{4}+\mathrm{CO} \leftrightarrow 3 \mathrm{FeO}+\mathrm{CO}_{2}$
Reaction (9)
$\mathrm{FeO}+\mathrm{CO} \leftrightarrow \mathrm{Fe}+\mathrm{CO}_{2}$
Reaction (10)
$\mathrm{Fe}_{3} \mathrm{O}_{4}+\mathrm{H}_{2} \leftrightarrow 3 \mathrm{FeO}+\mathrm{H}_{2} \mathrm{O}$
Reaction (11)
$\mathrm{FeO}+\mathrm{H}_{2} \leftrightarrow \mathrm{Fe}+\mathrm{H}_{2} \mathrm{O}$
Reaction (12)

Some of the important slags forming reactions are represented by reactions 13 through 18 . Due to complexity and inhomogenity of the slag system some reactions are excluded.

$\mathrm{CaCO}_{3} \leftrightarrow \mathrm{CaO}+\mathrm{CO}_{2} \quad$ Reaction (13)

$\mathrm{CaO}+\mathrm{SiO}_{2} \leftrightarrow \mathrm{CaSiO}_{3} \quad$ Reaction (14) 
CHAPTER 2 THEORETICAL BACKGROUND -19-

$\begin{array}{ll}\mathrm{SiO}_{2}+2 \mathrm{C} \leftrightarrow \mathrm{Si}+2 \mathrm{CO} & \text { Reaction (15) } \\ \mathrm{FeO}+\mathrm{SiO}_{2} \leftrightarrow \mathrm{FeSiO}_{3} & \text { Reaction (16) } \\ \mathrm{FeSiO}_{3}+\mathrm{CaO} \leftrightarrow \mathrm{CaSiO}_{3}+\mathrm{FeO} & \text { Reaction (17) } \\ \mathrm{FeS}+\mathrm{CaO}+\mathrm{C} \leftrightarrow \mathrm{CaS}+\mathrm{FeO}+\mathrm{CO} & \text { Reaction (18) }\end{array}$

After the reduction of the iron ore (magnetite) according to reactions 712, the carbon diffusion reactions 19-21 into the metal lowers the melting temperature of the metal (this is until the eutectic composition is reached) as shown in Figure 2.3. The temperature versus carbon composition stability diagram is shown in Figure 2.3. Slag separation can only be achieved after the formation of two liquid products; slag and metal. This is due to the immiscibility and density difference.
$\mathrm{Fe}+\mathrm{C} \leftrightarrow \mathrm{Fe}(\mathrm{C})$
Reaction (19)
$3 \mathrm{Fe}+\mathrm{C} \leftrightarrow \mathrm{Fe}_{3} \mathrm{C}$
Reaction (20)
$3 \mathrm{Fe}+2 \mathrm{CO} \leftrightarrow \mathrm{Fe}_{3} \mathrm{C}+\mathrm{CO}_{2}$
Reaction (21)
$3 \mathrm{Fe}+\mathrm{CO}+\mathrm{H}_{2} \leftrightarrow \mathrm{Fe}_{3} \mathrm{C}+\mathrm{H}_{2} \mathrm{O}$
Reaction (22) 
The kinetics of these reactions are enhanced by agglomeration of an iron ore source, flux, and reductant/carburizer together. The close contact of the reacting materials and availability of large number of reacting sites enhances the direct reduction and slag forming reactions. Also, the internal gas generation ,and small diffusion distances in the sample enhances the indirect reduction reactions, reducing gas regeneration, slag forming and carburization reactions (Nascimento et al, 1998 ; Mourao and Capacchi, 1996 ; Agrawal et al, 2000 ; Goksel ,1977 ; Goksel et al, 1991 ; Goksel et al, 1988)

\subsubsection{Slag Separation Requirements and Iron - Iron Carbide Metastable System}

One of the most important features of the pig iron nugget process is the separation of impurities from the metal by formation of fusible slag. The slag separation requirements for the pig iron nugget process are schematically shown in Figure 2.2. It can be seen from Figure 2.2 that slag separation can only be achieved after formation of two immiscible liquid phases, metal and slag. During the reduction of magnetite to pure iron, slag forming reactions take place. The slag formed melts at lower temperatures (around $1200^{\circ} \mathrm{C}$ ) than $1535^{\circ} \mathrm{C}$ which is the melting temperature for the pure iron produced. Carburization of the pure iron is required for lowering its melting temperature and obtaining a melt. These phenomena will be investigated by the study of the iron carbon metastable phase diagram. 


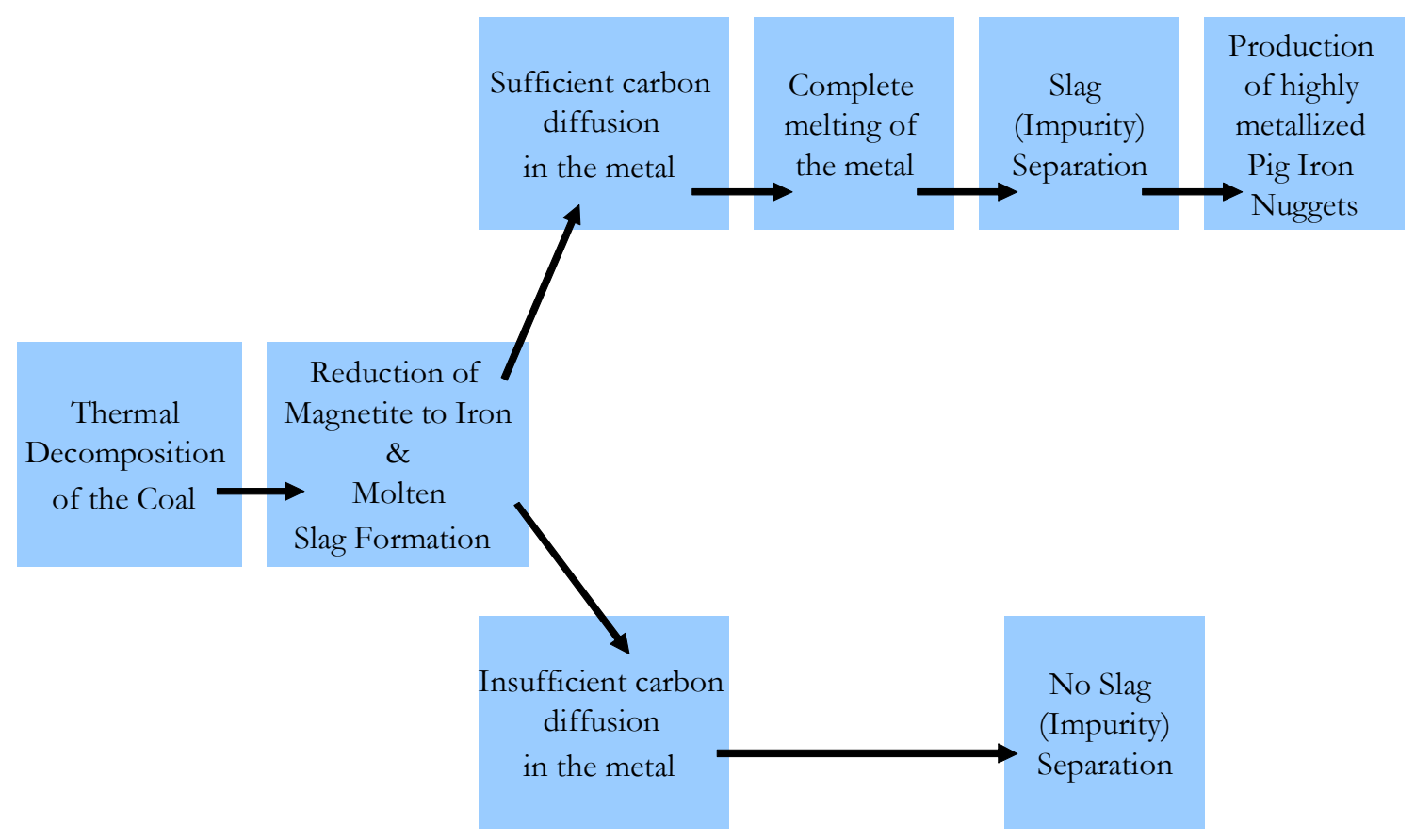

Figure 2.2 The schematic diagram showing the slag separation requirements for pig iron nugget process

\section{Iron - Iron Carbide Metastable System}

A portion of the iron - iron carbide phase diagram is shown in Figure 2.3. Figure 2.3 is not a true equilibrium diagram since the metastable intermetallic compound iron carbide $\mathrm{Fe}_{3} \mathrm{C}$ (cementite) $(6.67 \mathrm{wt} \% \mathrm{C}$ and $93.3 \%$ $\mathrm{Fe}$ ), is not a true equilibrium phase. The stable equilibrium phase diagram is similar to the one shown in Figure 2.3 but contains graphite instead of cementite $\left(\mathrm{Fe}_{3} \mathrm{C}\right)$. For iron-carbon alloys with low silicon content (example: pig iron nuggets), cementite $\left(\mathrm{Fe}_{3} \mathrm{C}\right)$ is kinetically favored over graphite. It is shown in Figure 2.3 that for alloys with less than $0.8 \mathrm{wt} \% \mathrm{C}$, cementite $\left(\mathrm{Fe}_{3} \mathrm{C}\right)$ can form 
CHAPTER 2 THEORETICAL BACKGROUND -22-

when the temperature drops below $723^{\circ} \mathrm{C} . \mathrm{Fe}_{3} \mathrm{C}$ will remain as a compound indefinitely at room temperature. However when subjected to required heat treatment (furnace temperature $650-700{ }^{\circ} \mathrm{C}$, residence time several years) it will gradually decompose into $\alpha$-Fe and graphite (carbon) which will remain upon subsequent cooling to room temperature (Callister ,1997). The decomposition of cementite $\left(\mathrm{Fe}_{3} \mathrm{C}\right)$ to $\mathrm{Fe}$ and graphite can be promoted with silicon additions.

Pure iron, upon heating, experiences changes in its crystal structure as shown in Figure $2.3(0 \mathrm{wt} \% \mathrm{C})$. When pure liquid iron cools down to $1535^{\circ} \mathrm{C}$ it initially transforms into a body centered cubic structure, $\delta$ ferrite (delta iron). On further cooling down to $1403{ }^{\circ} \mathrm{C}$ the body centered cubic structure transforms to a face centered cubic structure $\gamma$ iron (gamma iron). This face centered cubic structure transforms back to a body centered cubic structure known as $\alpha$ ferrite (alpha iron) when $910{ }^{\circ} \mathrm{C}$ is reached.

These three allotropic forms of iron, and carbon as an interstitial solute, form solid solutions which are represented on Figure 2.3 by $\delta$-ferrite (delta iron) $(\delta$-Fe), $\alpha$-ferrite (alpha iron) $(\alpha-\mathrm{Fe})$ and $\gamma$-iron (Austenite) $(\gamma$-Fe); single phase fields (McGowan, 2003). The solubility of carbon in each of these three phases is a function of temperature. The $\alpha$-ferrite and $\delta$-ferrite both have body centered cubic structures, each with different lattice parameters. As the phase diagram indicates (see Figure 2.3) carbon is only slightly soluble in $\alpha$-ferrite and $\delta$-ferrite. This is due to the shape and size of the body centered cubic interstitial positions. These positions cannot accommodate the carbon atoms as well as the face centered cubic structure interstitial sites (Callister, 1997). The maximum solubility of carbon in $\alpha$-ferrite is 0.0218 wt $\%$ at $723{ }^{\circ} \mathrm{C}$ which decreases with decreasing temperature to $0.008 \mathrm{wt} \%$ at room temperature. The maximum 
CHAPTER 2 THEORETICAL BACKGROUND -23-

solubility of carbon in $\delta$-ferrite is $0.09 \mathrm{wt} \%$ at $1495{ }^{\circ} \mathrm{C}$. Austenite has a face centered cubic structure; this structure allows it to dissolve more carbon due to the larger interstitial positions available when compared to body centered cubic structure. Although carbon is an austenite stabilizer and expands the temperature range of stability, austenite is not stable below $723^{\circ} \mathrm{C}$ when only alloyed with carbon (Krauss, 1990). The maximum solubility of carbon in austenite is $2.08 \mathrm{wt} \%$ at $1148{ }^{\circ} \mathrm{C}$ (this solubility is approximately 100 times greater than the maximum solubility for $\alpha$-ferrite) which decreases to $0.08 \%$ at $723{ }^{\circ} \mathrm{C}$ (Smith, 1993).

The reactions which can be used to define the two phase regions on Figure 2.3 are: the eutectic reaction, the eutectoid reaction, and the peritectic reaction. At the eutectic point, liquid with $4.30 \mathrm{wt} \% \mathrm{C}$ at $1147 \mathrm{C}$ decomposes to austenite $(\gamma-\mathrm{Fe})$ and cementite $\left(\mathrm{Fe}_{3} \mathrm{C}\right)$ (iron carbide) upon cooling. The eutectic reaction is an isothermal reversible reaction, and can be written as:

$$
\text { Liquid }(4.3 \% \mathrm{C}) \rightarrow \text { austenite }(\gamma-\mathrm{Fe})+\text { cementite }\left(\mathrm{Fe}_{3} \mathrm{C}\right)
$$

At the eutectoid point, solid austenite $(\gamma-\mathrm{Fe})$ with $0.8 \mathrm{wt} \% \mathrm{C}$ at $723 \mathrm{C}$ decomposes to $\alpha$ ferrite and cementite $\left(\mathrm{Fe}_{3} \mathrm{C}\right)$ upon cooling. The eutectoid reaction is an isothermal reversible reaction, and can be written as:

Austenite $(\gamma-\mathrm{Fe}) \rightarrow \alpha$ ferrite + cementite $\left(\mathrm{Fe}_{3} \mathrm{C}\right)$ 
The eutectoid microstructure, alternating layers of $\mathrm{Fe}_{3} \mathrm{C}$ and $\alpha$ ferrite is called pearlite. Pearlite is not a phase, but is a recognizable microconstituent, and forms by slow cooling from the austenite region. In plain iron carbon alloys (see Figure 2.3.) the average composition of the pearlite is identical to that of the austenite from which it grows.

At the peritectic reaction point, liquid iron with $0.53 \mathrm{wt} \% \mathrm{C}$ and $\delta$-Fe with 0.09 wt $\% \mathrm{C}$ at $1495 \mathrm{C}$ transforms into austenite. This reaction can be written as:

Liquid $(0.53 \% \mathrm{C})+\delta$-Fe $(0.09 \% \mathrm{C}) \rightarrow$ Austenite $(\gamma-\mathrm{Fe})$ 


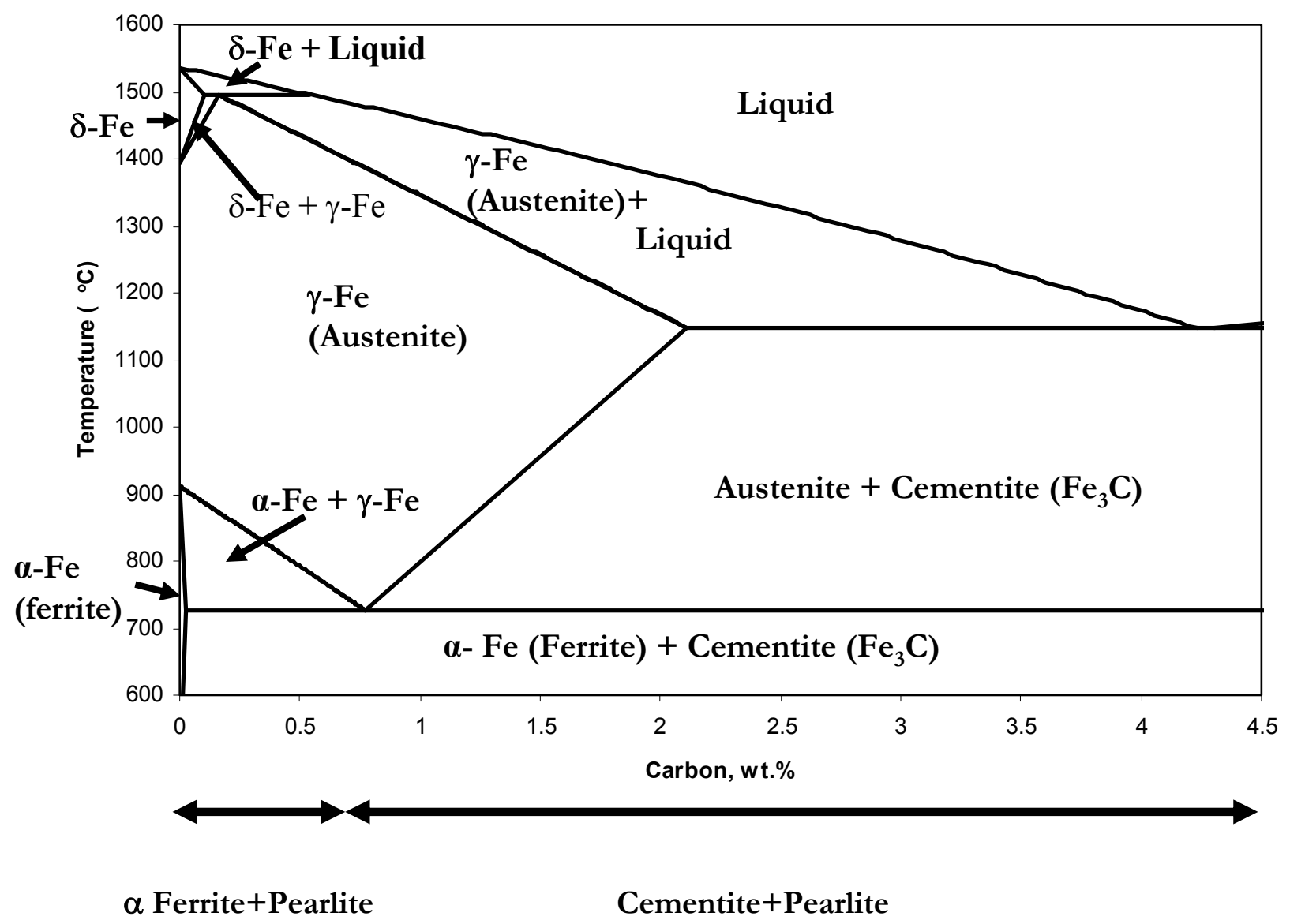

Figure 2.3 The portion of the iron - iron carbide metastable phase diagram (Krauss, 1990). The occurrence regions of $\alpha$ ferrite + Pearlite, and cementite + Pearlite microsconstituents are shown under equilibrium cooling conditions. 


\subsection{White Cast Iron}

The cast irons are a class of ferrous alloys with carbon content 2 to $4 \%$ and silicon content 1 to $3 \%$, in addition to other alloying elements (Smith, 1993). It can be estimated from Figure 2.3 that alloys with this carbon composition range become completely liquid at temperatures between approximately $1150^{\circ} \mathrm{C}$ and $1425^{\circ} \mathrm{C}$. Cast irons solidify as heterogeneous alloys and always have more than one phase and micro-constituent in their microstructure. During solidification of iron-carbon alloys the carbon is distributed in solid solution in austenite and the eutectic product of cementite $\left(\mathrm{Fe}_{3} \mathrm{C}\right)$ or graphite.

Four basic types of cast irons include: gray cast iron, white cast iron, malleable iron, and ductile iron (Smith, 1993). Each has specific microstructural characteristics due to the distribution of carbon in the system:

(i) In gray cast iron most of the carbon is in the form of graphite flakes;

(ii) In malleable cast iron most of the carbon is in the form of irregularly shaped graphite nodules;

(iii) In ductile cast iron most of the free carbon is in the form of graphite spheres;

(iv) In white cast iron most of the carbon is in the form of cementite $\left(\mathrm{Fe}_{3} \mathrm{C}\right)$. 
CHAPTER 2 THEORETICAL BACKGROUND -27-

Microstructural examination is the most effective technique for identification of cast irons. This examination is based on the form and shape in which the major portion of the carbon occurs in the iron. Chemical analysis is not definitive in identifying the various types of cast irons since the chemical compositions overlap as shown in Table I.

If for a low-silicon cast iron (less than $1.0 \mathrm{wt} \% \mathrm{Si}$ ), the carbon in the molten iron remains combined with iron in the form of iron carbide (cementite) it is called white cast iron (see Figure 2.4). The chemical composition of the white cast iron compared with blast furnace pig iron is shown in Table I. Throughout this research microstructural examination was used for identification of white cast iron, which has a comparable chemical composition with blast furnace pig iron.

The white cast iron microstructure shown in Figure 2.4 does not contain free graphite as does gray iron, malleable iron, or ductile iron. The fracture surface of this alloy appears white. In Figure 2.4 the dark grey areas represent the dendritic grains of austenite which formed first upon cooling (see Figure 2.3). Austenite dendrites transform by nucleation and growth to pearlite (alternating layers of $\mathrm{Fe}_{3} \mathrm{C}$ and $\alpha$-ferrite) under equilibrium cooling conditions. In Figure 2.4 light areas represents the eutectic iron carbide (cementite).

The hardness of white cast iron is dependent on the amount of cementite $\left(\mathrm{Fe}_{3} \mathrm{C}\right)$ in the structure, and the cooling rate. In general, as the carbon content increases the hardness increases due to increased amount of cementite in the structure (see Table 2.II). As the (equilibrium) cooling rate increases the hardness increases due the decrease in interlamellar spacing (the spacing between the $\mathrm{Fe}_{3} \mathrm{C}$ and $\alpha$-ferrite layers) of pearlite (see Table 2.II). 
CHAPTER 2 THEORETICAL BACKGROUND - 28-

Table 2.I Chemical composition ranges for typical unalloyed cast irons and blast furnace pig iron.

\begin{tabular}{|c|c|c|c|c|c|}
\hline Element & $\begin{array}{c}\text { Blast Furnace } \\
\text { Pig Iron wt \% } \\
\text { (Peacy and } \\
\text { Davenport, 1979) }\end{array}$ & $\begin{array}{c}\text { White Cast } \\
\text { Iron wt\% } \\
\text { (Smith, 1993) }\end{array}$ & $\begin{array}{c}\text { Gray Iron wt\% } \\
\text { (Smith, 1993) }\end{array}$ & $\begin{array}{c}\text { Malleable Iron } \\
\mathbf{w t} \% \text { (Smith, } \\
1993)\end{array}$ & $\begin{array}{c}\text { Ductile Iron } \\
\mathbf{w t} \% \\
\text { (Smith, 1993) }\end{array}$ \\
\hline $\mathrm{C}$ & $4-5$ (saturated) & $1.8-3.6$ & $2.5-4.0$ & $2.00-2.60$ & $3.0-4.0$ \\
\hline $\mathrm{Si}$ & $0.3-1$ & $0.5-1.9$ & $1.0-3.0$ & $1.10-1.60$ & $1.8-2.8$ \\
\hline $\mathrm{S}$ & 0.03 & $0.06-0.2$ & $0.02-0.25$ & $0.04-0.18$ & $<0.03$ \\
\hline $\mathrm{P}$ & $<1$ & $0.06-0.18$ & $0.05-1.0$ & $<0.18$ & $<0.10$ \\
\hline $\mathrm{Mn}$ & $0.1-2.5$ & $0.25-0.80$ & $0.25-1.0$ & $0.20-1.00$ & $0.10-1.00$ \\
\hline
\end{tabular}

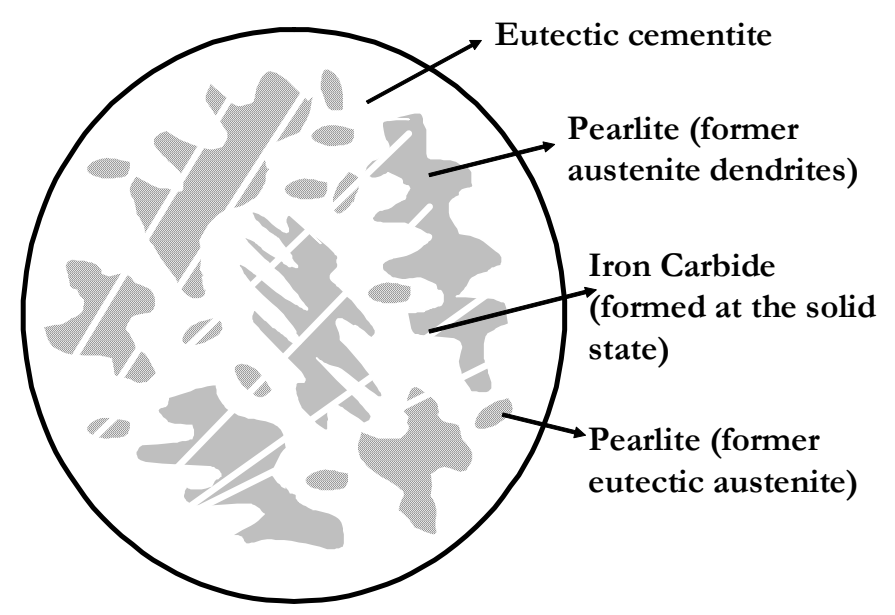

Figure 2.4 The schematic representation of the white cast iron microstructure at room temperature. The dark grey areas represents the former austenite dendrites which transformed to Pearlite (the eutectoid microstructure, alternating layers of $\mathrm{Fe}_{3} \mathrm{C}$ and $\alpha$ ferrite), and white areas represents the eutectic iron carbides (cementite). Cementite is hard, brittle and dominates the microstructure. 
Table 2.II Typical Vickers hardness values for certain iron-carbon alloys

(Vander Voort,1999)

\begin{tabular}{|c|c|}
\hline Material & HVN \\
\hline$\alpha$-Ferrite & 80 \\
\hline Pearlite (Fine interlammellar spacing) & 400 \\
\hline Pearlite (Coarse interlammellar spacing) & 250 \\
\hline Cementite $\left(\mathrm{Fe}_{3} \mathrm{C}\right)$ & 800 \\
\hline Alloy carbides & 1400 \\
\hline Mild Steel (0.1-1.2 wt \% C) & 140 \\
\hline Hardened Steel (Martensitic) & 900 \\
\hline
\end{tabular}




\section{Chapter 3 Experimental}

The broad purposes of the experiments were to (i) produce pig iron nuggets and develop procedures for their physical and chemical analysis and (ii) identify the furnace temperature and residence time dependent process requirements.

The experiments involved firing of the dried green balls made out of magnetite ore, coal, limestone and bentonite in a laboratory scale resistance box furnace at various furnace temperatures $\left(1425^{\circ} \mathrm{C}, 1435^{\circ} \mathrm{C}, 1445^{\circ} \mathrm{C}, 1450^{\circ} \mathrm{C}\right.$, $1455^{\circ} \mathrm{C}, 1465^{\circ} \mathrm{C}, 1475^{\circ} \mathrm{C}, 1485^{\circ} \mathrm{C}$ and $1495{ }^{\circ} \mathrm{C}$ ) and various furnace residence times (16 min, $22 \mathrm{~min}, 28 \mathrm{~min}, 34 \mathrm{~min}, 40 \mathrm{~min}, 50 \mathrm{~min}$, and $60 \mathrm{~min}$ ).

\subsection{Raw Matenials}

The green balls to be fired were made in a laboratory scale balling drum shown in Figure 3.1 utilizing the balling mixture which is composed of the following:

(i) $\quad 71.84 \%$ magnetite ore as an iron source

(ii) $\quad 0.66 \%$ dry wt. bentonite clay as binder

(iii) $\quad 7.5 \%$ dry wt. limestone as flux, and 
(iv) $20 \%$ dry wt. high volatile bituminous coal as reducing and carburizing agent.

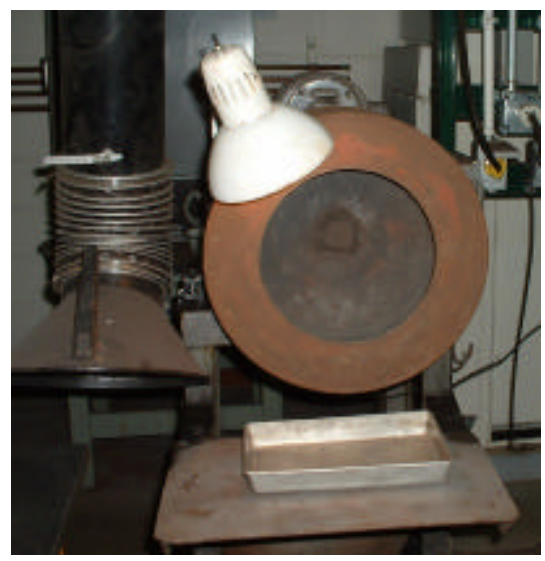

Figure 3.1 Laboratory scale pelletizing drum with overall diameter $40.6 \mathrm{~cm}$ (16 in), mouth diameter $25.4 \mathrm{~cm}$ (10 in) and depth $17.8 \mathrm{~cm}$ (7in) rotating in a counter-clock wise direction at $35 \mathrm{rpm}$.

The magnetite concentrate utilized as an iron source had $80 \%$ particle size passing 25 microns (500 mesh). The x-ray diffraction pattern of the magnetite concentrate utilized is shown in Figure 3.2 It can be seen from Figure 3.2 that only silicate gangue is present in the magnetite concentrate. 


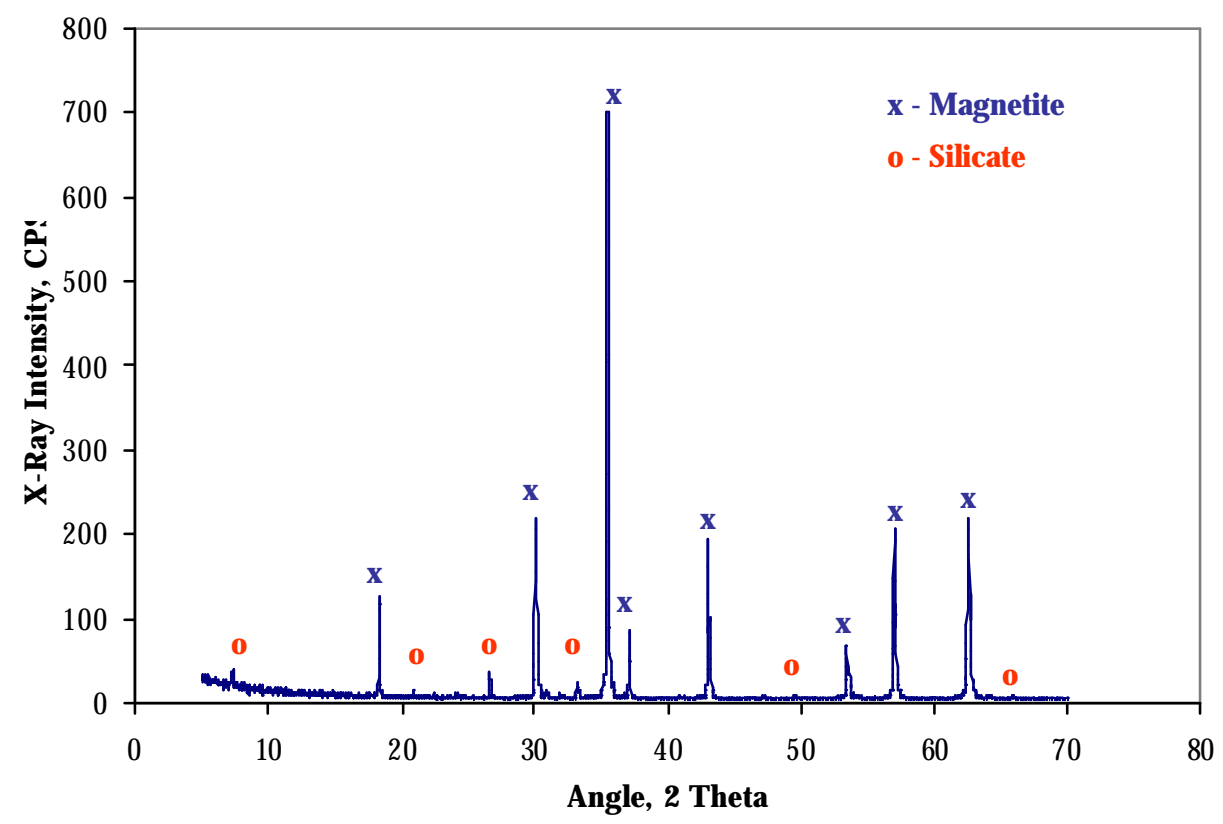

Figure 3.2 The x-ray diffraction pattern of the magnetite concentrate utilized as an iron source.

The bentonite clay utilized as a binder was a Na montmorillonite based clay and had $85 \%$ particle size passing 75 microns (200 mesh). The chemical analysis of the bentonite clay utilized is shown in Table 3.I.

The limestone was utilized as flux. The x-ray diffraction of the limestone utilized is shown in Figure 3.3. It can be seen from Figure 3.3 that the limestone was pure calcium carbonate $\left(\mathrm{CaCO}_{3}\right)$. 
Table 3.I The chemical analysis of the bentonite clay utilized as binder

\begin{tabular}{|c|c|}
\hline Analysis & \% \\
\hline $\mathrm{SiO}_{2}$ & 34.62 \\
\hline $\mathrm{Al}_{2} \mathrm{O}_{3}$ & 23.16 \\
\hline $\mathrm{Fe}_{2} \mathrm{O}_{3}$ & 5.49 \\
\hline $\mathrm{CaO}$ & 9.63 \\
\hline $\mathrm{MgO}$ & 2.11 \\
\hline $\mathrm{Na}_{2} \mathrm{O}$ & 1.06 \\
\hline $\mathrm{K}_{2} \mathrm{O}$ & 0.39 \\
\hline $\mathrm{TiO}_{2}$ & 1.25 \\
\hline $\mathrm{MnO}_{2}$ & 0.01 \\
\hline $\mathrm{P}_{2} \mathrm{O}_{5}$ & 2.20 \\
\hline $\mathrm{SrO}$ & 0.39 \\
\hline $\mathrm{BaO}$ & 0.53 \\
\hline $\mathrm{SO}_{3}$ & 5.93 \\
\hline Loss on ignition & 13.24 \\
\hline
\end{tabular}

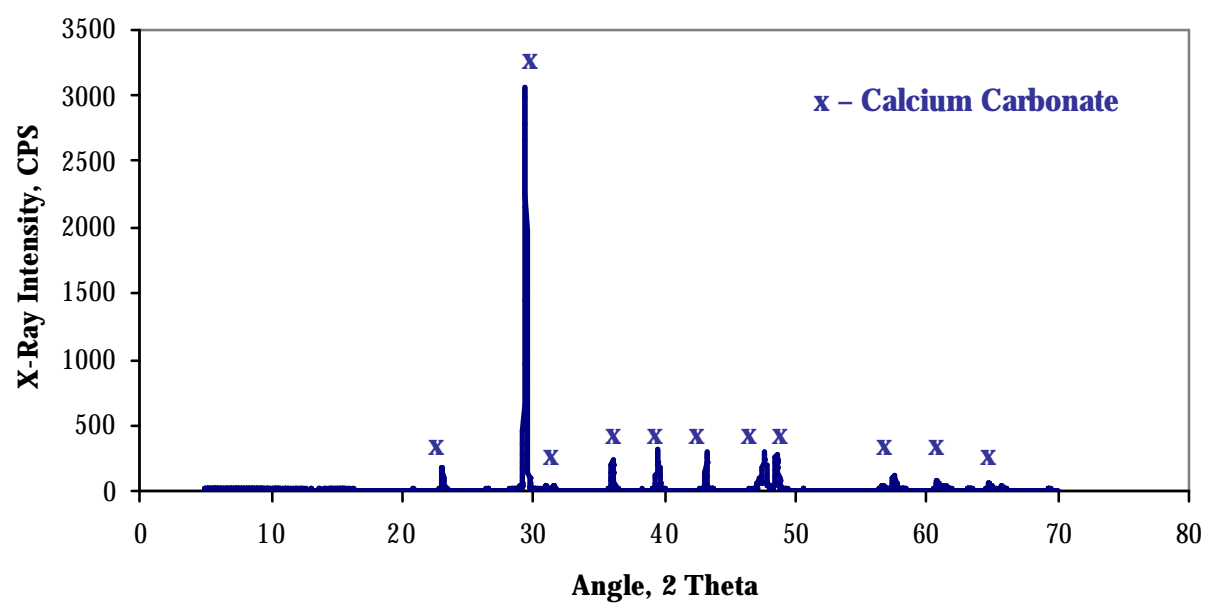

Figure 3.3 The x-ray diffraction pattern of the limestone utilized as flux. 
High volatile bituminous coal utilized as reducing and carburizing agent had - 20 mesh particle size distribution. The proximate and ultimate analysis of the coal is shown in Table 3.II.

Table 3.II The proximate and ultimate analysis of the coal utilized as reducing and carburizing agent.

\section{Proximate Analysis}

\begin{tabular}{|c|c|c|c|}
\hline & As Received & Moisture Free & AST M Method \\
\hline Moisture \% & 6.47 & & ASTM D 3302 \\
\hline Ash \% & 7.34 & 7.85 & ASTM D 3174 \\
\hline Sulfur \% & 2.11 & 2.25 & ASTM D 4239 \\
\hline BTU/ LB & 13,154 & 14,064 & ASTM D 1989 \\
\hline Volatile \% & 30.73 & 32.85 & ASTM D 3175 \\
\hline Fixed Carbon \% & 55.46 & 59.29 & ASTM D 3172 \\
\hline
\end{tabular}

\section{Ultimate Analysis}

\begin{tabular}{|c|c|c|c|}
\hline & As Received & Moisture Free & AST M Method \\
\hline Carbon \% & 72.89 & 77.93 & ASTM D 5373 \\
\hline Hydrogen \% & 4.78 & 5.11 & ASTM D 5373 \\
\hline Nitrogen \% & 1.30 & 1.39 & ASTM D 5373 \\
\hline Oxygen \% & 5.11 & 5.46 & ASTM D 3176 \\
\hline
\end{tabular}




\subsection{Procedures}

The experimental procedures for dried green ball and pig iron nugget production are shown in Figure 3.4(Anameric and Kawatra, 2004; Anameric et al., 2005). The physical and chemical analysis techniques utilized for nugget identification and characterization are shown in Figure 3.5.

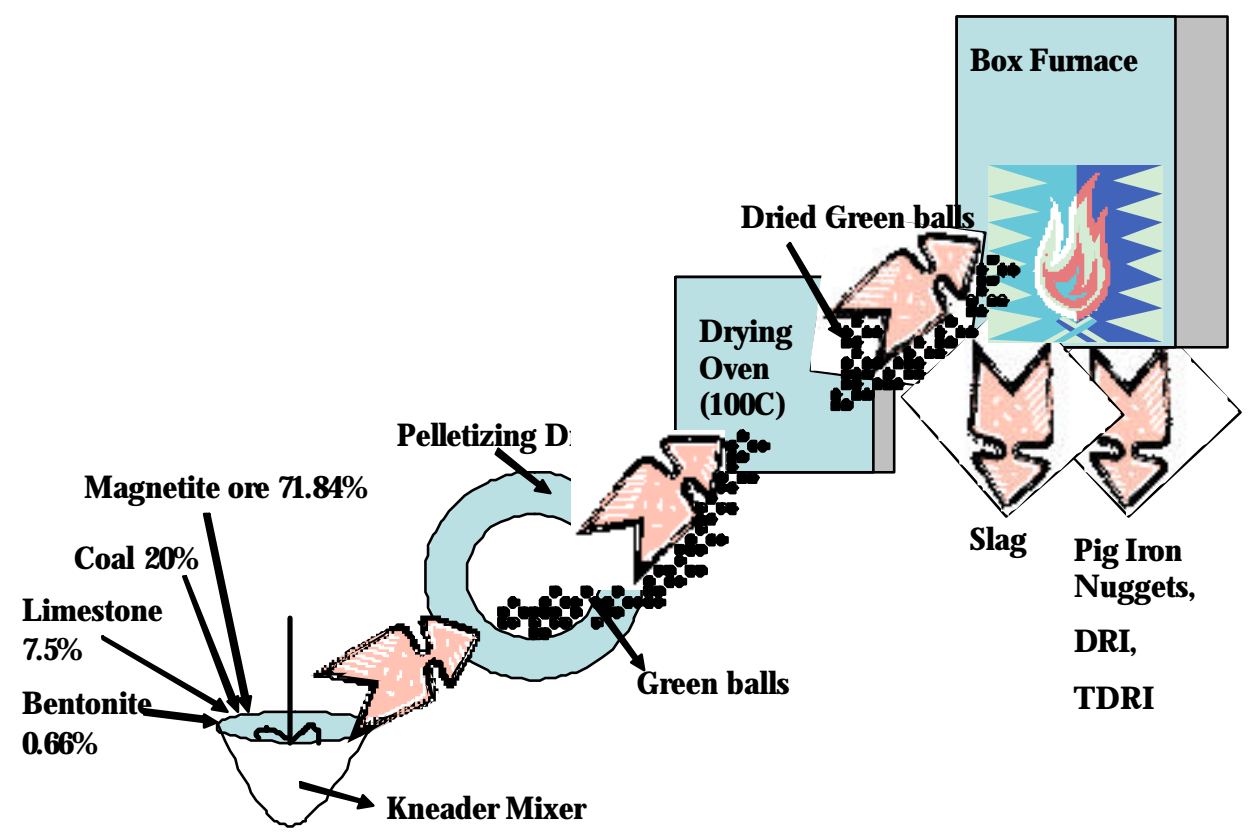

Figure 3.4 Schematic drawing of the experimental set-up used for production of dried green balls and pig iron nuggets. 
The dried green ball production and firing procedure can be summarized as follows (see Figure 3.4) (Kawatra and Ripke, 2001; A nameric and Kawatra, 2004; A nameric et al., 2005):

(i) The balling mixture, magnetite concentrate, limestone, coal, and bentonite were mixed in a kneader- mixer (Readco Type- A Mixer, $350 \mathrm{rpm}$ with $150 \mathrm{rpm}$ orbital motion),

(ii) After mixing the material was delumped through a $2.4 \mathrm{~mm}$ ( 8 mesh) screen prior to agglomeration,

(iii) A laboratory scale pelletizing drum (Figure 3.1) was utilized agglomerating the balling mixture,

(iv) The seeds were made adding small amount of material in the drum and moistening it with distilled water,

(v) After seeding, additional material and distilled water was added to make the green ball,

(vi) These green balls were removed from the drum periodically and screened between $12.7 \mathrm{~mm}$ and $11.2 \mathrm{~mm}(1 / 2 \times 7 / 16 \mathrm{in})$ in diameter,

(vii) Finished green balls were dried at $105^{\circ} \mathrm{C}(220 \mathrm{~F})$ in Blue M (Illinois, USA) forced air-drying oven for 20 - 24 hours to produce dried green balls 
(viii) These dried green balls were fired in a Thermolyne (subsidiary of Sybrou) 46100 type small-scale, high temperature, resistance laboratory box furnace utilizing clay graphite crucibles (diameter 4 $\mathrm{cm}$, height $5 \mathrm{~cm}$ )
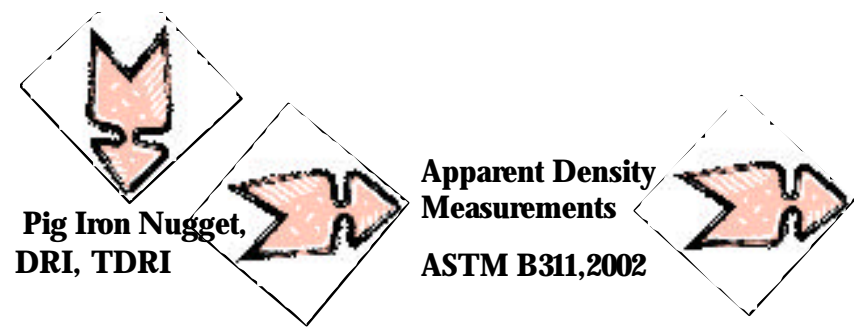
Mounting of the nuggets on epoxy resin AST M E 3,2001

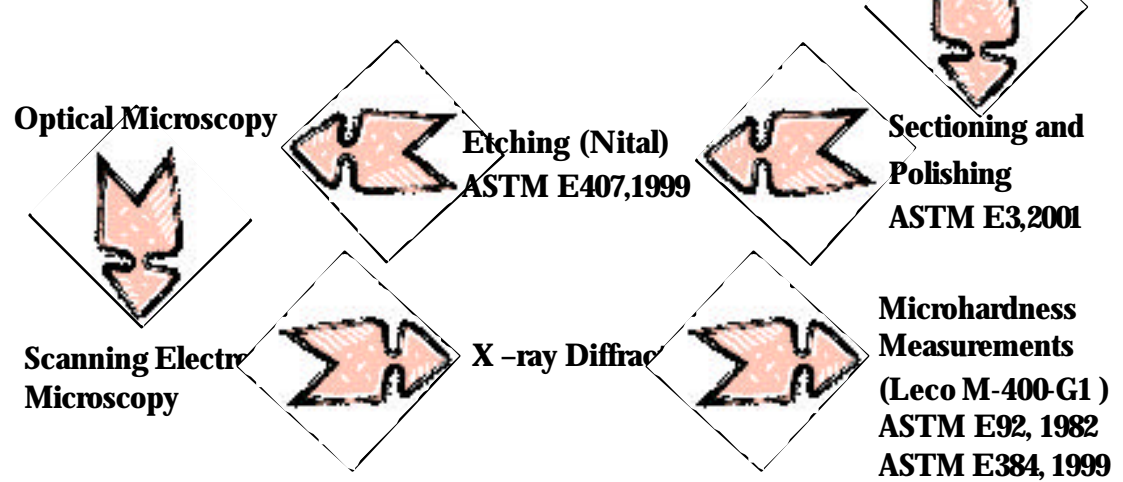

(a)

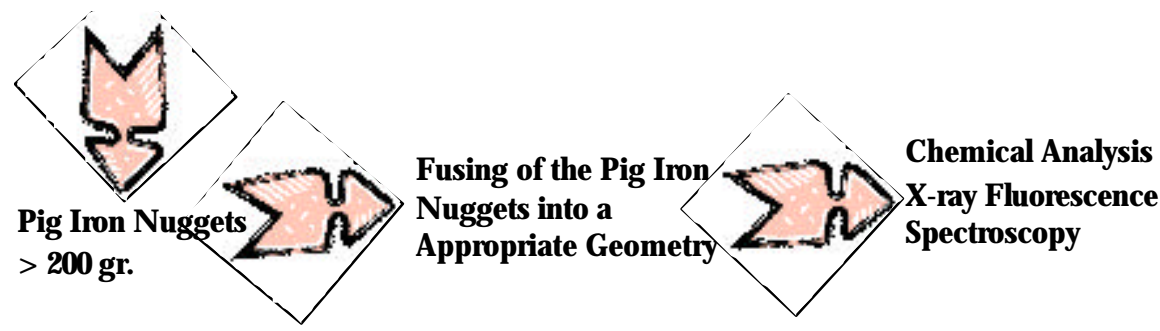

(b)

Figure 3.5 (a) Schematic drawing of the experimental set up used for analyzing the pig iron nuggets produced (b) Schematic drawing of the experimental set up used for chemical analysis of the pig iron nuggets produced. 
The physical and chemical analysis techniques (see Figure 3.5) were utilized in order to investigate the following:

(i) Apparent density measurements were utilized for the evaluation of degree of metallization, porosity and slag separation.

(ii) O ptical microscopy was utilized for phase identification, microstructural characterization and relating the pig iron nugget microstructure to known microstructures.

(iii) Scanning electron microscopy was utilized for further characterization of the microstructure with accompanying electron dispersive spectroscopy (ED S) of the phases and constituents.

(iv) X-ray diffraction was utilized for further phase identification and characterization of microstructure.

(v) X-ray fluorescence spectroscopy was utilized for obtaining a chemical analysis of the pig iron nuggets which was compared with blast furnace pig iron.

(vi) Microhardness measurements, for detection of the bulk carbon content change (1kg load) (16 measurements from one end to the other end on the metallized area). 


\subsubsection{Apparent Density Measurements}

Apparent density is the relation of the mass of a dry material to its volume including pores. The volume of displaced distilled water method (ASTM B 311-93, 2002) was utilized for apparent density measurements. The sample was weighed in air $\left(\mathrm{W}_{\mathrm{AIR}}\right)$ and weighed when submerged in distilled water $\left(\mathrm{W}_{\text {LIQ }}\right)$. The density of the water used for calculation was $1 \mathrm{~g} / \mathrm{cm}^{3}\left(\rho_{\text {LIQUID }}\right)$. The apparent density was calculated utilizing Equation 3:
$\Delta \mathrm{W}=\left(\mathrm{W}_{\text {AIR }}-\mathrm{W}_{\text {LIQ }}\right)=\mathrm{W}_{\text {DISPLACED LIQUID }}$
Equation 1
$\mathrm{V}_{\text {SAMPLE }}=\mathrm{V}_{\text {DISPLACED LIQUID }}=\left(\Delta \mathrm{W} / \rho_{\text {LIQUID }}\right)$
Equation 2
$\rho_{\text {SAMPLE }}=\left(\mathrm{W}_{\text {AIR }} * \rho_{\text {LIQUID }}\right)^{*} \Delta \mathrm{W}$
Equation 3

where $\mathrm{W}_{\text {AIR }}$ is the sample weight, $\mathrm{W}_{\text {LIQ }}$ is the sample weight when it is submerged in distilled water, $\rho_{\text {LIQUID }}$ is the distilled water density, $\rho_{\text {SAMPLE }}$ is the sample apparent density, $\mathrm{V}_{\text {SAMPLE }}$ is the sample volume, and $\mathrm{V}_{\text {DISPLACED LIQ UID }}$ is the displaced liquid volume. 


\subsubsection{Optical Microscopy, Scanning Electron Microscopy, and X-ray Diffraction}

Microstructural feature evaluation is an extremely useful method for analyzing product quality, physical and mechanical properties. Each type of microstructure and product is developed to characteristic property changes due to specific processing routes (Vander Voort, 1984).

Optical microscopy,scanning electron microscopy, X-ray diffraction was used for identification and characterization of the following microstructural features:

i. Austenite ( $\gamma$-iron), soft phase which forms first and transforms to Pearlite, alternating layers of $\alpha$-ferrite and cementite upon cooling

ii. $\alpha$-Ferrite, soft matrix phase with elements in solid solution, ductile

iii. Cementite $\left(\mathrm{Fe}_{3} \mathrm{C}\right)$, intermetallic hard phase, brittle

The samples were mounted, sectioned, polished, and etched for microstructural analysis (ASTM E 3, 2001) (see Figure 3.5). Samples were mounted in epoxy resin for easy handling purposes (for keeping the sample edges flat and convenient hold of the sample). Their sizes were reduced by substantial grinding (sectioning) for further preparation purposes. Then they were polished to obtain a highly reflective surface for microscopic examination. O nly limited amount of information can be obtained from as-polished samples, 
therefore they were etched to relieve microstructural features (Vander Voort, 1986). This was accomplished by etching the surface with Nital $4 \%$. Nital used consisted of 4\% nitric acid $\left(\mathrm{HNO}_{3}\right)$ in methanol (ASTM E 407, 1999). The etched samples were repolished and then analyzed utilizing scanning electron microscopy and X-ray diffraction for identification of the phases and microconstituents present.

\subsubsection{Chemical Analysis}

The chemical analysis of the pig iron nuggets was investigated in order to be able to:

(i) Better define and compare the pig iron nuggets with blast furnace pig iron,

(ii) Calculate the $\%$ metallization obtained by the process utilizing the equation 4 :

\footnotetext{
$\%$ Metallization $=\left(\% \mathrm{Fe}_{\text {nugget }} * \mathrm{M}_{\text {nugget }}\right) /\left(\% \mathrm{Fe}_{\text {dried green ball }} * \mathrm{M}_{\text {dried green ball }}\right)$ Equation 4
}

where $\mathrm{M}_{\text {nugget }}$ is the weight of the pig iron nugget, $\mathrm{M}_{\text {dred green ball }}$ is the weight of the dried green ball, $\% \mathrm{Fe}_{\text {nugget }}$ is the percent iron concentration of the pig iron nugget, and $\% \mathrm{Fe}_{\text {dried green ball }}$ is the percent iron content of the dried green ball. 
The chemical analysis was done by fusing approximately 200 grams of pig iron nuggets produced at same furnace temperature and residence time were fused into a disc and analyzing them utilizing X-ray florescence spectroscopy.

\subsubsection{Microhardness Measurements}

Microhardness is a measure of a material's resistance to abrasion or indentation. In this study, microhardness measurements were conducted on the metallized portion of the product to reflect process resulting compositional changes, solidification rate variations, and subsequent heat treatment variations. For example, as the carbon content of the pig iron nugget increases the hardness increases due to increasing amount of very hard constituent, cementite (Krauss, 1990). Microhardness measurements were conveniently used because they were taken without seriously damaging the samples (Vander Voort, 1984, 1986, 1999).

Vickers microhardness measurements were made (see Figure 3.6) by impressing a square-based pyramid diamond shaped indenter onto a surface of the sample to be measured; utilizing an instrument containing a microscope (Leco M-400-G 1) (ASTM E 92-82, 1997, ASTM E 384, 1999). The load used was $1 \mathrm{~kg}$. The impression was made for a period of $10 \mathrm{sec}$. after which the indenter is automatically removed. The length of the diagonals of the impression was measured in the microscope, and arithmetic mean ,d, was calculated. The Vickers hardness number VHN $\left(\mathrm{kg} / \mathrm{mm}^{2}\right)$ was computed by dividing the load by the indentation area using Equation 6(Vander Voort and Lucas, 1998):

HVN $=$ Constant $*$ (Test force $/$ Surface area of the indentation)

Equation 5 
$\mathrm{HVN}=1854.4^{*} \mathrm{P} / \mathrm{d}^{2}$

\section{Equation 6}

where $\mathrm{P}$ is the load in grams, and $\mathrm{d}$ is the arithmetic mean of the diagonal length in microns.

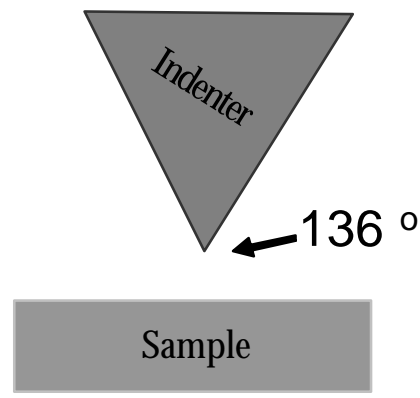

BEFORE

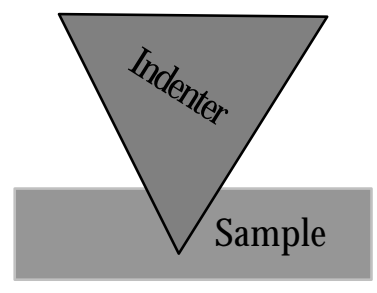

DURING

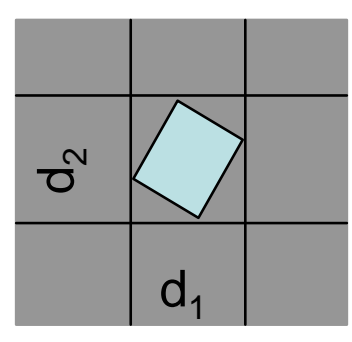

AFTER

Figure 3.6 The schematic representation of Vickers hardness measurements 


\section{Chapter 4 Results and Discussions}

\subsection{Products}

Throughout the heat treatment (firing) of the dried green balls thermal decomposition of the coal, slag forming reactions, slag melting and reduction of iron oxide to pure iron take place. After the reduction of iron oxide (magnetite) to pure iron; depending on the furnace temperature and residence time, the formation of three chemically and physically different products were observed. These products were:

i. $\quad$ Direct reduced iron (DRI) (see Figure 4.4)

ii. Transition direct reduced iron (TDRI)(see Figure 4.5)

iii. $\quad$ Pig iron nuggets and slag (see Figure 4.7).

These products were produced by increasing carburization of the pure iron during heat treatment, involving three different operational areas in the iron carbon metastable phase diagram. In the temperature range $1400-1475^{\circ} \mathrm{C}$ :

(i) At low carbon concentrations (see Figure 4.1) first a solid $\delta$ - iron forms which on cooling transforms to $\gamma$-iron (austenite), and finally to $\alpha$-ferrite. As the carbon content increases austenite ( $\gamma$-iron) will form which will also transform to $\alpha$-ferrite/ $\alpha$-ferrite + iron carbide on cooling. These solid state products are called direct reduced iron (DRI). 
(ii) As the carbon concentration increases beyond the austenite solidus (see Figure 4.1) a mixture of solid and liquid ( $\gamma$-iron and liquid) forms, and on cooling austenite ( $\gamma$-iron) transforms to $\alpha$-ferrite and cementite; and the liquid solidifies in a manner to include dendritic austenite $(\gamma$-iron) and a eutectic product containing cementite. Liquid and solid state products are called transition direct reduced iron (TDRI).

(iii) Further carbon concentration increases (see Figure 4.1) lead to $100 \%$ liquid formation which solidifies in a manner like white cast iron to form pig iron nuggets which give microstructures shown schematically in Figure 2.4.

Slag separation can only be achieved after the formation of two immiscible liquid phases; molten metal and molten slag. The partial melting observed in the TDRI results with partial slag separation. In contrast the complete melting of the metal in the pig iron nugget results in complete slag separation. Since there is no melting in the DRI formation, slag separation cannot be observed.

According to the iron-iron carbide metastable phase diagram, if sufficient carbon diffusion can be obtained, production of pig iron nuggets (molten metal) at furnace temperatures lower than $1400{ }^{\circ} \mathrm{C}$ is possible (see Figure 4.1). If this is the case, at furnace temperatures $>1147^{\circ} \mathrm{C}$, and $<1400^{\circ} \mathrm{C}$, after reduction of magnetite to pure iron, austenite will form. Solid state carbon diffusion will take place until the carbon content of austenite is high enough to form a melt (100\% liquid). The possibility of producing pig iron nuggets under the conditions stated above $\left(1147^{\circ} \mathrm{C}<\right.$ furnace temperature $<1400{ }^{\circ} \mathrm{C}$ ) (furnace residence times $>2$ hours) was also investigated. Examples of the direct reduced iron (DRI) produced by firing the dried green balls at furnace 
temperatures $1200 \mathrm{C}$ and $1350 \mathrm{C}$ with residence times 3 hours and 2.5 hours are shown in Figures 4.2 and 4.3 respectively. This experimental set up has a maximum residence time limitation of 3 hours, thus for this set up it can be seen from these figures (Figures 4.2 and 4.3) that pig iron nuggets can not be produced at furnace temperatures $>1147^{\circ} \mathrm{C}$, and $<1400^{\circ} \mathrm{C}$.

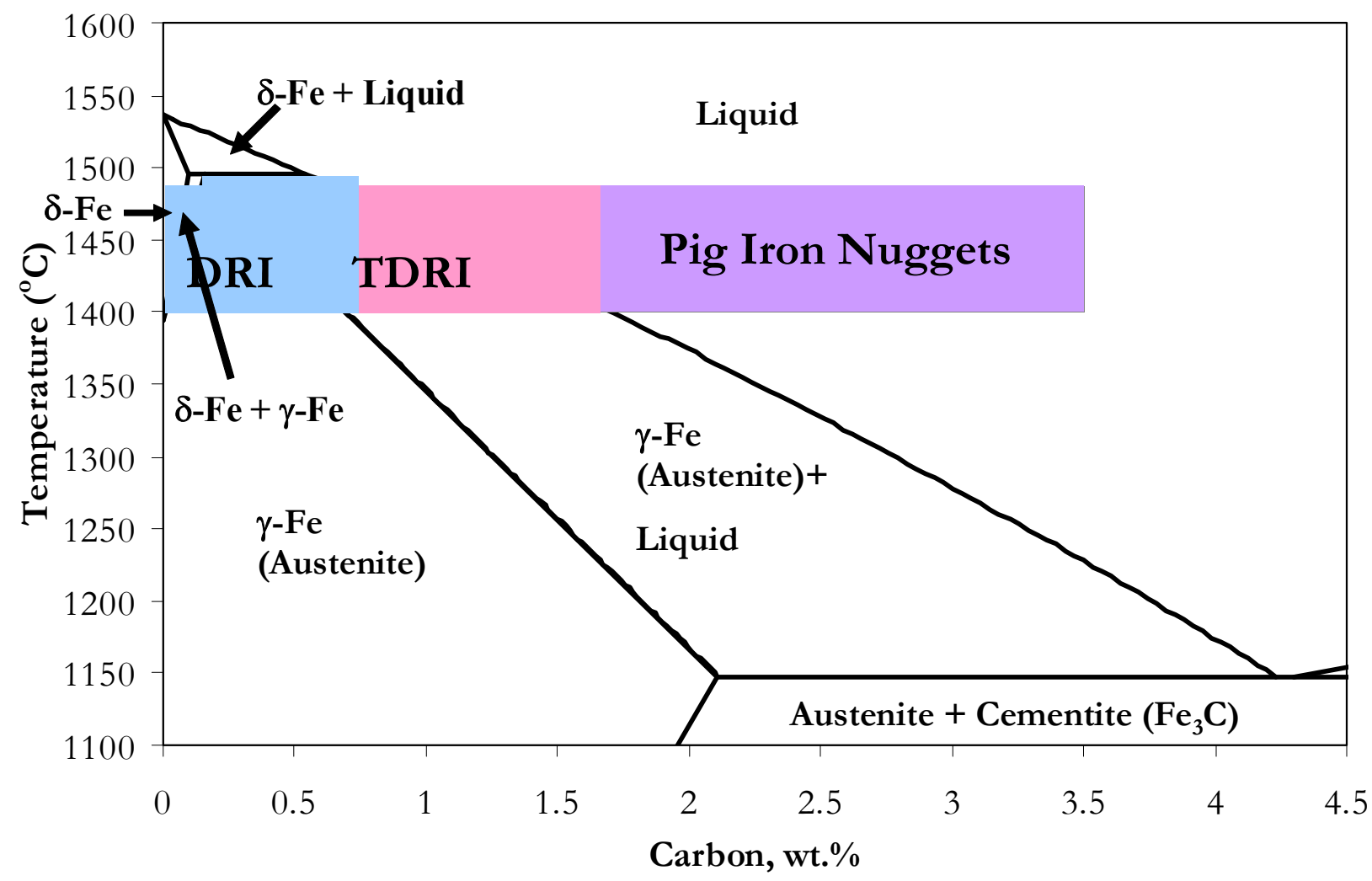

Figure 4.1 A portion of the iron-carbon metastable phase diagram, where the operational regions investigated for DRI, TDRI, and pig iron nuggets is shown. 
However, pig iron nuggets were conclusively produced at furnace temperatures higher than $1400{ }^{\circ} \mathrm{C}$. For operational temperatures higher than $1400{ }^{\circ} \mathrm{C}$, after reduction of magnetite to pure iron, delta iron (instead of austenite) forms. Solid state carbon diffusion takes place forming D RI, and TD RI. After TD RI solid- liquid state carbon diffusion takes place until the pig iron nuggets are formed. After pig iron nugget production at higher furnace temperatures and residence times more carbon dissolves in the system. Thus, the maximum carbon diffusion which can be obtained in these nuggets is $3.5 \%$ (see Table 4.I).

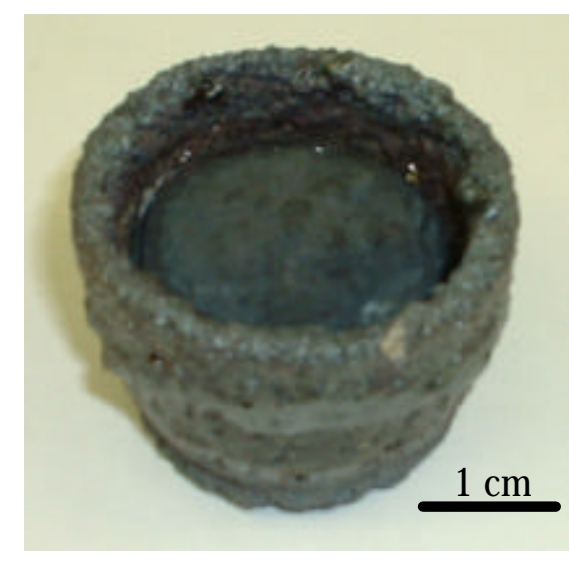

Figure 4.2 An example of the direct reduced iron produced at furnace temperature $1200^{\circ} \mathrm{C}$ and furnace residence times 3 hours. 


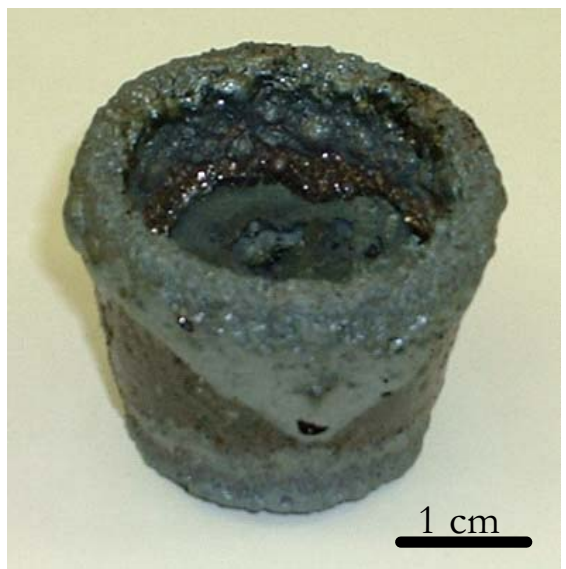

Figure 4.3 An example of the direct reduced iron produced at furnace temperature $1350{ }^{\circ} \mathrm{C}$ and furnace residence times 2.5 hours.

\subsubsection{Direct Reduced Iron (DRI)}

Direct reduced iron produced was a complete solid state product, had a sponge like structure and low apparent density (Figure 4.4). The metallized portion of the DRI did not melt. In addition, slag was not separated from the metallized portion. 


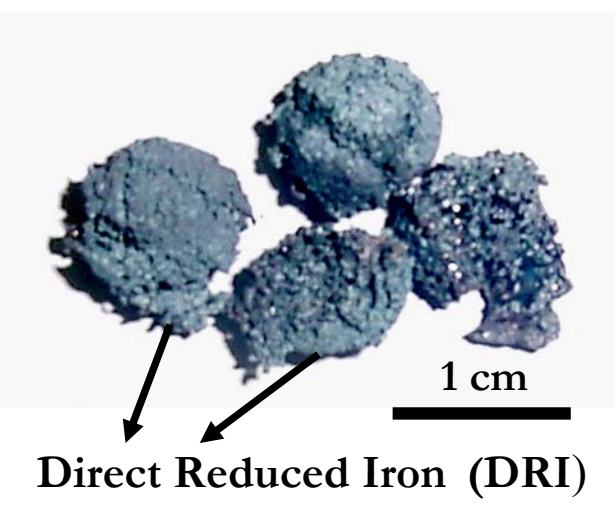

Figure 4.4 The direct reduced iron produced at furnace temperature $1425{ }^{\circ} \mathrm{C}$ and furnace residence time $16 \mathrm{~min}$. Its apparent density is lower than pig iron nuggets. This is due to porosity, and the intimate mixture of slag and metallic iron ( $\alpha$ ferrite).

\subsubsection{Transition Direct Reduced Iron (TDRI)}

The transition direct reduced iron (TDRI) produced shown at Figure 4.5 had a higher apparent density than DRI due to partial slag separation, reduced amount of pores, and higher metallization. TDRI is produced when more carbon dissolves in DRI and the metallized portion partially melts (see Figure 4.1). As a result of this partial melting, partial slag separation can be achieved. 


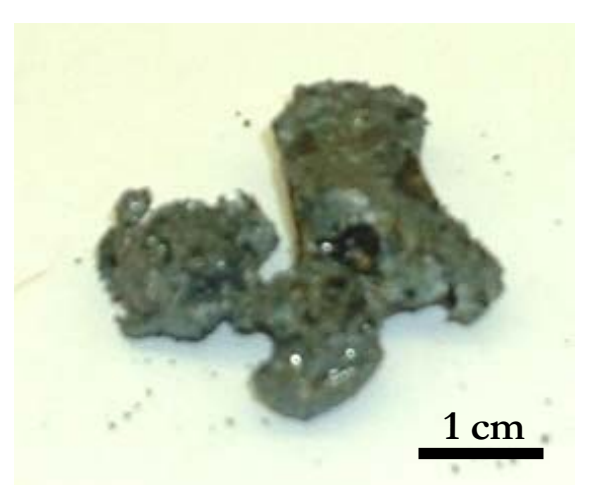

Figure 4.5 The transition direct reduced iron produced at furnace temperature $1425{ }^{\circ} \mathrm{C}$ and furnace residence time $28 \mathrm{~min}$. Its apparent density is lower than pig iron nuggets, and higher than DRI. This is due to the reduced amount of porosity, and partial slag separation, and higher metallization.

\subsubsection{Pig Iron Nuggets}

The iron nuggets produced had a pebble shape structure and high apparent density. Both molten slag and the pig iron nugget (see Figure 4.1) were observed (see Figure 4.6) when the crucible was pulled out of the furnace. Due to the immiscibility of the liquid phases, slag was cleanly separated from the nugget producing a slag free product. The pig iron nugget accompanied by its slag is shown in Figure 4.7. 


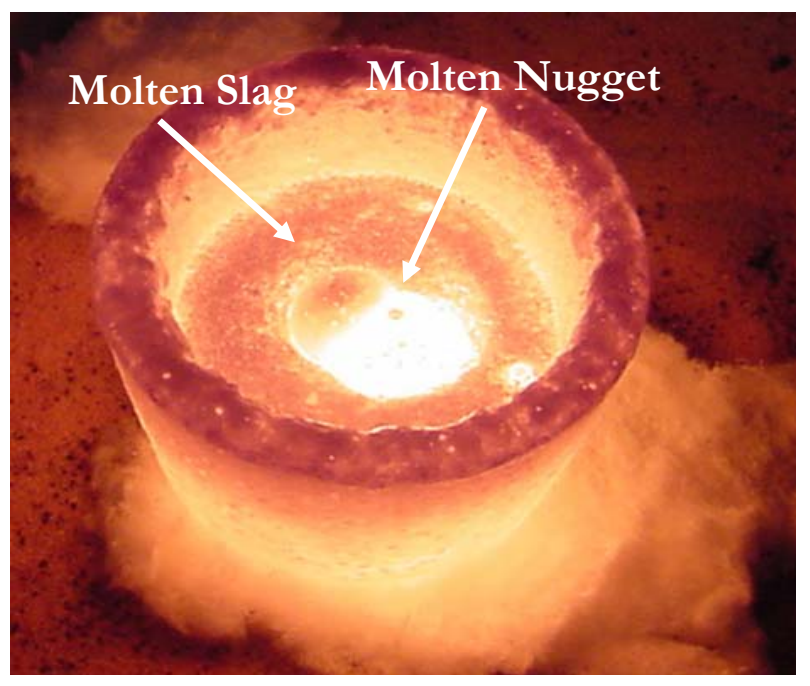

Figure 4.6 Molten iron nugget and molten slag observed when the crucible was pulled out of the furnace. The molten nugget shown was made at furnace temperature $1450{ }^{\circ} \mathrm{C}$ and residence time $22 \mathrm{~min}$.

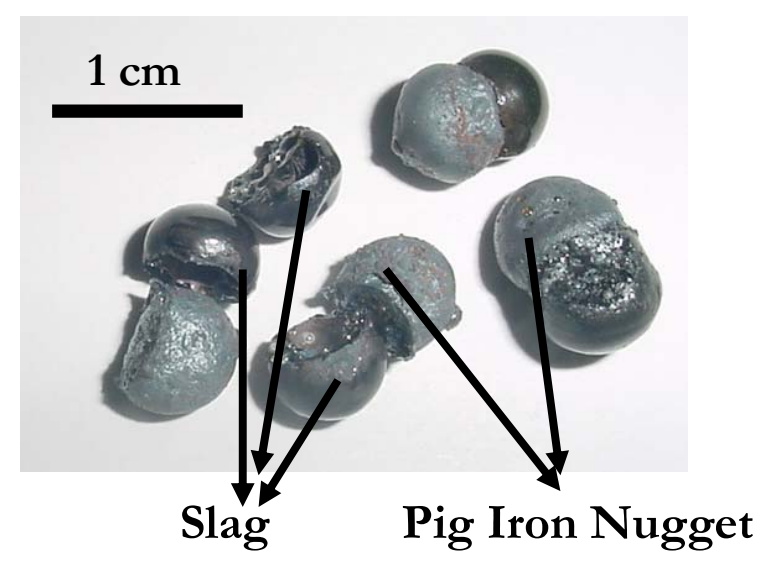

Figure 4.7 Pig iron nuggets made at furnace temperature $1450{ }^{\circ} \mathrm{C}$ and residence time 22 min, accompanied with their slag. Slag can easily be separated by physical means. 


\subsubsection{Chemical Analysis and Degree of Metallization}

The chemical analysis of the pig iron nuggets was investigated in order to be able to better define and compare them with white cast iron and blast furnace pig iron. The chemical analysis of the pig iron nugget produced at furnace temperatures $1450{ }^{\circ} \mathrm{C}$ and $1475^{\circ} \mathrm{C}$ and residence times $22 \mathrm{~min}$ and 28 min along with blast furnace pig iron and white cast iron is shown in Table 4.I

Table 4.I A comparison of the chemical compositions of the blast furnace pig iron, white cast iron and pig iron nuggets.

\begin{tabular}{|c|c|c|c|}
\hline Element & $\begin{array}{c}\text { Blast Furnace Pig Iron } \\
\% \\
\text { (Peacy and Davenport, } \\
1979 \text { ) }\end{array}$ & $\begin{array}{c}\text { White Cast Iron } \\
\% \\
\text { (Smith, 1993) }\end{array}$ & $\begin{array}{c}\text { Pig Iron Nuggets } \\
\%\end{array}$ \\
\hline $\mathrm{Fe}$ & $90-95.5$ & $93.3-97.3$ & $95-97$ \\
\hline $\mathbf{C}$ & $4-5$ & $1.8-3.6$ & $1.7-3.5$ \\
\hline Si & $0.3-1$ & $0.5-1.9$ & $\sim 0.8$ \\
\hline $\mathbf{S}$ & 0.03 & $0.06-0.2$ & $0.2-0.8$ \\
\hline $\mathbf{P}$ & $<1$ & $0.06-0.18$ & $\sim 0.12$ \\
\hline Mn & $0.1-2.5$ & $0.25-0.80$ & $\sim 0.12$ \\
\hline
\end{tabular}


It can be seen from Table 4.I that pig iron nuggets contain equivalent or more $\%$ iron than blast furnace pig iron. Pig iron nuggets contain an equivalent amount of carbon when compared with white cast iron.

The metallization degree of the pig iron nuggets produced was calculated using equation 4 (see page 33).

The degrees of metallization for pig iron nuggets was found to be $94-97$ $\%$ which was equivalent to degrees of metallization for blast furnace pig iron.

\subsubsection{Summary - Pig Iron Nuggets versus Blast Furnace Pig Iron}

Pig iron nuggets which have comparable physical and chemical properties with blast furnace pig iron were produced. The comparison of some of the properties of the pig iron nuggets produced and blast furnace pig iron is shown in Table 4.II. 
Table 4.II The comparison of some of the properties of the pig iron nuggets and blast furnace pig iron.

\begin{tabular}{|c|c|c|}
\hline & Blast Furnace Pig Iron & Pig Iron Nuggets \\
\hline$\% \mathrm{Fe}$ & $\begin{array}{c}90-95.5 \% \text { (Peacy and Davenport, } \\
1979)\end{array}$ & $95-97 \%$ \\
\hline$\% \mathrm{C}$ & $\begin{array}{c}4 \% \text { (saturated) (Peacy and } \\
\text { Davenport, 1979) }\end{array}$ & $1.7-3.5\left(\right.$ In the form of $\left.\mathrm{Fe}_{3} \mathrm{C}\right)$ \\
\hline$\%$ Metallization & $\begin{array}{c}94-98 \%(\text { Peacy and Davenport, } \\
1979)\end{array}$ & $94-97 \%$ \\
\hline$\% \mathrm{Si}$ & $0.3-1$ & $\sim 0.8$ \\
\hline $\begin{array}{l}\text { Density or Apparent Density } \\
\qquad\left(\mathrm{gr} / \mathrm{cm}^{3}\right)\end{array}$ & $7.2 \mathrm{gr} / \mathrm{cm}^{3}$ (Weiss, 1985) & $6.5-7 \mathrm{gr} / \mathrm{cm}^{3}$ \\
\hline Presence of Gangue Minerals & $\begin{array}{c}\text { Removal of gangue minerals by } \\
\text { slag separation }\end{array}$ & $\begin{array}{c}\text { Removal of gangue minerals by } \\
\text { slag separation }\end{array}$ \\
\hline Operational Temperatures & $\begin{array}{c}\text { Above the fusion temperature of } \\
\text { the iron }(>1535 \mathrm{C})\end{array}$ & $\begin{array}{c}\text { Below the fusion temperature of } \\
\text { the iron }(<1535 \mathrm{C})\end{array}$ \\
\hline $\begin{array}{c}\text { Reducing - Carburizing Agent } \\
\text { Utilized }\end{array}$ & Metallurgical grade Coke & Coal \\
\hline
\end{tabular}

It can be Table 4.II that pig iron nuggets produced comparable high apparent densities, high iron concentration and high degrees of metallization with blast furnace pig iron. Similar to blast furnace process throughout the pig iron process the gangue minerals contained in the feed were fused into slag phase. This slag phase was separated from the metal by obtaining a metal melt. However, unlike blast furnace process the melting of the metal was accomplished by the carburization and subsequent melting temperature decrease. 
CHAPTER 4 RESULTS AND DISCUSSIONS - -55-

\subsection{Fumace Residence Time Effects on Pig Iron Nugget Production}

D ried green balls were fired at a furnace temperature of $1425^{\circ} \mathrm{C}$ and residence times of $16 \mathrm{~min}, 22 \mathrm{~min}, 28 \mathrm{~min}, 34 \mathrm{~min}, 40 \mathrm{~min}, 50 \mathrm{~min}$ and $60 \mathrm{~min}$ to observe the DRI, TD RI, and pig iron nugget formations. The results are summarized in Figure 4.8 and 4.9. Pictures of D RI, TDRI, and pig iron nuggets produced at constant furnace temperature of $1425^{\circ} \mathrm{C}$ and their residence times are shown in Figures 4.8 and 4.9. Direct reduced iron was produced at furnace temperature of $1425^{\circ} \mathrm{C}$ and residence times of $10 \mathrm{~min}, 16 \mathrm{~min}$, and $22 \mathrm{~min}$. Transition direct reduced iron was produced at furnace temperature of $1425{ }^{\circ} \mathrm{C}$ and residence time pf $28 \mathrm{~min}$. The pig iron nuggets were produced at furnace temperature of $1425^{\circ} \mathrm{C}$ and residence times of $=40 \mathrm{~min}$.

The formation of the DRI, TDRI and pig iron nuggets was dependent on the carbon composition of the metallic iron (see Figure 3.1). Therefore, as the furnace residence time increases: (i)the amount of carbon diffused in the metal increases, and (ii) the melting point of the metallized portion decreases (until the eutectic point $(4.3 \% \mathrm{C}$ ) is reached (see Figure 2.3)) which results in the formation of pig iron nuggets. 


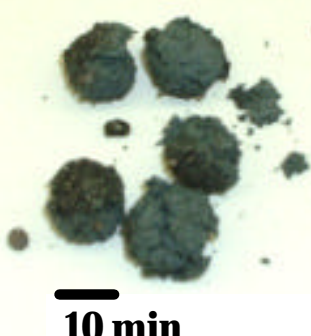

$10 \mathrm{~min}$

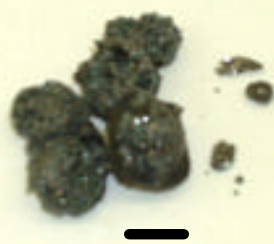

$16 \mathrm{~min}$

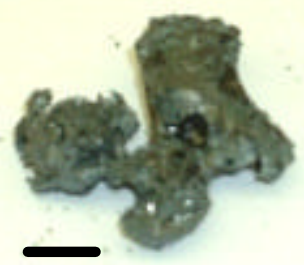

$28 \mathrm{~min}$

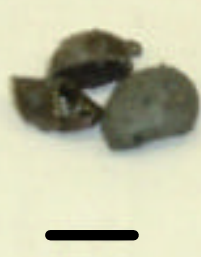

$40 \mathrm{~min}$

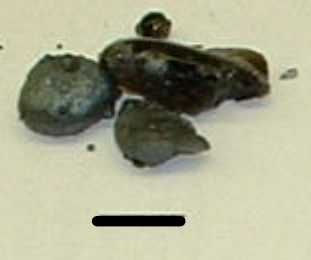

$60 \mathrm{~min}$

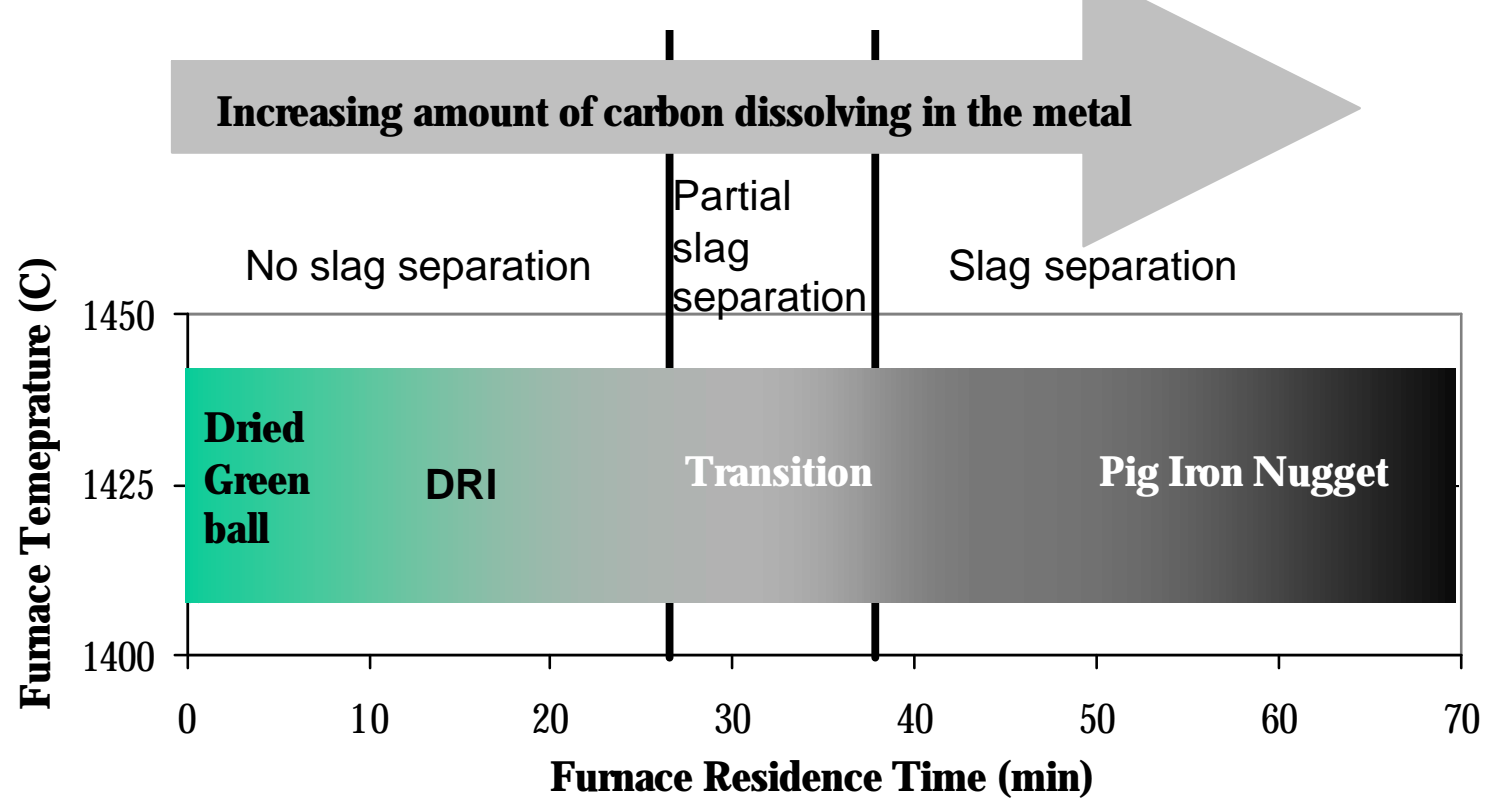

Figure 4.8 The summary of the experimental work conducted for determining the residence times required for pig iron nugget making at $1425^{\circ} \mathrm{C}$ furnace temperature. The pictures of the DRI, TDRI and pig iron nuggets produced are shown on the top of the figure. The scale bars shown are $1 \mathrm{~cm}$. 


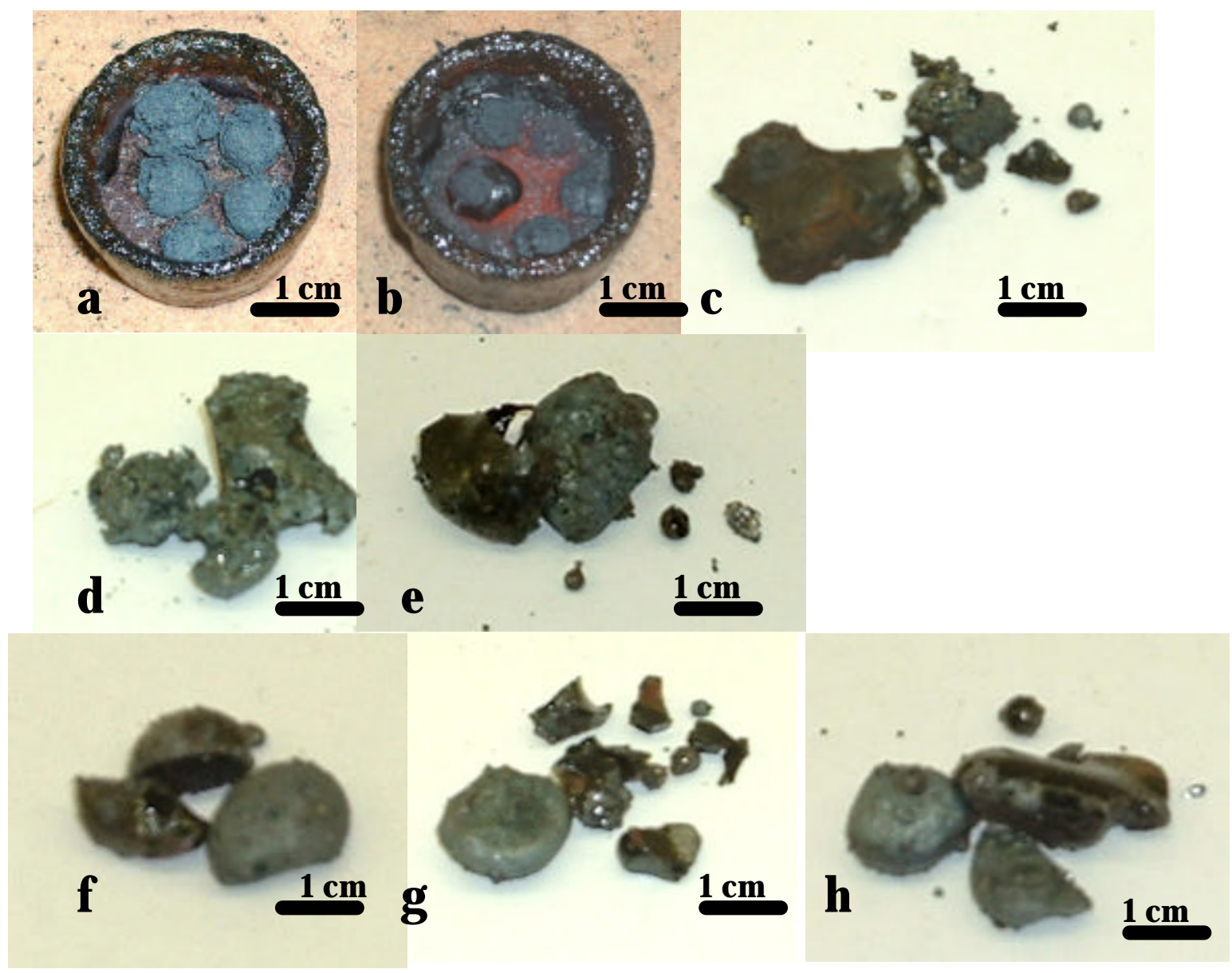

Figure $4.9(\mathbf{a}, \mathbf{b}, \mathbf{c})$ The direct reduced iron (D RI) produced at residence times $10 \mathrm{~min}, 16 \mathrm{~min}$, and $22 \mathrm{~min}$ respectively. The metallized portion is a solid state product; slag was not separated from the metal. (d,e) The transition direct reduced iron (TDRI) produced at residence times $28 \mathrm{~min}$, and $32 \mathrm{~min}$ respectively. The metallized portion is a solid and liquid state product; slag was partially separated from the metal. $(\mathbf{f}, \mathbf{g}, \mathbf{h})$ The pig iron nugget (PIN) and slag produced at residence times $40 \mathrm{~min}, 50 \mathrm{~min}$, and $60 \mathrm{~min}$. The metallized portion is a liquid state product, slag was completely separated from the metal. 
CHAPTER 4 RESULTS AND DISCUSSIONS - -58-

\subsubsection{Optical Microscopy and Scanning Electron Microscopy}

\subsubsection{Direct Reduced Iron}

The optical micrographs for direct reduced iron (D RI) made at a furnace temperature of $1425{ }^{\circ} \mathrm{C}$ and furnace residence time of $16 \mathrm{~min}$ and $22 \mathrm{~min}$ are shown in Figures $4.10(\mathrm{a}-\mathrm{c})$, and 4.12 (a-c), respectively. In these figures the whitest areas represent the metallized portion of the D RI, light grey areas (tree like structures) represent the wustite $(\mathrm{FeO})$ dendrites and the dark grey areas represent the slag matrix. The presence of a dendritic structure implies the fernlike crystal growth of a phase, in this case wustite ( $\mathrm{FeO}$ ), upon slow cooling. Both structures (Figures 4.10 (a-c) and 4.12 (a-c)) have heterogeneous microstructures including both slag and the metallized material. Similar slag inclusion microstructures for early iron-making practices have been reported by Morton and Wingrove (1969), Maddin (1975) and Blomgren and Tholander (1986).

For the direct reduced iron produced at a residence time of $16 \mathrm{~min}$, no obvious iron carbides were observed in the metallized portion (Figure 4.10 (c)). However, for the direct reduced iron produced at longer residence time of 22 min, iron carbides were observed within the metallized portion of the microstructure (Figure 4.12 (c)). It can be inferred from Figure 2.3 that the diron formed at $1425^{\circ} \mathrm{C}$ eventually transformed to austenite, as carbon content increased, which then transformed to $\alpha$-ferrite and cementite during cooling. 


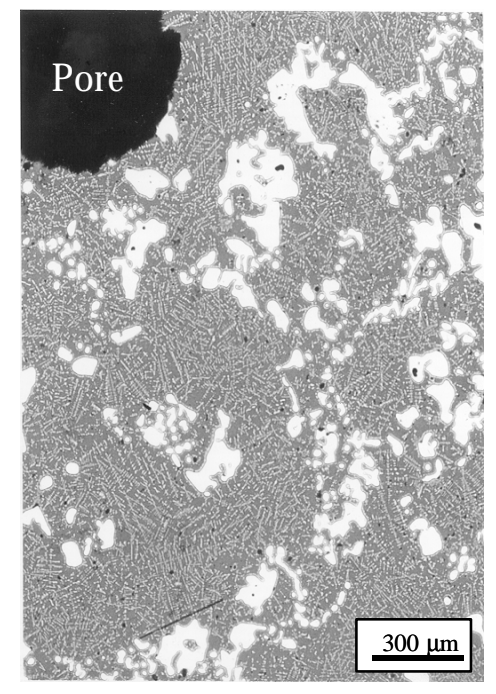

(a)

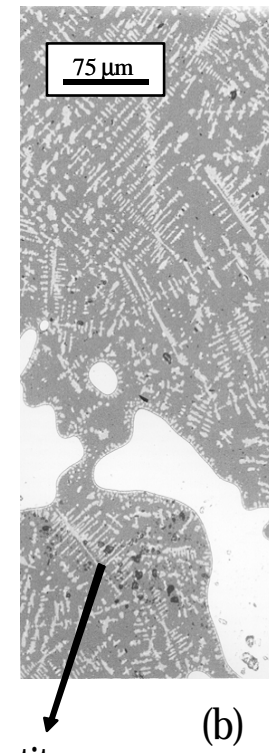

Wustite dendrites in slag matrix

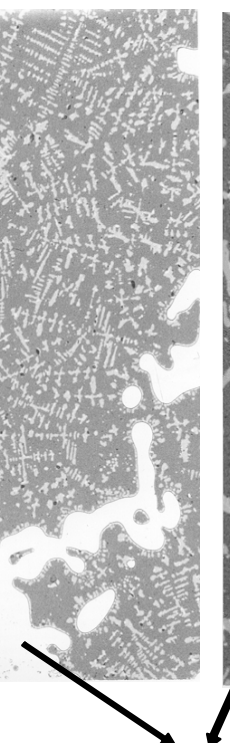

Alpha iron

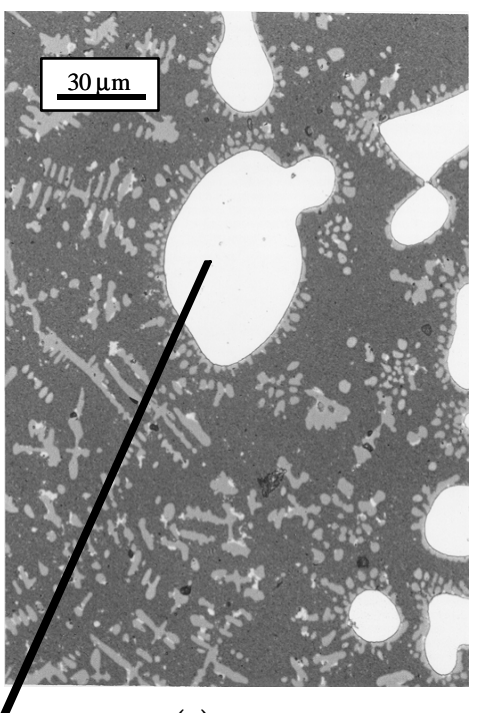

(c)

Figure 4.10 (a-c) Optical micrograph of a cross section of a direct reduced iron produced at furnace temperature $1425^{\circ} \mathrm{C}$ furnace residence time $16 \mathrm{~min}$, for various magnifications (Nital etch)

Identification of the phases: alpha iron, wustite, and slag matrix and constituents were made utilizing scanning electron microscopy and local chemical analysis (EDS). The backscattered image for the D RI produced at the $16 \mathrm{~min}$. residence time is shown in Figure 4.11. The secondary image for the D RI produced at $22 \mathrm{~min}$. residence time is shown in Figure 4.13. The phases identified utilizing this method and their approximate chemical composition is given on Table 4.III. 


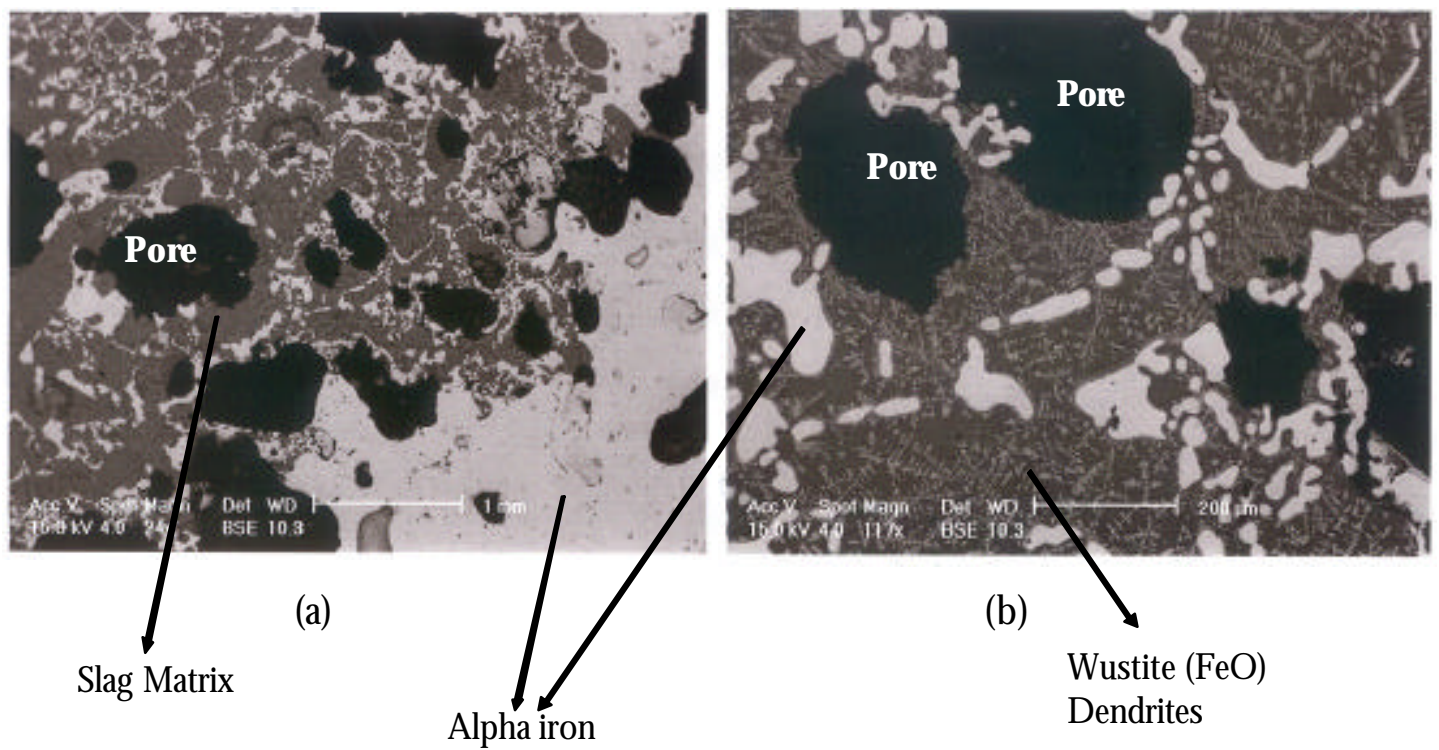

Figure 4.11 $(\mathbf{a}, \mathbf{b})$ SEM backscattered images for the D RI made at furnace temperature $1425^{\circ} \mathrm{C}$ furnace residence time $16 \mathrm{~min}$ for varying magnifications.

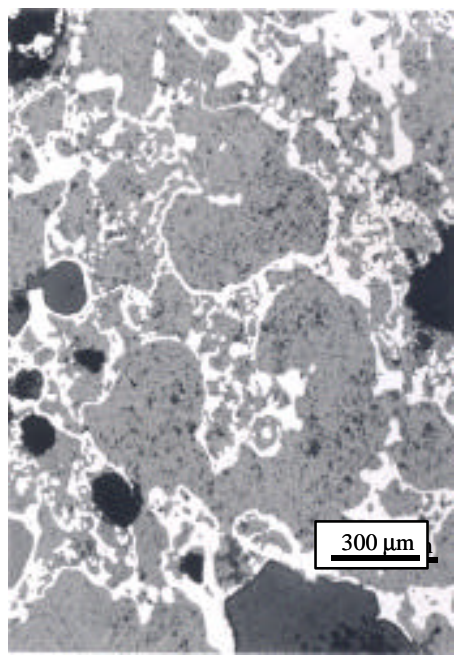

(a)

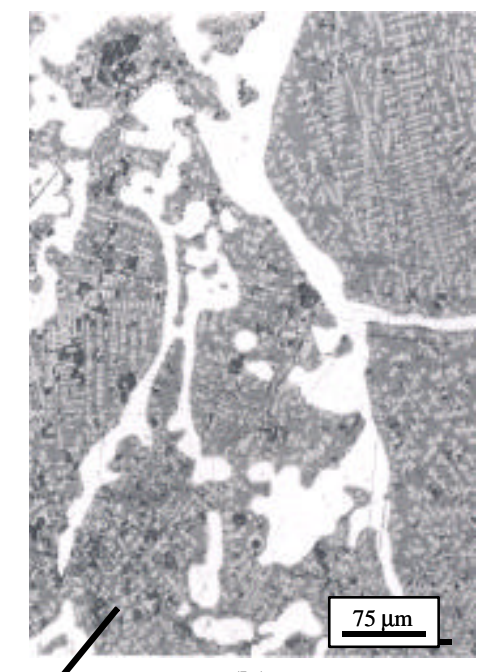

(b)

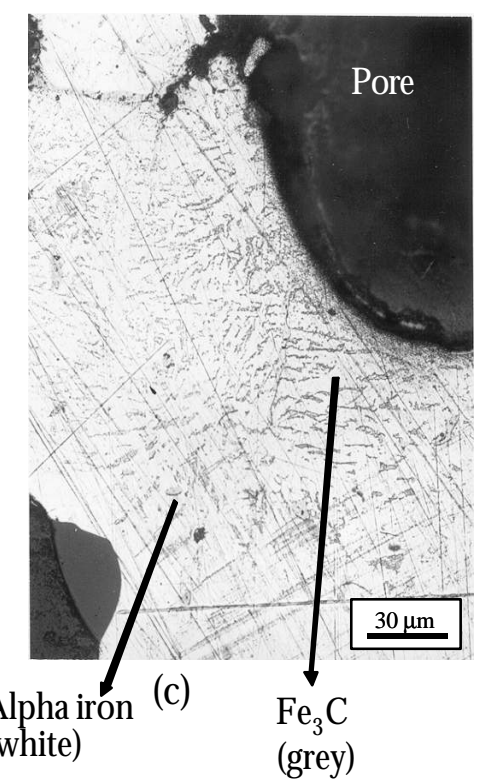

Wustite (FeO) dendrites in slag matrix

Figure 4.12 (a-c) Optical micrograph of a cross section of a direct reduced iron produced at furnace temperature $1425^{\circ} \mathrm{C}$ and furnace residence time $22 \mathrm{~min}$, for various magnifications (Nital etch) 


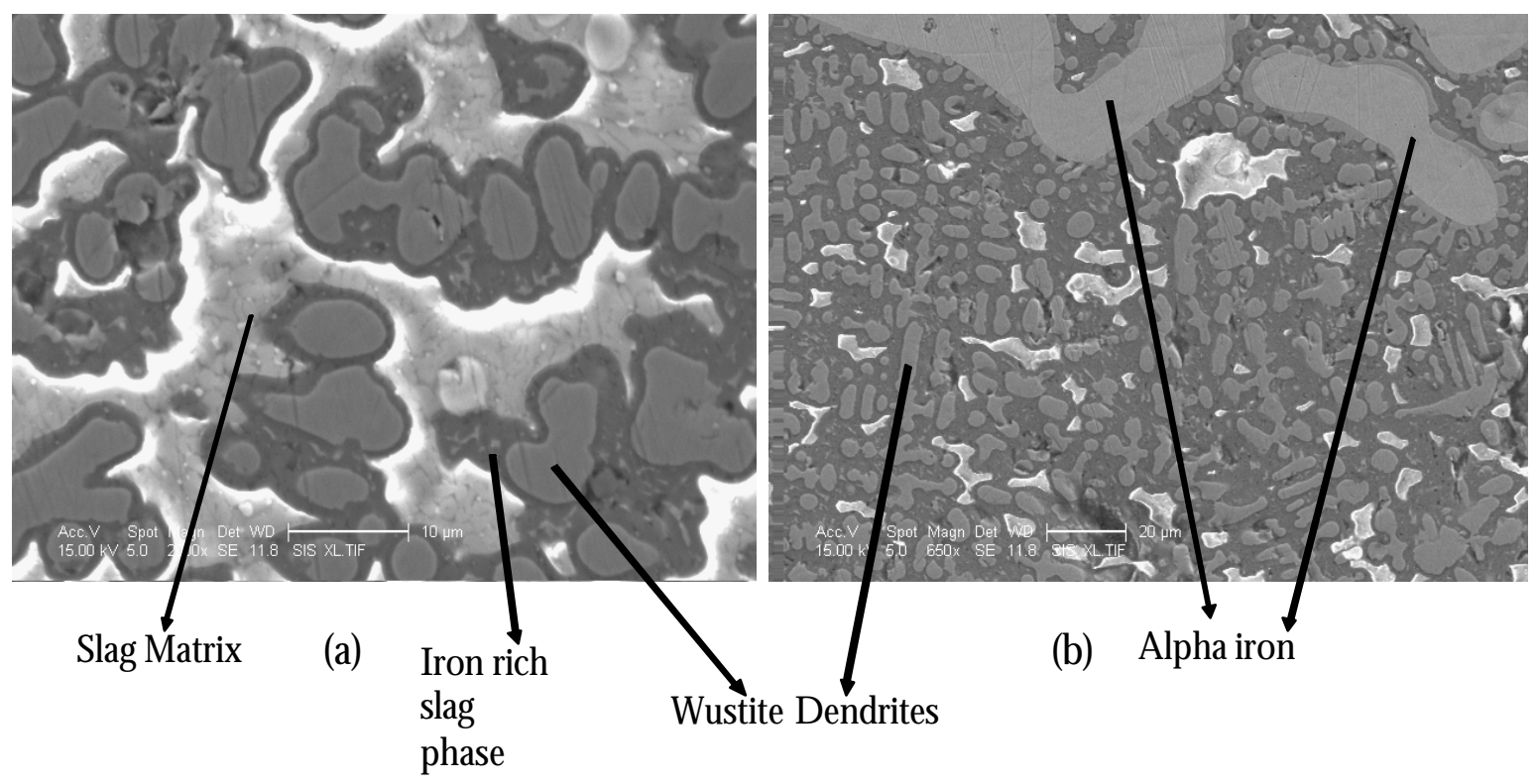

Figure 4.13 (a-b) SEM secondary images for the D RI made at furnace temperature $1425^{\circ} \mathrm{C}$ and furnace residence time $22 \mathrm{~min}$ for varying magnifications. 
Table 4.III The approximate local chemical analysis of the wustite, Fe rich slag phase, and $\alpha$-Fe present in the D RI (production furnace residence time $22 \mathrm{~min}$ ) microstructure.

\begin{tabular}{|c|c|c|c|}
\hline Element & $\begin{array}{c}\text { Wustite (Fe0) Dendrites } \\
\%\end{array}$ & $\begin{array}{c}\text { Fe Rich Slag Phase } \\
\%\end{array}$ & $\begin{array}{c}\alpha-\text { Fe } \\
\text { (Metallized portion of the } \\
\text { DRI) } \\
\%\end{array}$ \\
\hline $\mathrm{Fe}$ & 72.58 & 31.31 & 99.9 \\
\hline $\mathrm{C}$ & 5.39 & 3.76 & 0.1 \\
\hline 0 & 21.29 & 29.46 & - \\
\hline $\mathrm{Si}$ & 0.42 & 15.87 & - \\
\hline $\mathrm{P}$ & 0.10 & 0.51 & - \\
\hline $\mathrm{S}$ & 0.22 & 0.59 & - \\
\hline $\mathrm{Mg}$ & - & 1.28 & - \\
\hline $\mathrm{Al}$ & - & 1.62 & - \\
\hline $\mathrm{Ca}$ & - & 15.61 & \\
\hline
\end{tabular}

\subsubsection{Pig Iron Nuggets}

Pig iron nuggets were produced at higher furnace residence times. The optical micrographs of the pig iron nugget made at the $1425{ }^{\circ} \mathrm{C}$ furnace temperature and $50 \mathrm{~min}$ and $60 \mathrm{~min}$ furnace residence times are shown in Figures 4.14 and 4.15 respectively. These microstructures (Figures 4.14 and 4.15) were composed of a dendritic pattern of fine pearlite (dark grey areas) and interdendritic eutectic mixture of cementite and Pearlite (light area). They were very similar to the suggested characteristic of white cast iron structure in Figure 2.4. (D avis, 1990; Mehl, 1972; Smith, 1993; Callister, 1997; Anameric and 
Kawatra, 2004; Anameric et al, 2005). It can be seen from Figure 2.3 that during cooling of molten pig iron nuggets austenite dendrites first formed from the liquid followed by eutectic reaction, liquid transforming into austenite and cementite $\left(\mathrm{Fe}_{3} \mathrm{C}\right)$ at $1147^{\circ} \mathrm{C}$. The cooling in the solid state below $1147^{\circ} \mathrm{C}$ resulted in first cementite $\left(\mathrm{Fe}_{3} \mathrm{C}\right)$ precipitating within the existing austenite as plates. Upon further cooling when eutectoid temperature was reacted all of the remaining austenite transformed to pearlite (alternating layers of iron carbide $\left(\mathrm{Fe}_{3} \mathrm{C}\right)$ and $\alpha$ ferrite). The iron carbide formed at the solid state appears to have penetrated the pearlite (transformed austenite) (Heine and Barton, 1977) (Radzikowska and Voort, 1998) (Mampaey, 2001) (Park and Verhoeven, 1996).

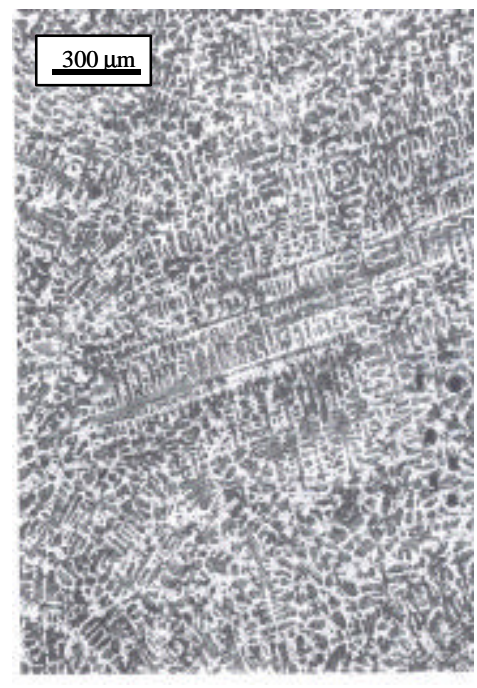

(a)

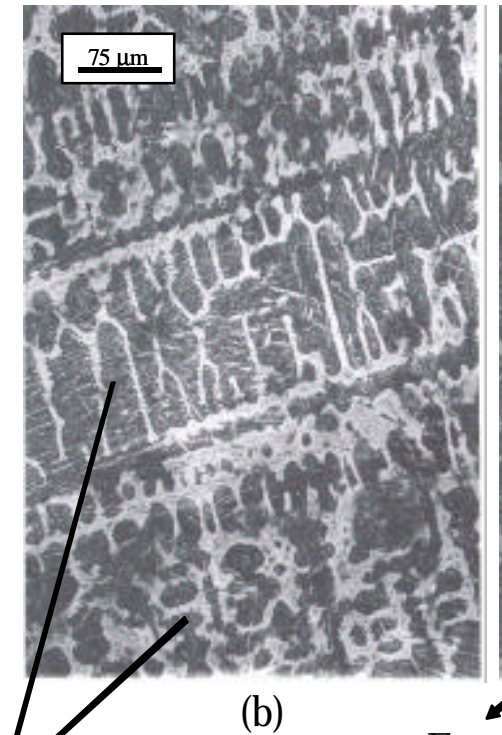

Eutectic Pearlite (former austenite dendrites)

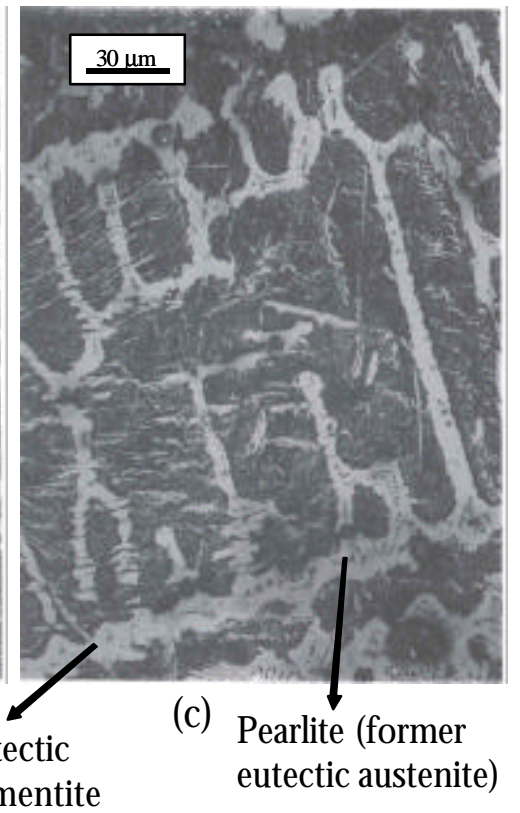

Figure 4.14 (a-c) Optical micrograph of a cross section of a pig iron nugget produced at furnace temperature $1425^{\circ} \mathrm{C}$ and furnace residence time $50 \mathrm{~min}$ for varying magnifications (Nital etch). 


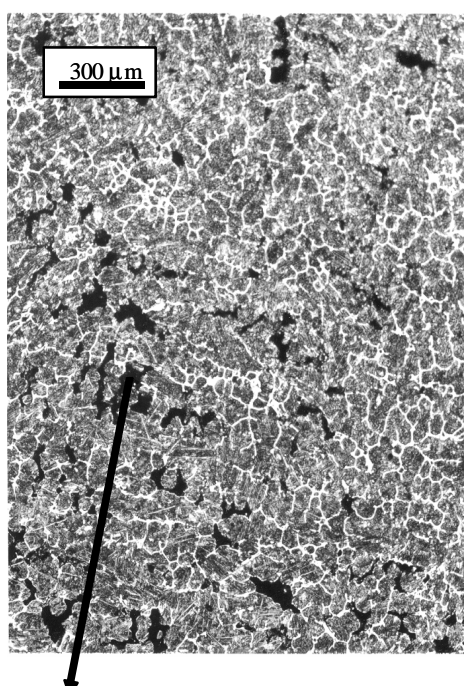

Porosity (a) Pearlite (former austenite dendrites)

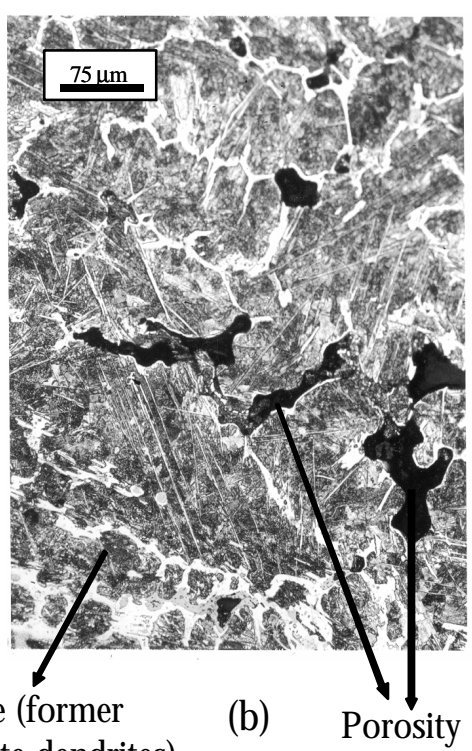

(b)

Porosity

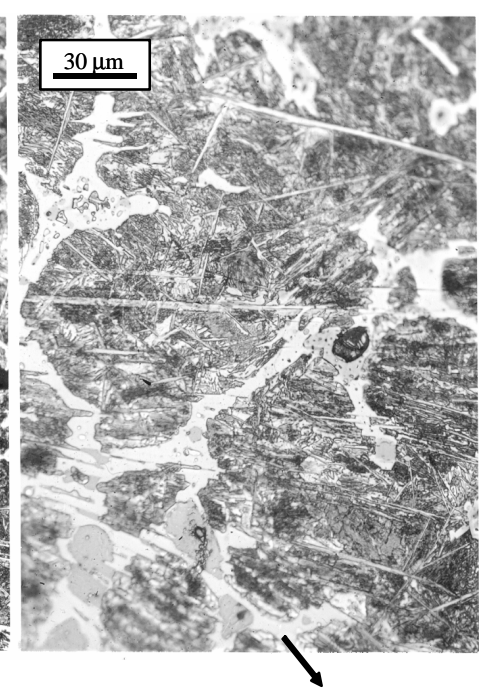

(c) Eutectic

Figure 4.15 (a-c) Optical micrograph of a cross section of a pig iron nugget produced at furnace temperature $1425^{\circ} \mathrm{C}$ and furnace residence time $60 \mathrm{~min}$ for varying magnifications (Nital etch).

\subsubsection{Microhardness Measurements}

The Vickers hardness measurements (1 kg load) (ASTM E 92-82, 1997 and ASTM E 384, 1999) on the metallized portion were taken to detect the increase in the cementite (iron carbide) amount in the microstructure with increasing furnace residence time (constant furnace temperature $1425^{\circ} \mathrm{C}$ ), since the Vickers hardness increases with increasing amount of dissolving carbon in the metallized portion (amount of carbides) (Krauss, 1990). 
The average Vickers hardness values of the D RI, TD RI, and pig iron nuggets made at varying furnace residence times is summarized in Figure 4.16 and Table 4.IV . The microhardness of the D RI produced varied between $60 \mathrm{HVN}$ and $120 \mathrm{HVN}$. The microhardness of the TD RI produced varied between $120 \mathrm{HVN}$ and $325 \mathrm{HVN}$. The microhardness of the pig iron nuggets produced varied between $325 \mathrm{HVN}$ and $420 \mathrm{HVN}$.

Table 4.IV The average Vickers hardness values of the D RI, TD RI, and pig iron nuggets made at various furnace residence times (constant furnace temperature 1425 C). 16 or more measurements were taken for each sample.

\begin{tabular}{|c|c|c|c|}
\hline $\begin{array}{c}\text { Fumace } \\
\text { Temperature }\left({ }^{0} \mathbf{C}\right)\end{array}$ & $\begin{array}{c}\text { Fumace Residence } \\
\text { Time (min) }\end{array}$ & HVN & Standard Deviation \\
\hline 1425 & 10 & 90.6 & 27.4 \\
\hline 1425 & 16 & 75.1 & 27.1 \\
\hline 1425 & 22 & 124.3 & 20.0 \\
\hline 1425 & 28 & 132.7 & 21.1 \\
\hline 1425 & 30 & 307.8 & 15.7 \\
\hline 1425 & 34 & 308.7 & 25.8 \\
\hline 1425 & 40 & 351.1 & 27.2 \\
\hline 1425 & 50 & 399.7 & 53.8 \\
\hline 1425 & 60 & 412.4 & \\
\hline
\end{tabular}




\section{DRI}

Transition

Pig Iron Nugget

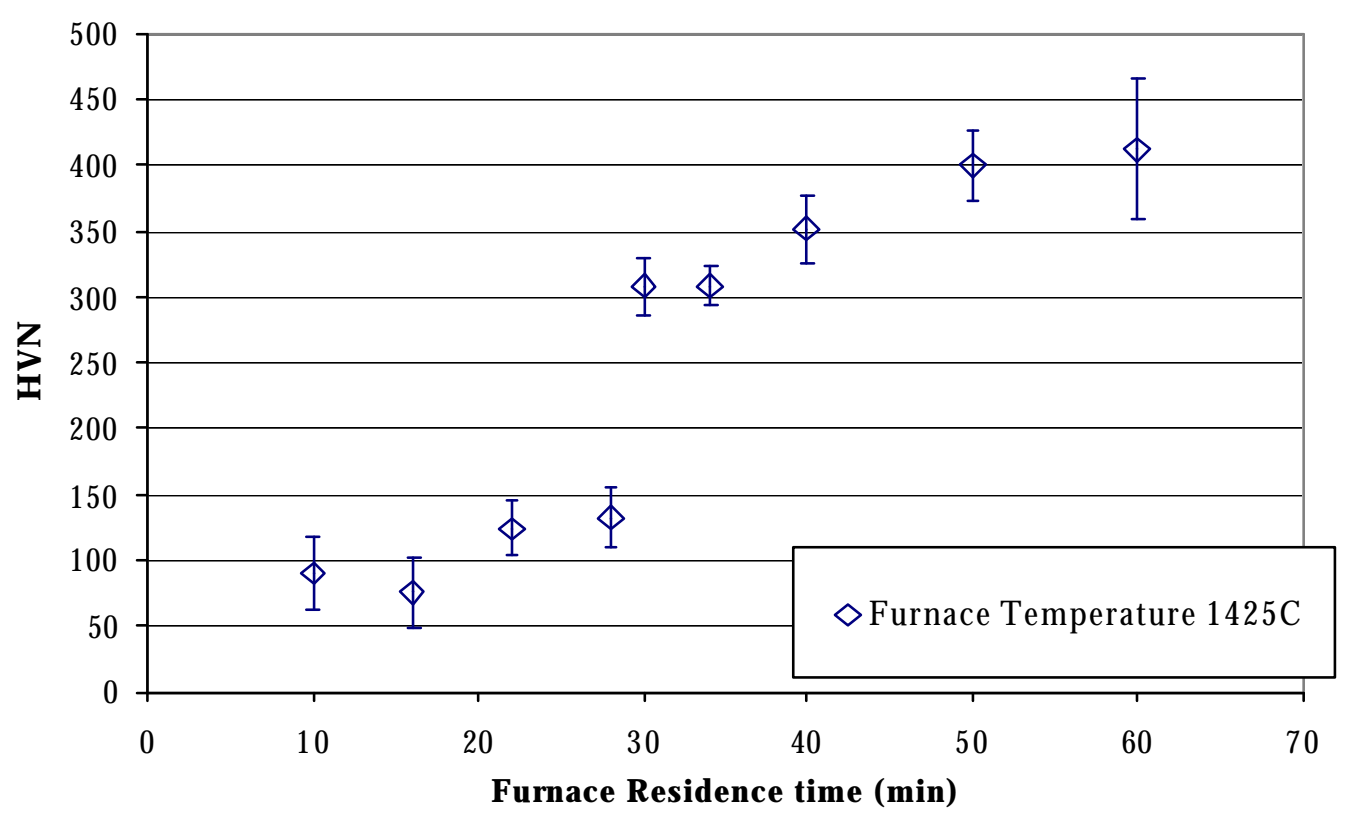

Figure 4.16 The average Vickers hardness values of the D RI, TD RI, and pig iron nuggets representing the increase in the amount of carbon in the system with increasing furnace residence time at constant furnace temperature $1425^{\circ} \mathrm{C}$. 16 or more measurements were taken from the metallized portion of each sample. 


\subsubsection{Apparent Density Measurements}

The apparent density measurements utilizing water displacement method (ASTM B311, 2002) were taken in order to detect the increase in the degree of metallization, increase in degree of slag separation, and decrease in degree of porosity. Since as the furnace residence time increases the degree of metallization increases, degree of slag separation increases and degree of porosity decreases (Lankford, et al. 1985)

The average apparent density values of the D RI, TD RI and pig iron nuggets made at varying furnace residence times is summarized in Figure 4.17 and Table 4.V. The apparent density of the D RI was lower than the apparent density of the TDRI and pig iron nuggets due to the intense mixture of low density slag and high density metallized iron. As the furnace residence time increased the degree of metallization and slag separation increased, and degree of porosity decreased resulting with higher apparent density TD RI. Continuing increase in the furnace residence time and consequent increase in the degree of metallization and slag separation and decrease in degree of porosity resulted with high apparent density pig iron nuggets. 
CHAPTER 4 RESULTS AND DISCUSSIONS - -68-

Table 4.V The average apparent density values of the D RI, TD RI, and pig iron nuggets made at various furnace residence times (constant furnace temperature $\left.1425^{\circ} \mathrm{C}\right)$.

\begin{tabular}{|c|c|c|c|}
\hline $\begin{array}{l}\text { Fumace Temperature } \\
\text { (C) }\end{array}$ & $\begin{array}{c}\text { Furnace Residence } \\
\text { Time (min) }\end{array}$ & $\begin{array}{c}\text { Apparent Density } \\
\left(\mathrm{g} / \mathrm{cm}^{3}\right)\end{array}$ & $\begin{array}{l}\text { Standard } \\
\text { Deviation }\end{array}$ \\
\hline 0 & 0 & 2.5 & 0.025 \\
\hline 1425 & 10 & 4.234 & 0.009 \\
\hline 1425 & 16 & 4.749 & 0.330 \\
\hline 1425 & 22 & 4.824 & 0.244 \\
\hline 1425 & 28 & 5.757 & 0.018 \\
\hline 1425 & 40 & 6.807 & 0.079 \\
\hline 1425 & 50 & 6.873 & 0.127 \\
\hline 1425 & 60 & 7.082 & 0.096 \\
\hline
\end{tabular}




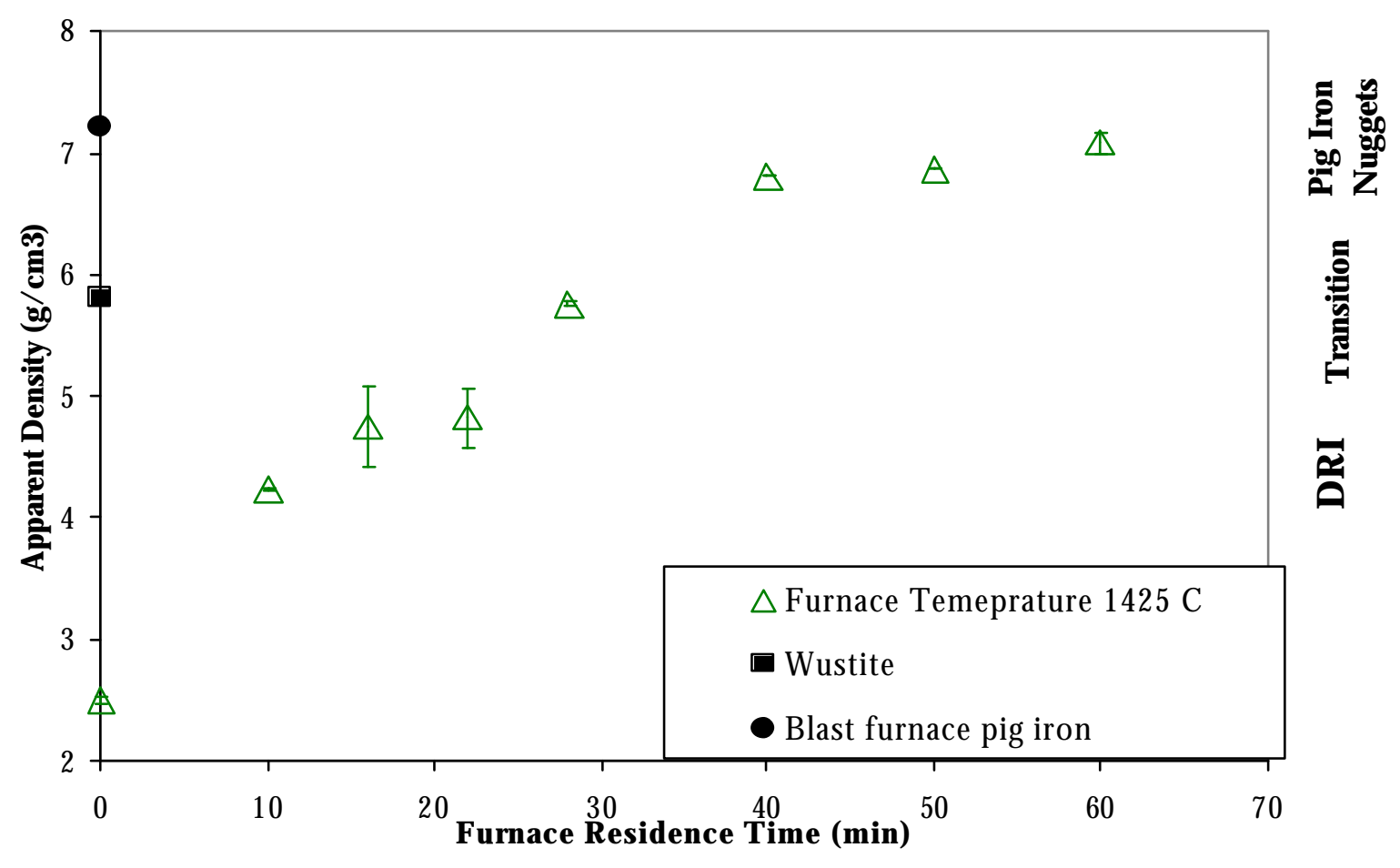

Figure 4.17 The average apparent density values of the D RI, TD RI, and pig iron nuggets representing the increase degree of metallization, slag separation, and decrease in degree of porosity with increasing furnace residence time at constant furnace temperature $1425^{\circ} \mathrm{C}$. 
CHAPTER 4 RESULTS AND DISCUSSIONS - -70-

\subsection{Fumace Temperature Effects on Pig Iron Nugget Production}

The dried green balls were fired at a furnace residence time of $10 \mathrm{~min}$ at furnace temperatures of $1415{ }^{\circ} \mathrm{C}, 1425^{\circ} \mathrm{C}, 1435{ }^{\circ} \mathrm{C}, 1445{ }^{\circ} \mathrm{C}, 1465{ }^{\circ} \mathrm{C}, 1475{ }^{\circ} \mathrm{C}$, $1485^{\circ} \mathrm{C}$ and $1495^{\circ} \mathrm{C}$ to observe the D RI, TD RI, and pig iron nugget formations. The DRI, TD RI, and pig iron nugget formations were dependent on the degree of carbon diffusion. As the furnace temperature increases: (i) the amount of carbon diffused in the metal is increases, (ii) the melting point of the metallized portion decreases (until the eutectic point $(4.3 \% \mathrm{C}$ ) is reached (see Figure 2.3$)$ ) which results in the formation of pig iron nuggets.

\subsubsection{Optical Microscopy}

\subsubsection{Direct Reduced Iron}

The optical micrographs for direct reduced iron (D RI) made at furnace residence time $10 \mathrm{~min}$ and furnace temperatures $1415^{\circ} \mathrm{C}$ and $1425^{\circ} \mathrm{C}$ are shown in Figures 4.18 (a-b) and 4.19 respectively. In these figures the whitest areas represent the metallized portion of the D RI, light grey areas (tree like structures) represent the wustite $(\mathrm{FeO})$ dendrites and the dark grey areas represent the slag matrix. No obvious carbides were observed in these structures and both had heterogeneous microstructures including both slag and the metallized material. Similar slag inclusion microstructures for early iron-making practices have been reported by Morton and Wingrove (1969), Maddin (1975) and Blomgren and Tholander (1986). 


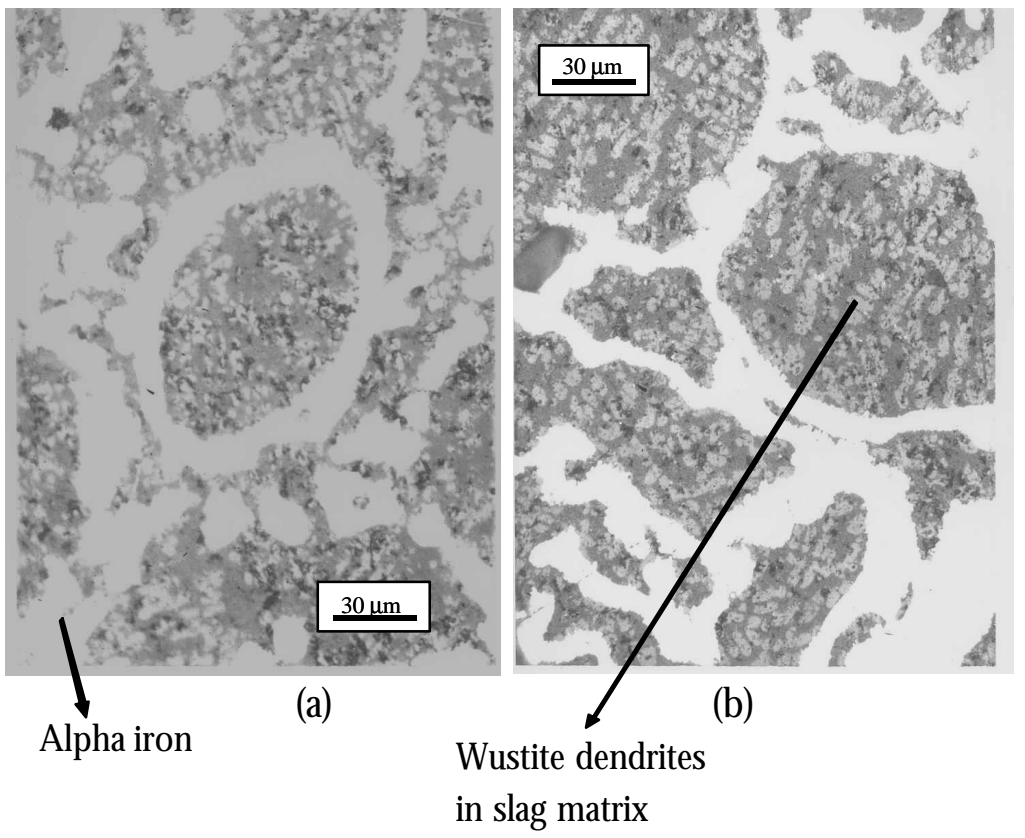

Figure 4.18 (a-b) O ptical micrograph of a cross section of a direct reduced iron produced at furnace temperature $1415{ }^{\circ} \mathrm{C}$ and furnace residence time $10 \mathrm{~min}$ (Nital etch)

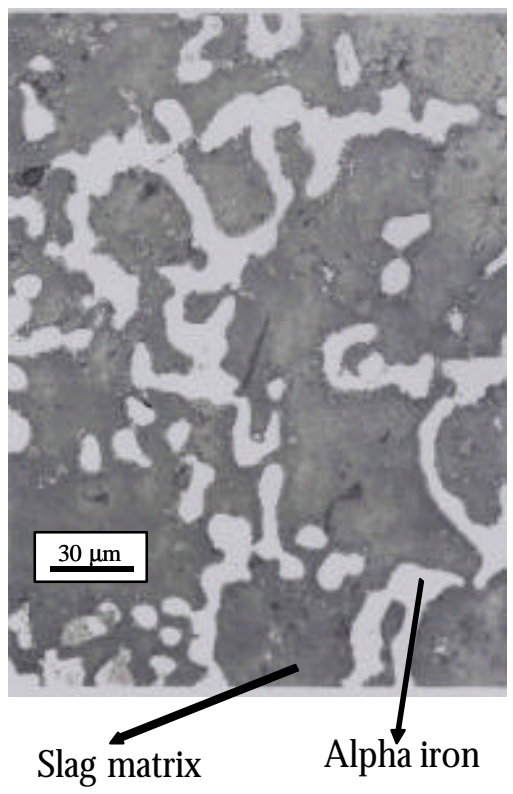

Figure 4.19 Optical micrograph of a cross section of a direct reduced iron produced at furnace temperature $1425{ }^{\circ} \mathrm{C}$ and furnace residence time $10 \mathrm{~min}$, (Nital etch) 


\subsubsection{Pig Iron Nuggets}

Pig iron nuggets were produced at higher furnace temperatures. The optical micrograph of the pig iron nuggets made at constant furnace residence time $10 \mathrm{~min}$ and furnace temperatures $1455^{\circ} \mathrm{C}, 1465{ }^{\circ} \mathrm{C}, 1475^{\circ} \mathrm{C}, 1485^{\circ} \mathrm{C}$, and $1495{ }^{\circ} \mathrm{C}$ are shown in Figures 4.20 to 4.24 respectively. These microstructures were composed of a dendritic pattern of fine pearlite (dark grey areas) and interdendritic eutectic mixture of cementite and Pearlite (light area). They were very similar to the suggested characteristic of white cast iron structure in Figure 2.4. (D avis, 1990; Mehl, 1972; Smith, 1993; Callister, 1997; Anameric and Kawatra, 2004; Anameric et al, 2005).

The phases and constituents present in the pig iron nugget microstructure are shown in Table 4.VI.

T able 4.VI The phases and constituents present in the pig iron nugget microstructures

\begin{tabular}{|c|c|}
\hline $\begin{array}{c}\text { Phases present in the pig iron nugget } \\
\text { microstructures }\end{array}$ & $\begin{array}{c}\text { Constituents present in the pig iron nugget } \\
\text { microstructures }\end{array}$ \\
\hline$\alpha$ ferrite (iron) & Eutectic cementite \\
\hline Iron carbide (cementite) & Pearlite (former austenite dendrites) \\
\hline Iron sulfide & Pearlite (former eutectic austenite) \\
\hline & Iron carbide (cementite) (solid state formation) \\
\hline
\end{tabular}




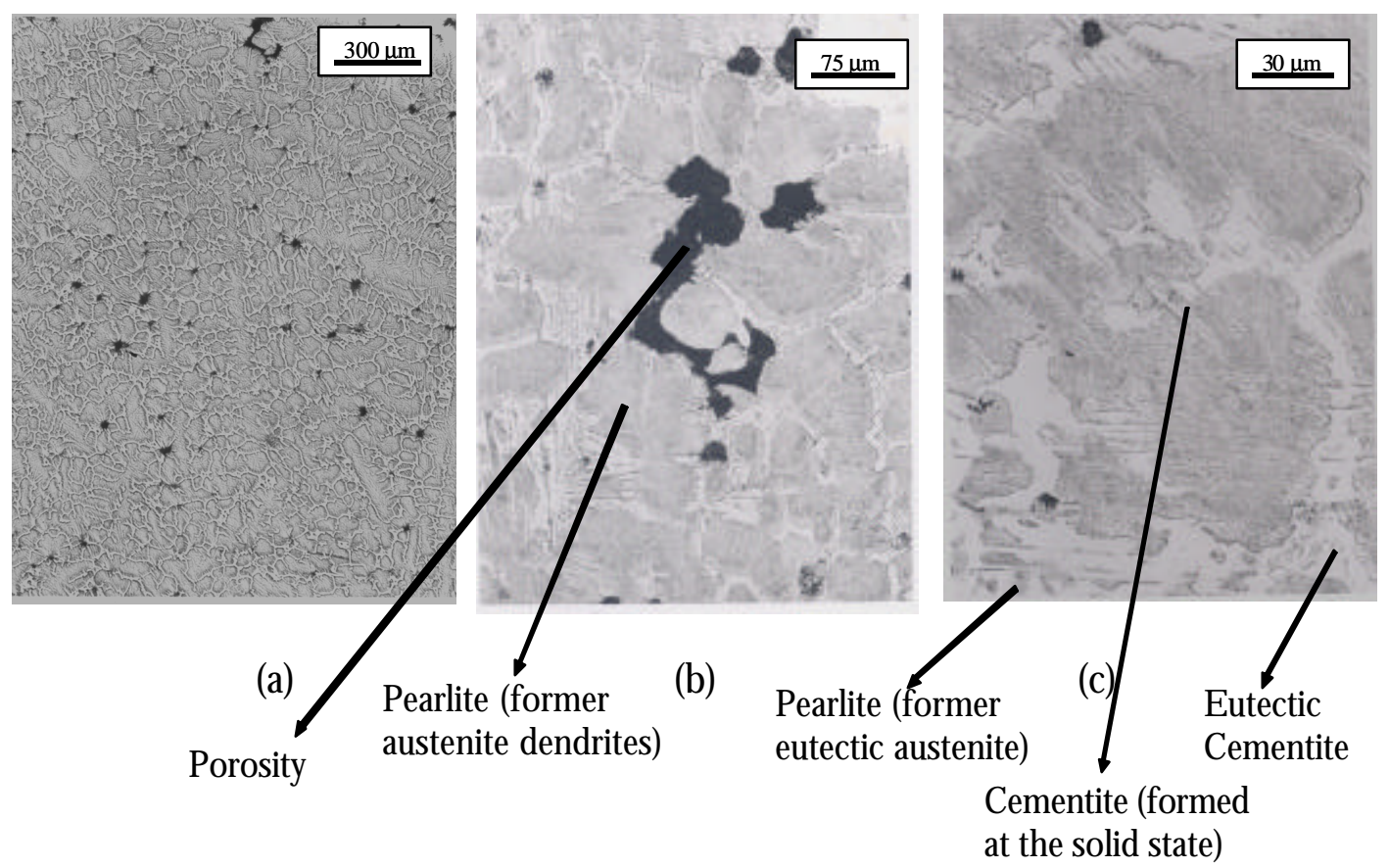

Figure 4.200 ptical micrograph of a cross section of a direct reduced iron produced at furnace temperature $1455^{\circ} \mathrm{C}$ and furnace residence time $10 \mathrm{~min}$, (Nital etch)

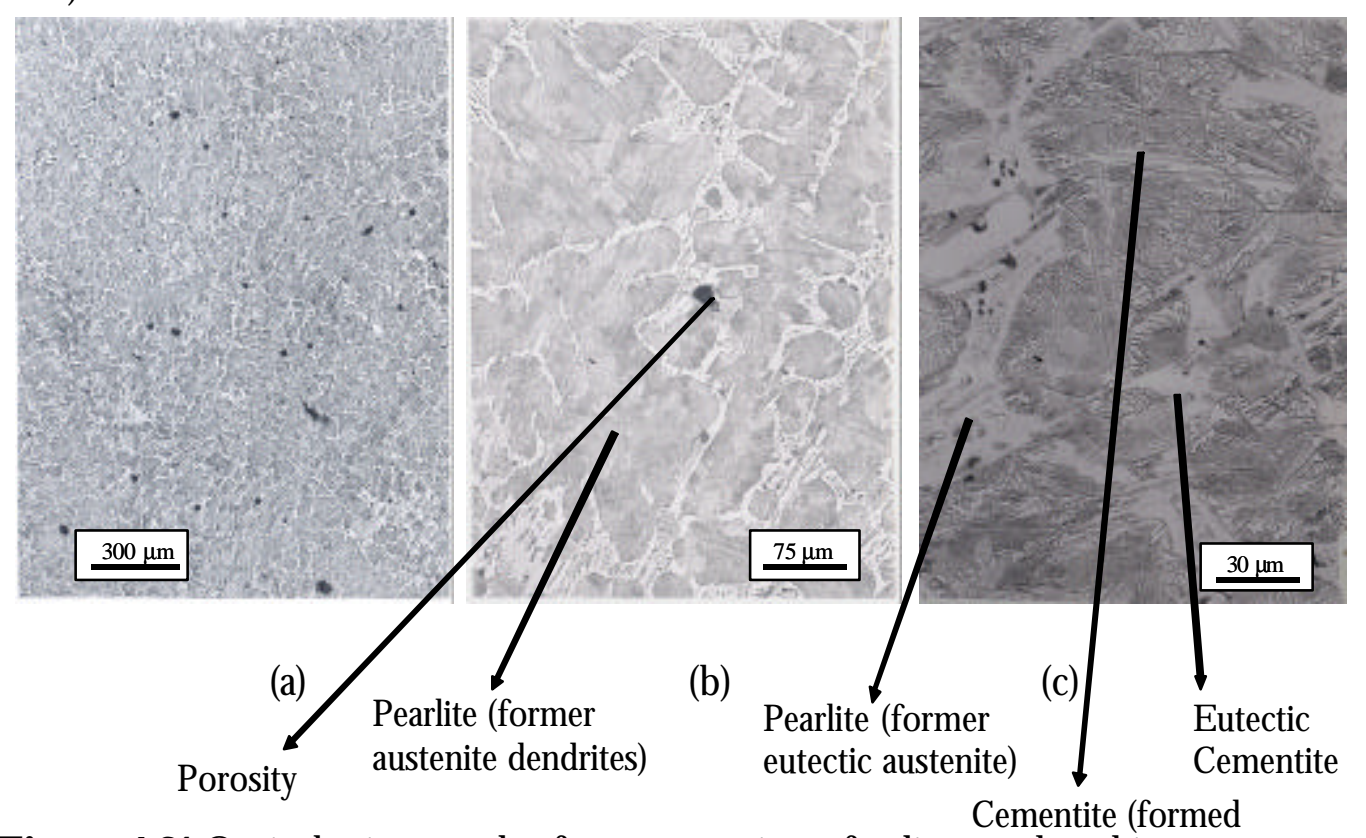

Figure 4.21 0 ptical micrograph of a cross section of a directradedusedd isame)

produced at furnace temperature $1465^{\circ} \mathrm{C}$ and furnace residence time $10 \mathrm{~min}$, (Nital etch) 


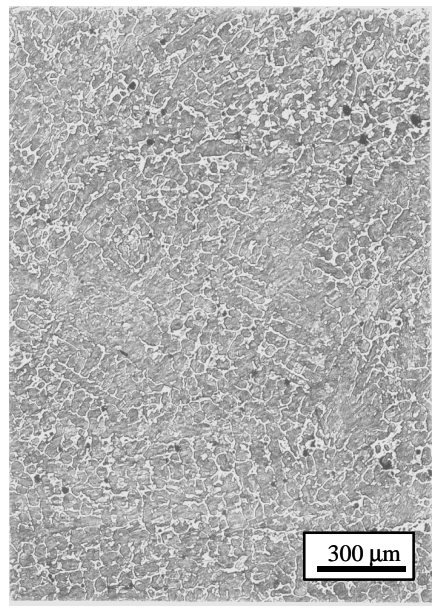

(a)

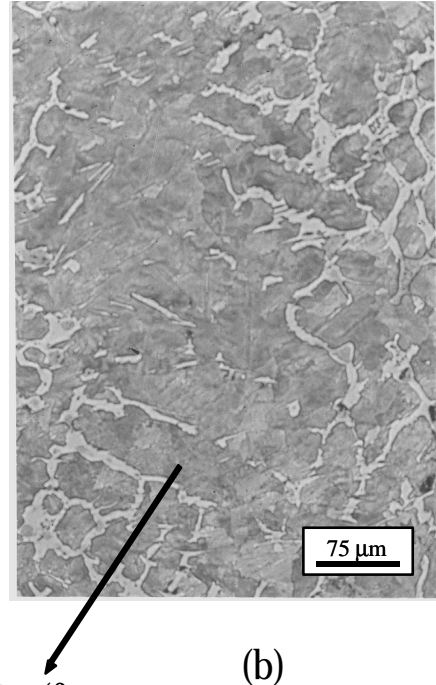

Pearlite (former austenite dendrites)

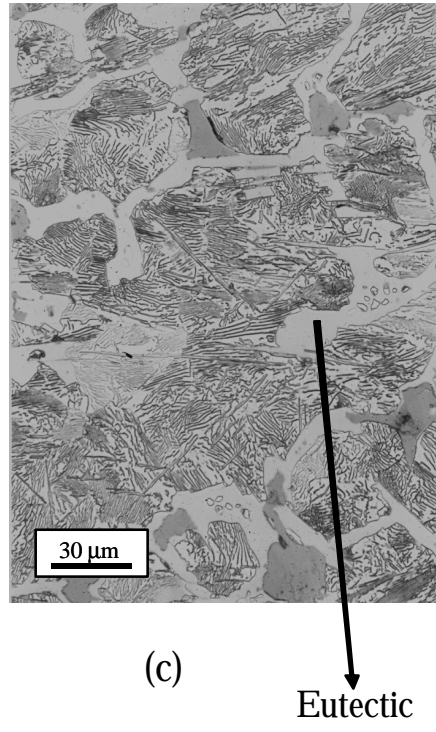

Cementite

Figure 4.220 ptical micrograph of a cross section of a direct reduced iron produced at furnace temperature $1475{ }^{\circ} \mathrm{C}$ and furnace residence time $10 \mathrm{~min}$, (Nital etch)

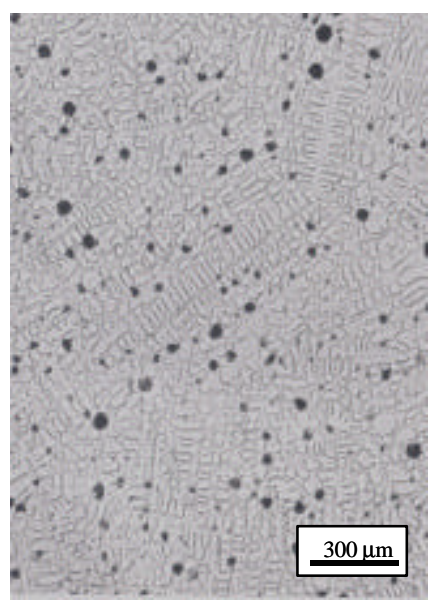

(a)

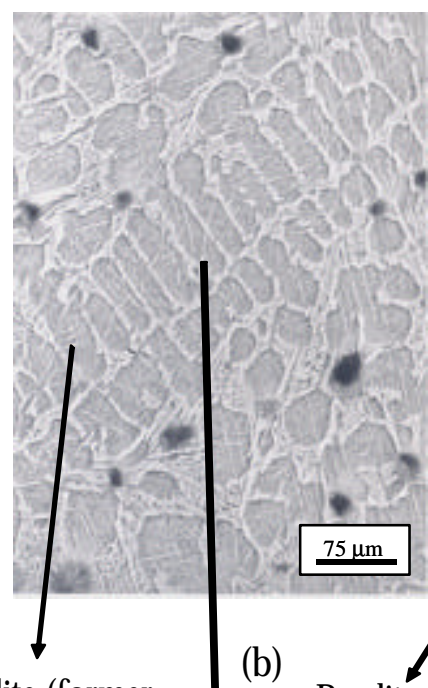

Pearlite (former eutectic austenite)

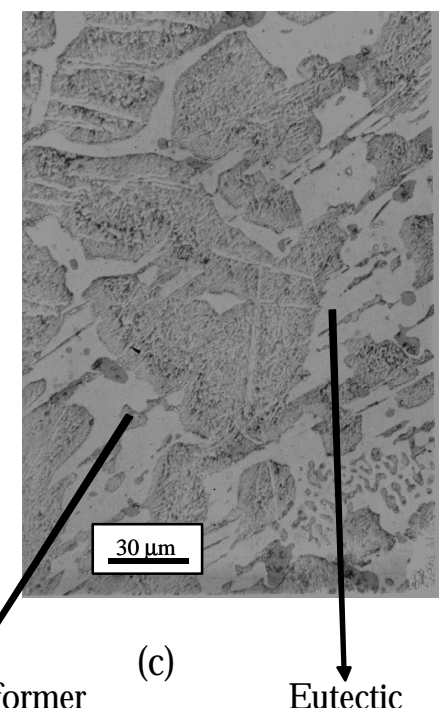

Cementite

Cementite (formed

at the solid state)

Figure 4.230 ptical micrograph of a cross section of a direct reduced iron produced at furnace temperature $1485^{\circ} \mathrm{C}$ and furnace residence time $10 \mathrm{~min}$, (Nital etch) 


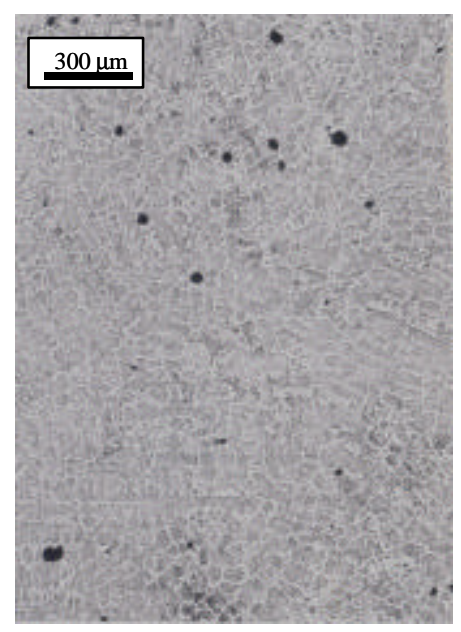

(a)

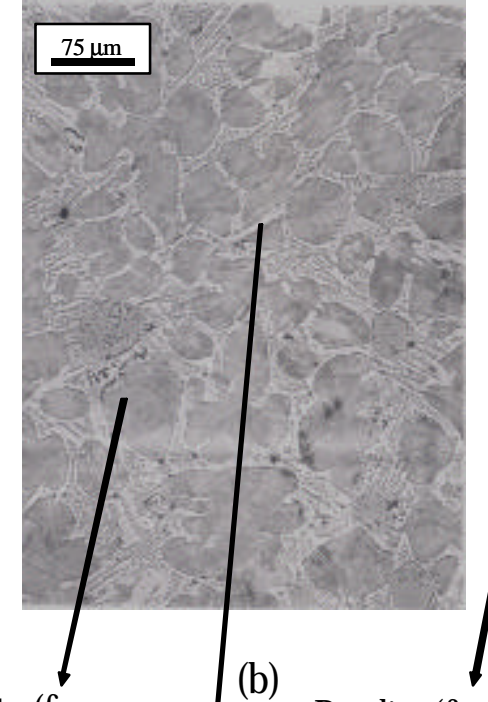

Pearlite (former eutectic austenite)

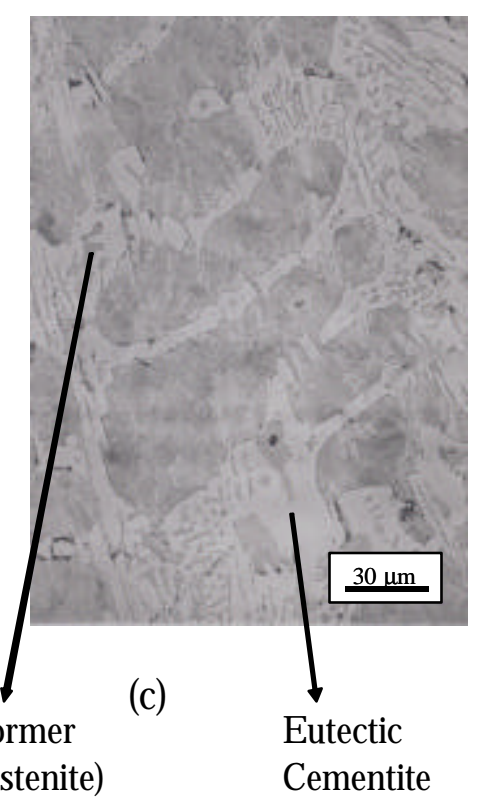

Cementite

Cementite (formed at the solid state)

Figure 4.240 ptical micrograph of a cross section of a direct reduced iron produced at furnace temperature $1495{ }^{\circ} \mathrm{C}$ and furnace residence time $10 \mathrm{~min}$, (Nital etch)

\subsubsection{Interpretation of Pig Iron N ugget Microstructures}

The metastable iron carbon phase diagram shown in Figure 4.25 will be utilized for the interpretation of the pig iron nugget microstructures. As an example, $3.3 \%$ wt carbon containing molten pig iron nugget cooling will be discussed. It can be seen from Figure 4.25, point B, that during cooling austenite dendrites containing $1.6 \% \mathrm{C}$ start forming in the liquid containing $3.3 \% \mathrm{C}$. A scanning electron microscopy image of the austenite dendrites present in the porosity of the pig iron nugget made at furnace temperature $1450{ }^{\circ} \mathrm{C}$ and residence time 22 min is shown in Figure 4.26. 
CHAPTER 4 RESULTS AND DISCUSSIONS -76-

When point $\mathrm{C}$ is reached the fraction of the austenite $(1.9 \% \mathrm{C})$ and liquid (3.9 \% C) present is calculated utilizing the lever rule (Smith, 1993; Callister, 1997) as follows:

Fraction of austenite dendrites $($ Point $\mathrm{C})=(3.9-3.3) /(3.9-1.9)=0.3$

Fraction of liquid $($ Point $C)=(3.3-1.9) /(3.9-1.9)=0.7$

When Point D (just before the eutectic reaction) is reached the fraction of austenite $(2.08 \% \mathrm{C})$ in the structure increases. This increase is calculated by lever rule as follows

Fraction of austenite dendrites $($ Point $\mathrm{D})=(4.3-3.3) /(4.3-2.08)=$ 0.45045

Fraction of liquid $($ Point D $)=(3.3-2.08) /(4.3-2.08)=0.54955$

At the eutectic temperature, $1147^{\circ} \mathrm{C}$, the remaining liquid $(4.3 \% \mathrm{C})$ transforms to eutectic austenite (2.08 \% C) and eutectic iron carbide (cementite) $\left(\mathrm{Fe}_{3} \mathrm{C}\right)(6.67 \% \mathrm{C})$ as shown in Point E. Fraction of austenite $(2.08 \% \mathrm{C})$ and iron carbide $(6.67 \% \mathrm{C})$ is calculated as follows:

Fraction of austenite $($ Point $E)=(6.67-3.3) /(6.67-2.08)=0.7342$

Fraction of eutectic austenite $($ Point $E)=0.7342-0.45045=0.283754$

Fraction of iron carbide $($ Point $E)=(3.3-2.08) /(6.67-2.08)=0.2658$

As the cooling proceeds in the solid state below the eutectic temperature the fraction of iron carbide increases. This increase is shown by the fraction of iron 
CHAPTER 4 RESULTS AND DISCUSSIONS - -77-

carbide calculations for point $F$ and $G$. At point $F$ and $G$ the fraction of iron carbide is calculated as follows respectively:

Fraction of iron carbide $($ Point $F)=(3.3-1.6) /(6.67-1.6)=0.3353$

Fraction of iron carbide $($ Point $G)=(3.3-1.1) /(6.67-1.1)=0.3949$

This increasing amount of iron carbide in the solid state appears to have penetrated in to the austenite (see Figures 4.20 trough 4.24 )(Heine and Barton, 1977; Radzikowska and Voort, 1998; Mampaey, 2001; Park and Verhoeven, 1996).

When Point $\mathrm{H}$ (just before the eutectoid reaction) is reached the fraction of iron carbide and austenite is calculated by lever rule as follows:

Fraction of iron carbide $($ Point $H)=(3.3-0.8) /(6.67-0.8)=0.4259$

Fraction of austenite $($ Point $H)=(6.67-3.3) /(6.67-0.8)=0.5741$

Finally when the eutectoid temperature $723{ }^{\circ} \mathrm{C}$ is reached the austenite transforms to pearlite which is a micro-constituent with alternating layers of $\alpha$ ferrite and iron carbide (cementite) as shown in Point I. The total fraction of iron carbide at this point is calculated as follows:

Fraction of iron carbide $($ Point I $)=(3.3-0.02) /(6.67-0.02)=0.4932$ 


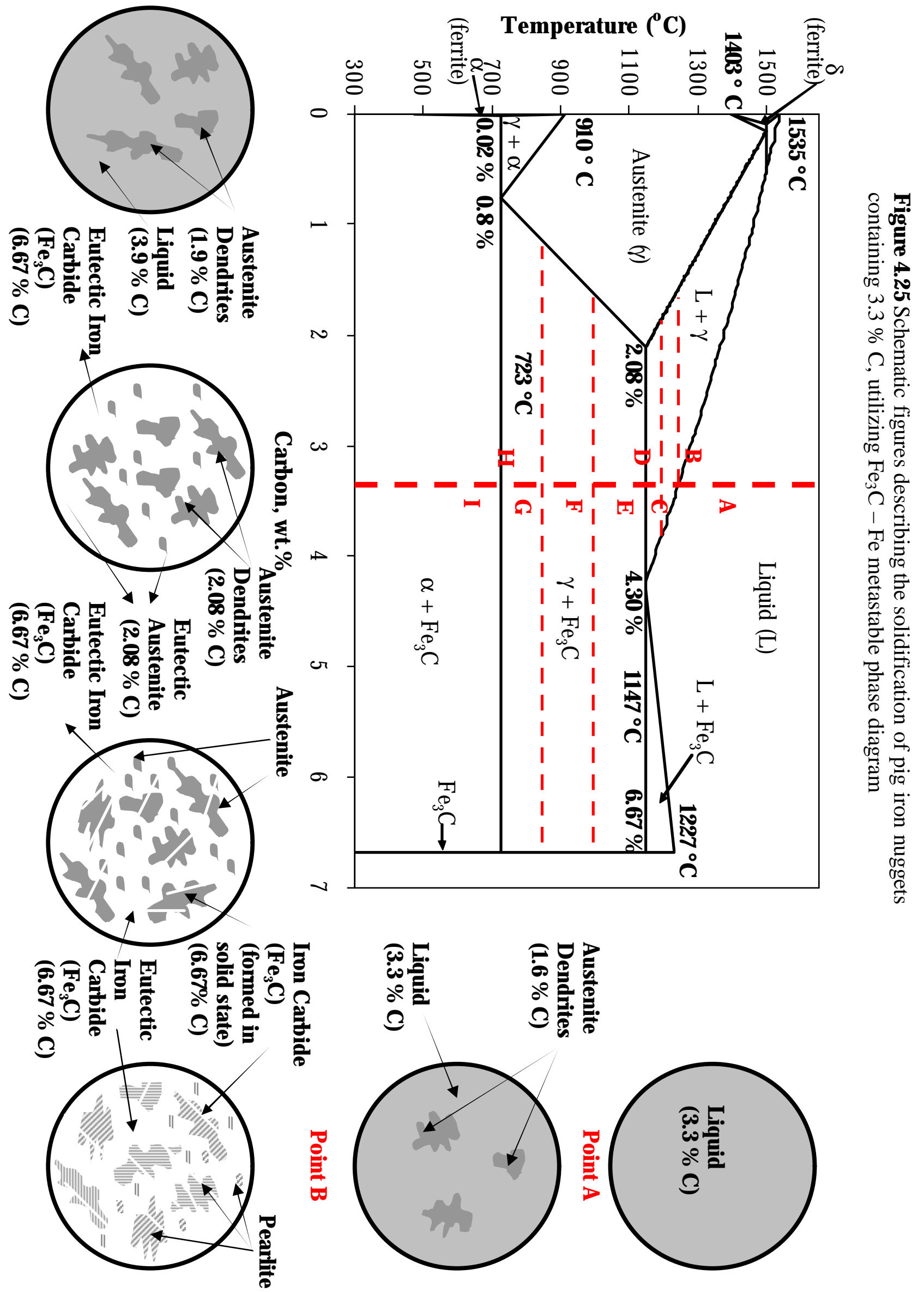




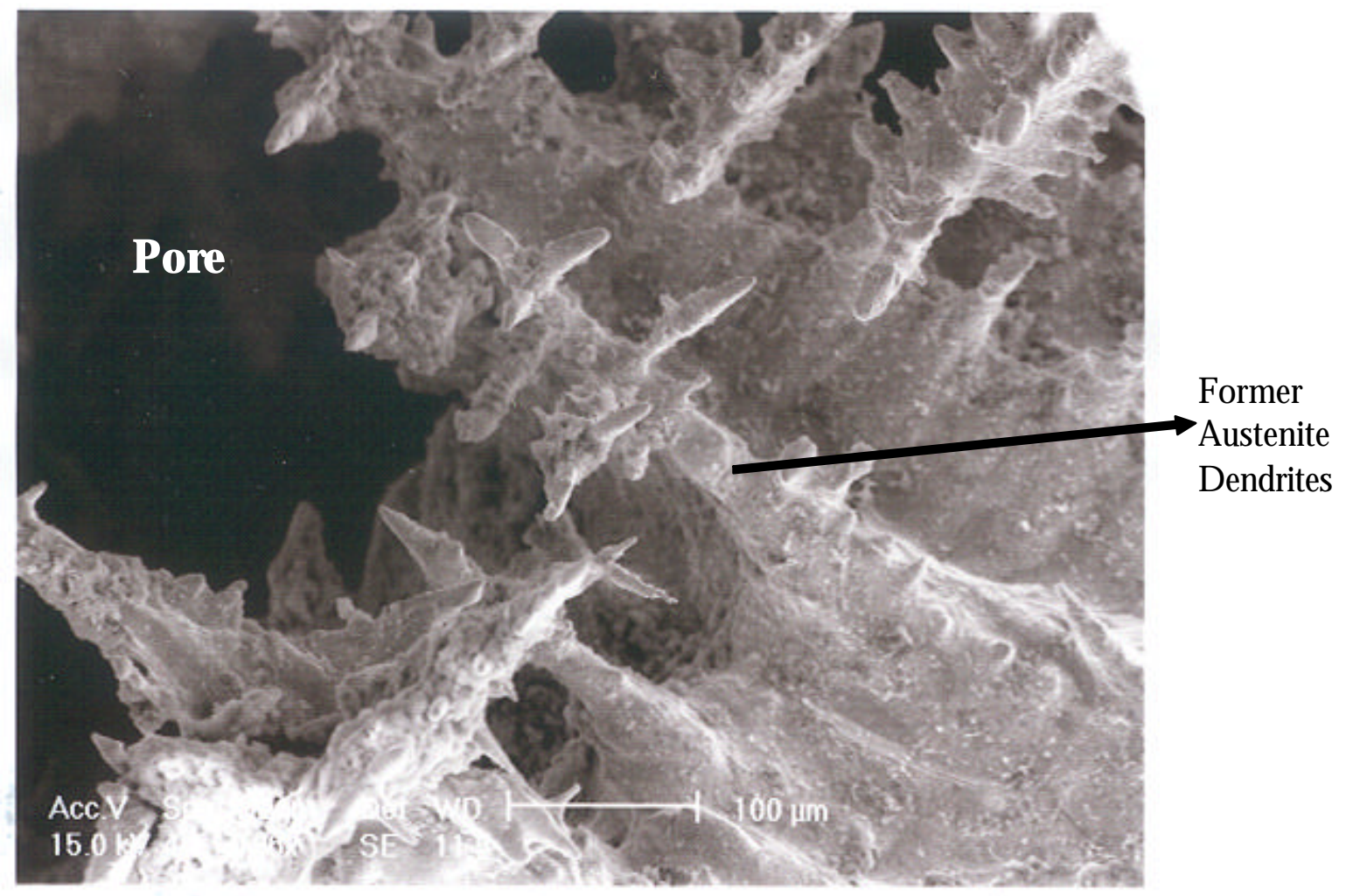

Figure 4.26 A scanning electron microscopy secondary image of the austenite dendrites present in the porosity of the pig iron nugget made at furnace temperature $1450^{\circ} \mathrm{C}$ and residence time $22 \mathrm{~min}$.

The final microstructure attained by this slow cooling scheme described in Figure 4.25 is similar to the reported white cast iron structure by Heine and Barton, 1977; Radzikowska and Voort, 1998; Mampaey, 2001; Park and Verhoeven, 1996 and pig iron nugget microstructures Figures 4.20 through 4.24 . 
CHAPTER 4 RESULTS AND DISCUSSIONS - -80-

\subsubsection{Microhardness Measurements}

The Vickers hardness measurements (1 kg load) (ASTM E 92-82, 1997 and ASTM E 384, 1999) on the metallized portion were taken to detect the increase in the cementite (iron carbide) amount in the microstructure with increasing furnace temperature (constant furnace residence time $10 \mathrm{~min}$ ), since the Vickers hardness increases with increasing amount of dissolving carbon in the metallized portion (amount of carbides) (Krauss, 1990).

Table 4.VII The average Vickers hardness values of the D RI, TD RI, and pig iron nuggets made at various furnace temperatures (constant furnace residence time 10 min).16 or more measurements were taken for each sample.

\begin{tabular}{|c|c|c|c|}
\hline $\begin{array}{c}\text { Furnace Temperature } \\
\left({ }^{\mathbf{0}} \mathbf{C}\right)\end{array}$ & $\begin{array}{c}\text { Furnace Residence } \\
\text { Time (min) }\end{array}$ & HVN & $\begin{array}{c}\text { Standand } \\
\text { Deviation }\end{array}$ \\
\hline 1425 & 10 & 90.6 & 27.4 \\
\hline 1435 & 10 & 263.7 & 20.2 \\
\hline 1445 & 10 & 353.9 & 41.1 \\
\hline 1465 & 10 & 369.6 & 56.2 \\
\hline 1475 & 10 & 349.7 & 31.8 \\
\hline 1485 & 10 & 401.3 & 58.7 \\
\hline 1495 & 10 & 431 & 62.8 \\
\hline
\end{tabular}


CHAPTER 4 RESULTS AND DISCUSSIONS -81-

The average Vickers hardness values of the D RI, TD RI, and pig iron nuggets made at varying furnace temperatures is summarized in Figure 4.27 and Table 4.VII. The Microhardness of the D RI produced varied between $60 \mathrm{HVN}$ and 120 HVN. The Microhardness of the TD RI produced varied between $120 \mathrm{HVN}$ and $325 \mathrm{HVN}$. The Microhardness of the pig iron nuggets produced varied between $325 \mathrm{HVN}$ and $550 \mathrm{HVN}$.

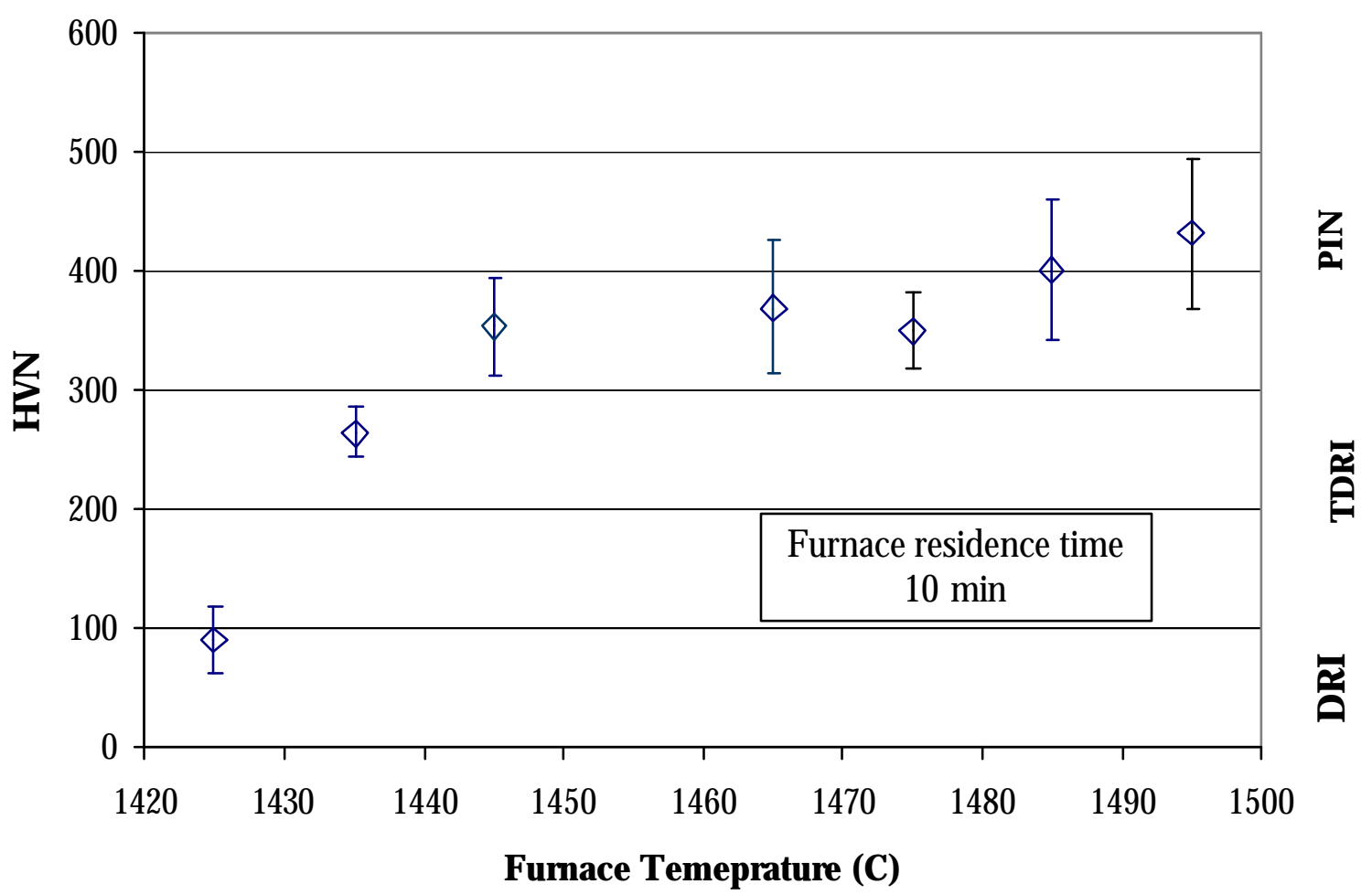

Figure 4.27 The average Vickers hardness values of the D RI, TD RI, and pig iron nuggets representing the increase in the amount of carbon in the system with increasing furnace temperature at constant furnace residence time $10 \mathrm{~min}$. 16 or more measurements were taken from the metallized portion of each sample. 
CHAPTER 4 RESULTS AND DISCUSSIONS -82-

\subsection{Optimization of 0 perating Fumace Temperature and Residence Time for Pig iron Nugget Production}

The dried green balls were fired at varying furnace temperatures and residence times

In order to be able to determine (i) the pig iron nugget formation threshold values and (ii) optimum operating furnace temperatures and residence times. The summary of the experimental results is shown in Figure 4.28.

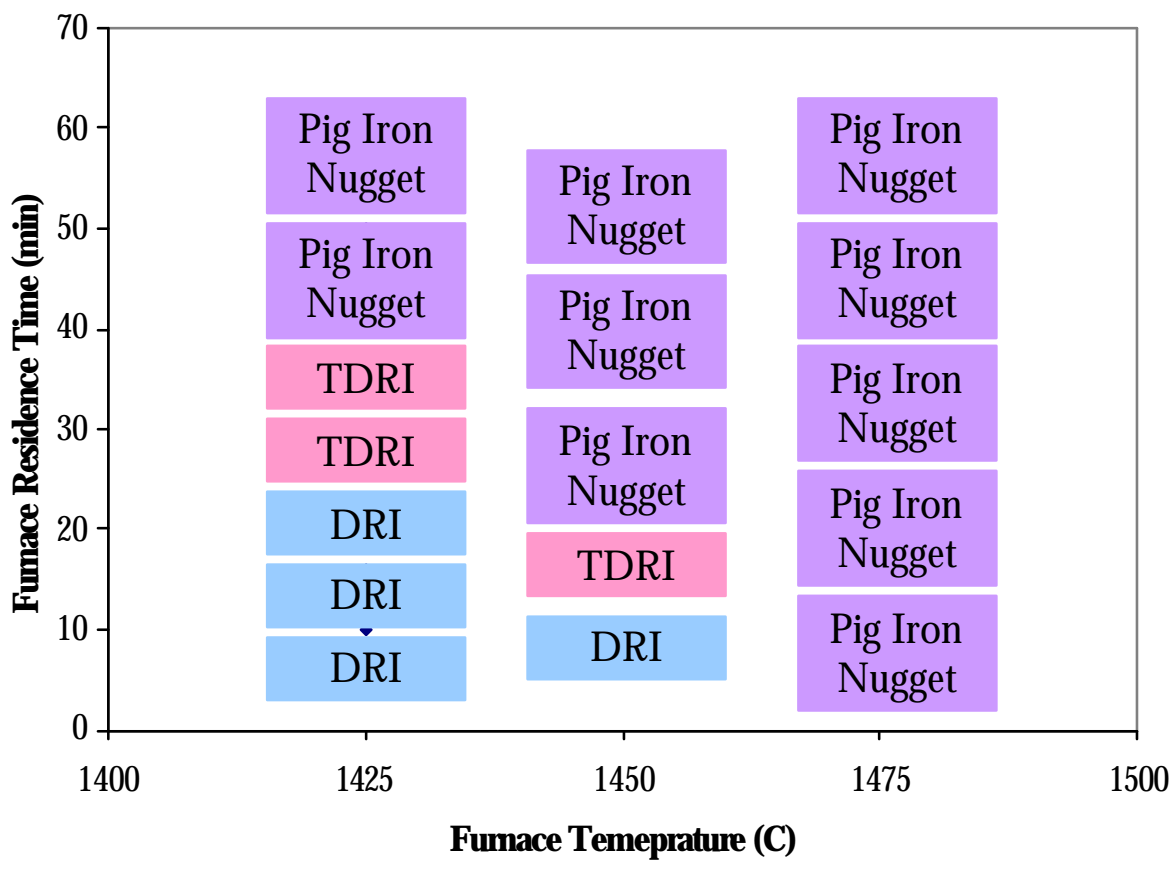

Figure 4.28 The summary of the experimental work conducted in order to be able to determine the optimum pig iron nugget making furnace temperatures and residence times. 


\subsubsection{Identification of Phases and Micro constituents}

The optical micrographs of the pig iron nuggets produced at furnace temperatures $1450^{\circ} \mathrm{C}$ and $1475^{\circ} \mathrm{C}$ and residence times $22 \mathrm{~min}$ and $28 \mathrm{~min}$ is shown in Figures 4.29 through 4.32.

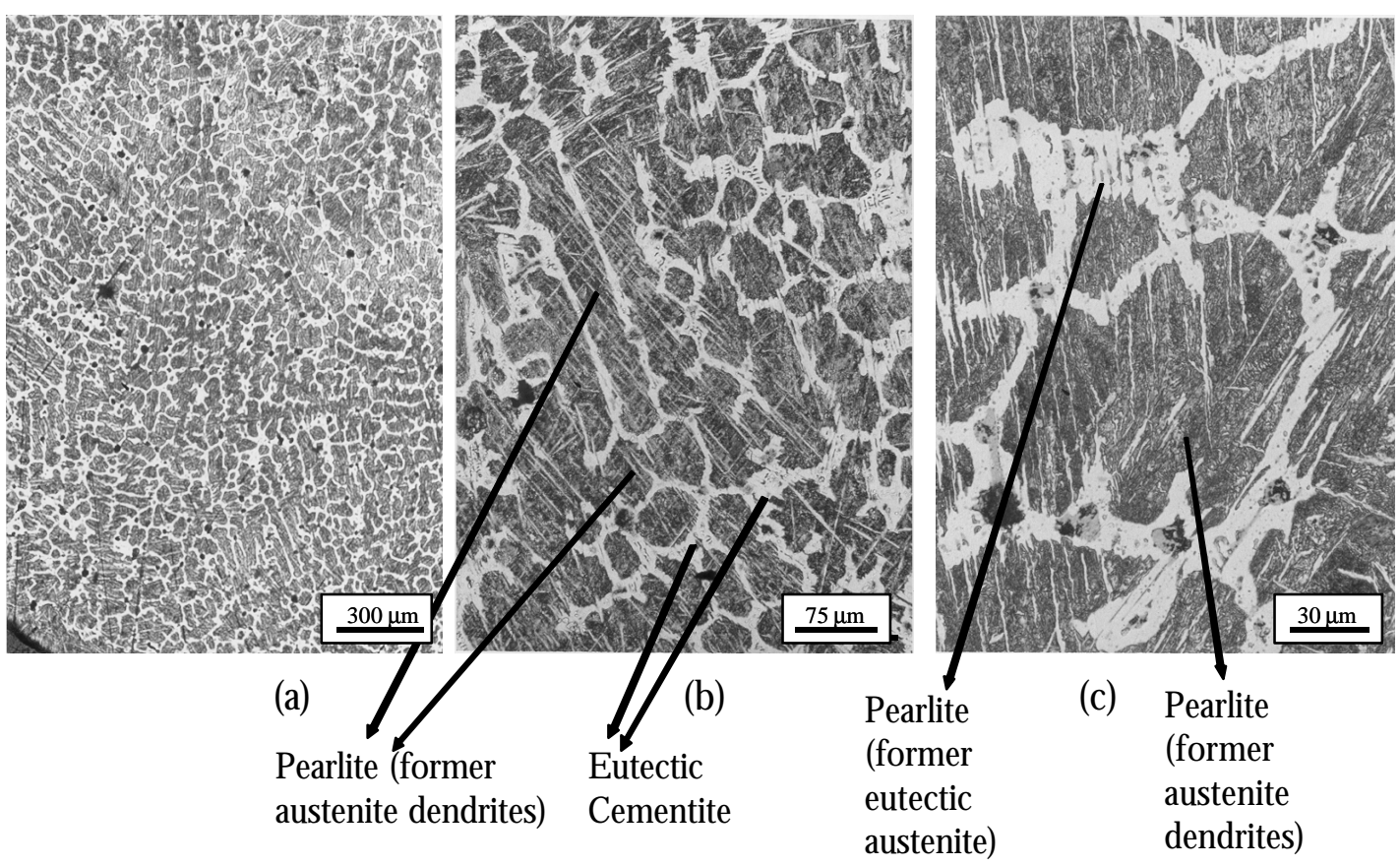

Figure 4.29 Optical micrographs of a cross section of the pig iron nuggets made at furnace temperature $1450{ }^{\circ} \mathrm{C}$ and furnace residence $22 \mathrm{~min}$ time for varying magnifications.(Nital etch) 


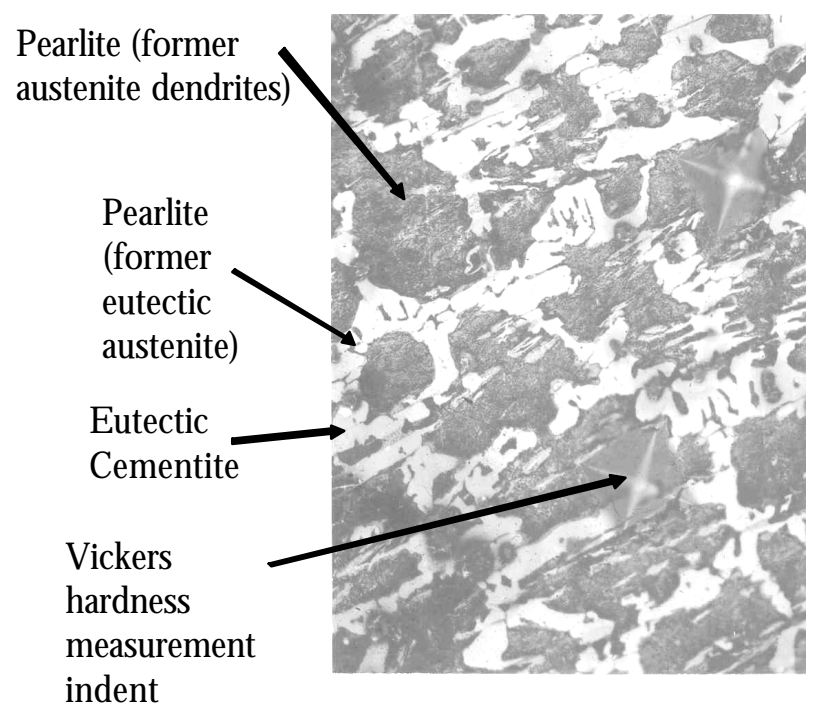

Figure 4.30 Optical micrographs of a cross section of the pig iron nuggets made at furnace temperature $1450{ }^{\circ} \mathrm{C}$ and furnace residence $28 \mathrm{~min}$ time.(Nital etch)

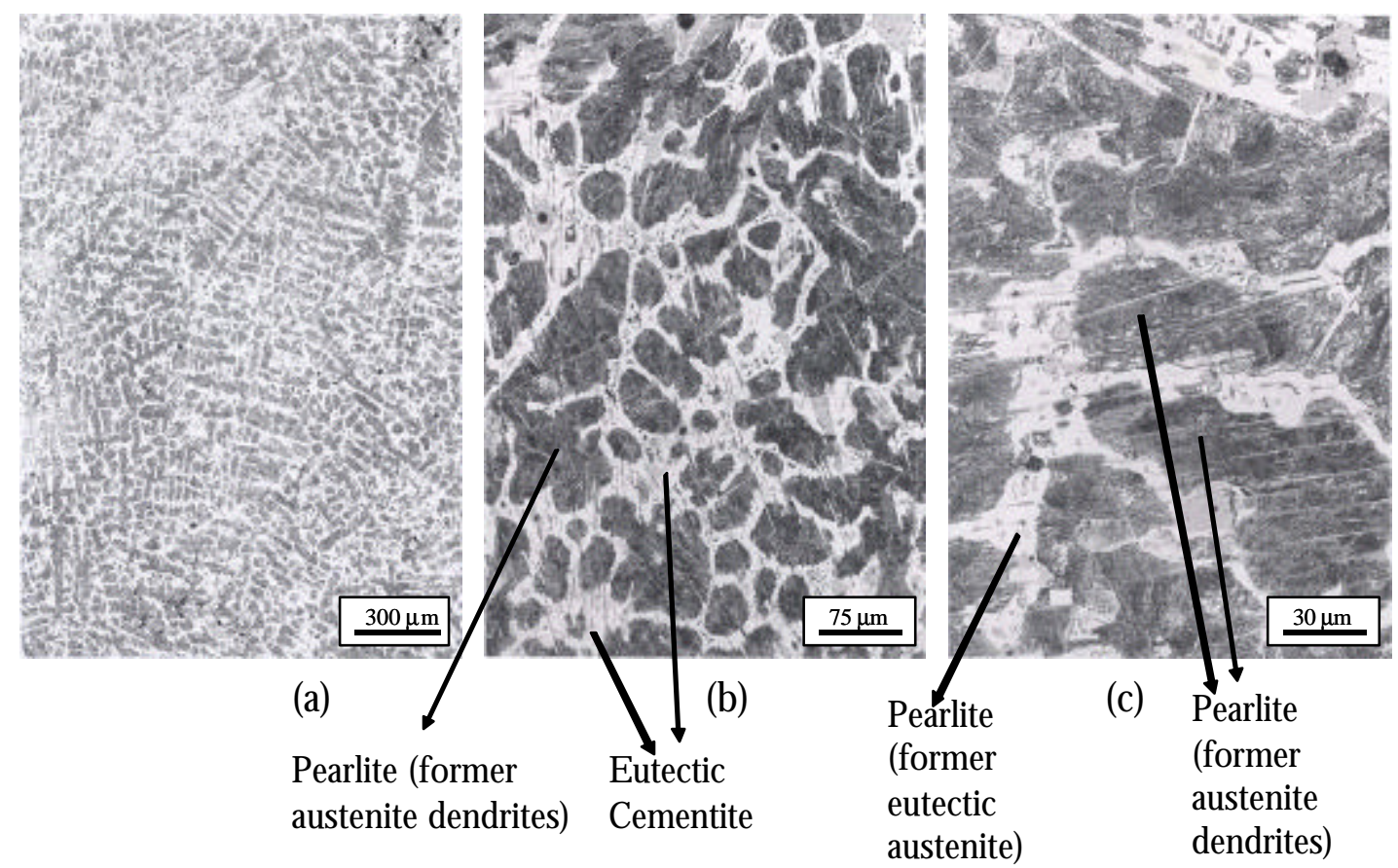

Figure 4.31 Optical micrographs of a cross section of the pig iron nuggets made at furnace temperature $1475^{\circ} \mathrm{C}$ and furnace residence $22 \mathrm{~min}$ time for varying magnifications.(Nital etch) 


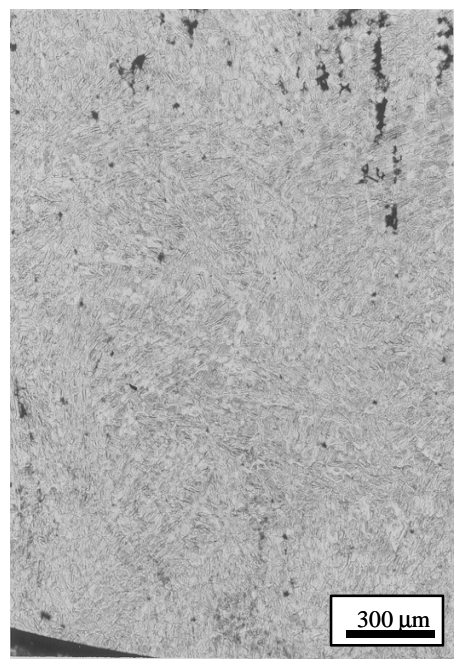

(a)

Pearlite (former austenite dendrites)

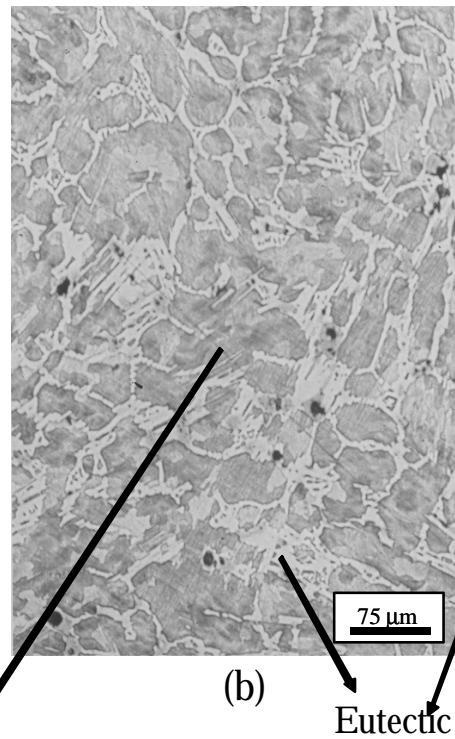

Cementite

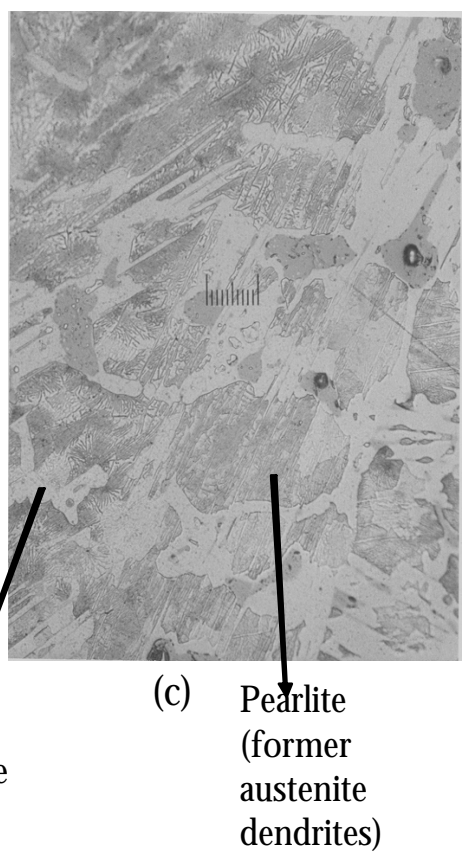

Figure 4.32 Optical micrographs of a cross section of the pig iron nuggets made at furnace temperature $1475^{\circ} \mathrm{C}$ and furnace residence 28 min time for varying magnifications.(Nital etch)

The pig iron nugget microstructures shown in Figures 4.29 through 4.32 are composed of (i) a dendritic pattern of fine pearlite (dark grey areas) , (ii) an interdendritic eutectic mixture of cementite (light areas) and pearlite (dark grey areas), and (iii) cementite which is formed in the solid state (light areas). These microstructures are very similar to the suggested characteristic of white cast iron structure (D avis, 1990;Mehl, 1972;Smith, 1993;Callister, 1997;Anameric and Kawatra, 2004;Heine and Barton, 1977;Radzikowska and Voort, 1998;Mampaey, 2001;Park and Verhoeven, 1996). 
CHAPTER 4 RESULTS AND DISCUSSIONS -86-

The phases and constituents present in the pig iron nugget microstructure were identified utilizing scanning electron microscopy (SEM) and local chemical analysis (ED S) and x-ray diffraction analysis.

Secondary SEM images for the pig iron nugget produced at furnace temperature $1475 \mathrm{C}$ and residence time $22 \mathrm{~min}$ is shown in Figure 4.33. The phases iron sulfide, iron carbide, and $\alpha$ ferrite identified utilizing local chemical analysis (ED S) and their approximate chemical compositions are given in Table 4.VIII. Utilization of high magnification images enabled the determination and identification of presence of iron sulfide phase as shown in Figure 4.33.

Table 4.VIII The approximate local chemical analysis of the phases present in the pig iron nugget produced at furnace temperature $1475{ }^{\circ} \mathrm{C}$ and residence time $22 \mathrm{~min}$.

\begin{tabular}{|c|c|c|}
\hline Element & $\begin{array}{c}\text { Iron Carbides } \\
\text { \% }\end{array}$ & $\begin{array}{c}\text { Iron Sulfide } \\
\text { \% }\end{array}$ \\
\hline $\mathrm{Fe}$ & $88.4-90.4$ & 59.7 \\
\hline $\mathrm{C}$ & $7.5-8.6$ & 2.62 \\
\hline $\mathrm{Si}$ & $0.3-0.5$ & 0.65 \\
\hline $\mathrm{P}$ & $<0.8$ & 1.33 \\
\hline $\mathrm{S}$ & $0.1-0.3$ & 33.86 \\
\hline
\end{tabular}




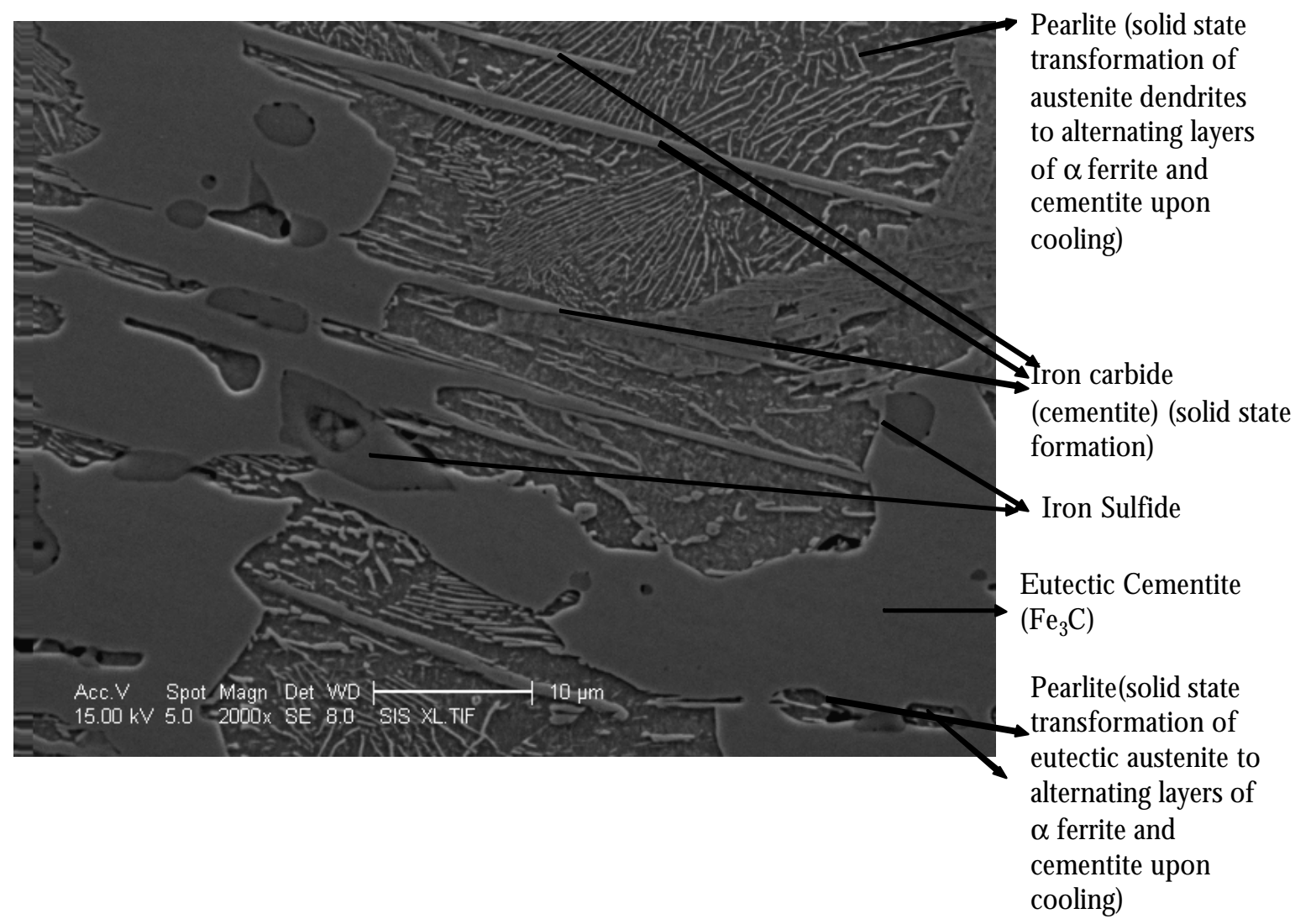

Figure 4.33 SEM secondary image of the pig iron nugget made at furnace temperature $1475^{\circ} \mathrm{C}$ and furnace residence time $22 \mathrm{~min}$.

The x-ray diffraction pattern of the pig iron nuggets produced at furnace temperature $1450^{\circ} \mathrm{C}$ and residence time $22 \mathrm{~min}$ is shown in Figure 4.34. It can be seen from Figure 4.34 that only iron ( $\alpha$ ferrite) and iron carbide microconstituents were identified from the pattern. 


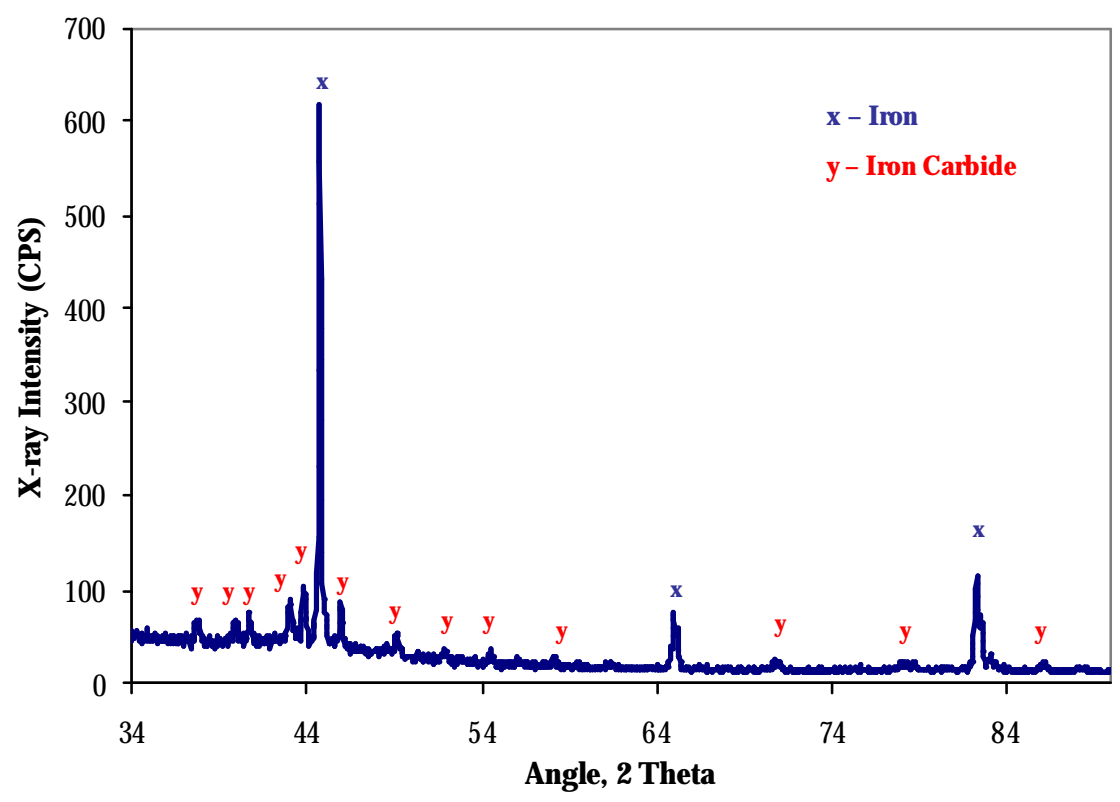

Figure 4.34The X-ray diffraction pattern of the pig iron nugget produced at furnace temperature $1450{ }^{\circ} \mathrm{C}$ and residence time $22 \mathrm{~min}$.

\subsubsection{Microhardness Measurements}

The Vickers hardness measurements (1 kg load) (ASTM E 92-82, 1997 and ASTM E 384, 1999) on the metallized portion were taken to detect the increase in the cementite amount in the microstructure with increasing furnace temperature and/ or residence time, since the Vickers hardness increases with increasing amount of dissolving carbon in the metallized portion (amount of carbides). The increase in the microhardness with increasing furnace temperature and residence time and the hardness ranges are shown in Figure 4.35 and Table 4.IX . 
There are two different types of iron carbides contributing to the microhardness of the structure. The first types are the iron carbides which are formed by solid state reactions. The second types are the iron carbides as cementite (eutectic product (see Figure 2.3)) which is formed by liquid state reactions. Solid state iron carbides are formed in D RI and solid state reacting sites available for TD RI (see Figure 4.25). Cementite was formed in liquid state reacting sites available for TD RI and pig iron nuggets (see Figure 4.25).The diffusion of carbon in the solid state is much slower than in the liquid state. Therefore, the large increase in hardness from DRI to TD RI and to pig iron nuggets (see Figure 4.35) was due to more and/ or rapid diffusion of carbon in the metallized portion. In other words, due to increasing amounts of eutectic cementite with increasing furnace temperature and residence times.

The necessary furnace residence times for making pig iron nuggets with required microhardness values can be interpolated from Figure 4.35. For example, the required furnace residence time for making pig iron nuggets with microhardness $350 \mathrm{HVN}$ at $1425 \mathrm{C}$ furnace temperature was $40 \mathrm{~min}$. The required furnace residence time for making pig iron nuggets with microhardness $350 \mathrm{HVN}$ at $1450^{\circ} \mathrm{C}$ furnace temperature was $24 \mathrm{~min}$. As the furnace temperature increases $25 \mathrm{C}$ (from $1425^{\circ} \mathrm{C}$ ) the furnace residence time required for making pig iron nuggets with $350 \mathrm{HVN}$ was reduced 0.6 times. The required furnace residence time for making pig iron nuggets with microhardness 350 $\mathrm{HVN}$ at $1475^{\circ} \mathrm{C}$ furnace temperature was $10 \mathrm{~min}$. As the furnace temperature increases $50 \mathrm{C}$ (from $1425^{\circ} \mathrm{C}$ ) the furnace residence time required for making pig iron nuggets with $350 \mathrm{HVN}$ was reduced 0.75 times. Carbon diffusion kinetics at high temperatures produces the same Microhardness value at lower residence times. 


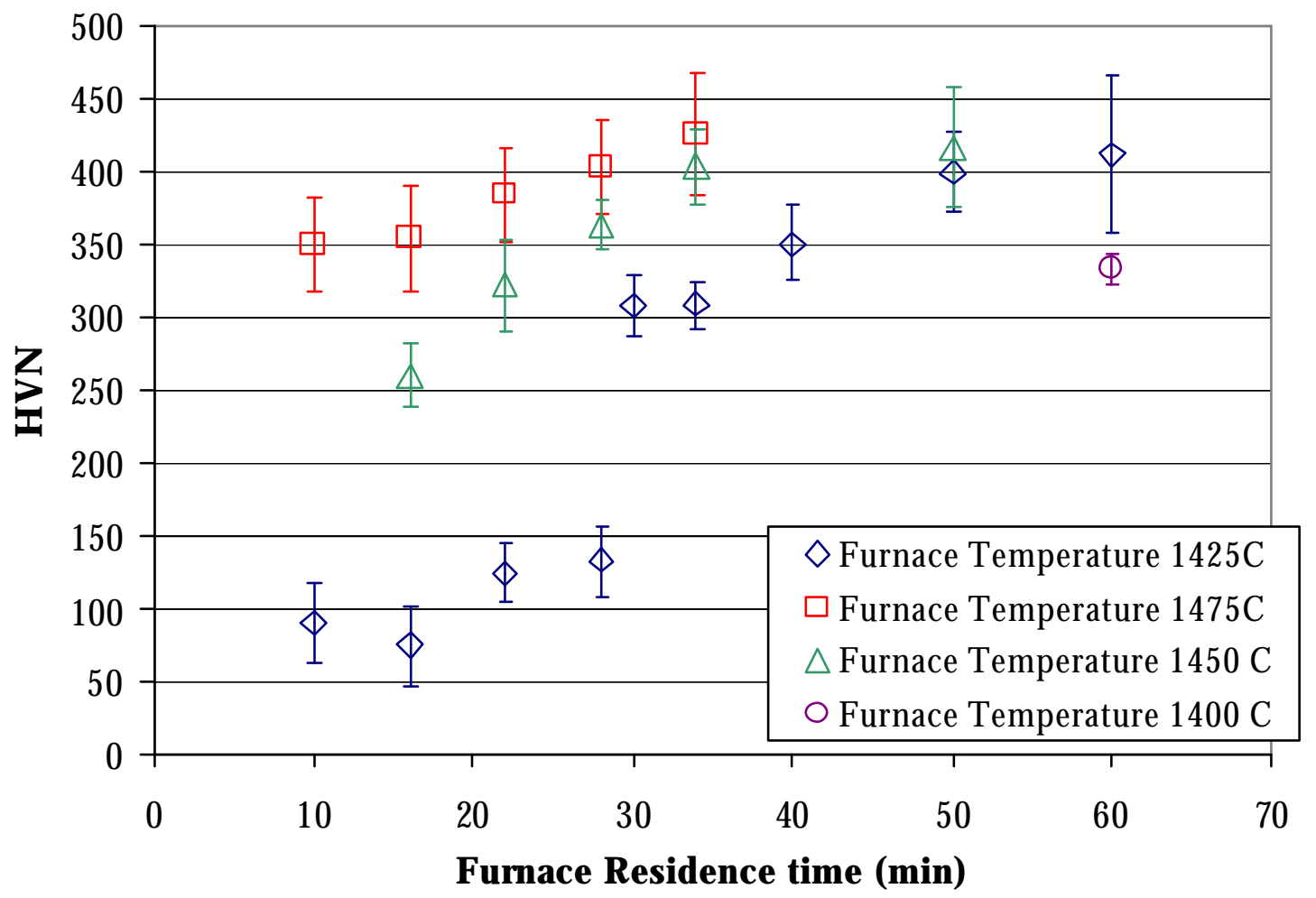

Figure 4.35 The average Vickers hardness values of the D RI, TD RI, and pig iron nuggets made at furnace temperatures $1425^{\circ} \mathrm{C}, 1450^{\circ} \mathrm{C}$, and $1475^{\circ} \mathrm{C}$ and residence times $16 \mathrm{~min}, 22 \mathrm{~min}, 28 \mathrm{~min}, 34 \mathrm{~min}, 40 \mathrm{~min}, 50 \mathrm{~min}$, and $60 \mathrm{~min} .16$ or more measurements were taken from each sample. 
CHAPTER 4 RESULTS AND DISCUSSIONS -91-

Table 4.IX The average Vickers hardness values of the D RI, TD RI, and pig iron nuggets made at various furnace temperature and residence times. 16 or more measurements were taken for each sample.

\begin{tabular}{|c|c|c|c|}
\hline $\begin{array}{l}\text { Furnace Temperature } \\
\qquad\left({ }^{\circ} \mathrm{C}\right)\end{array}$ & $\begin{array}{c}\text { Furnace Residence } \\
\text { Time (min) }\end{array}$ & HVN & $\begin{array}{l}\text { Standard } \\
\text { Deviation }\end{array}$ \\
\hline 1400 & 60 & 332.9 & 11.2 \\
\hline 1425 & 10 & $\begin{array}{l}90.6 \\
\end{array}$ & 27.4 \\
\hline 1425 & 16 & 75.1 & 27.1 \\
\hline 1425 & 22 & 124.3 & 20.0 \\
\hline 1425 & 28 & 132.7 & 23.4 \\
\hline 1425 & 30 & 307.8 & 21.1 \\
\hline 1425 & 34 & 308.7 & 15.7 \\
\hline 1425 & 40 & 351.1 & 25.8 \\
\hline 1425 & 50 & 399.7 & 27.2 \\
\hline 1425 & 60 & 412.4 & 53.8 \\
\hline 1435 & 10 & 263.8 & 20.2 \\
\hline 1445 & 10 & 353.9 & 41.1 \\
\hline 1450 & 16 & 260.4 & 21.5 \\
\hline 1450 & 22 & 322.6 & 31.6 \\
\hline 1450 & 28 & 363.6 & 16.8 \\
\hline 1450 & 34 & 403.9 & 25.2 \\
\hline 1450 & 50 & 416.5 & 40.5 \\
\hline 1465 & 10 & 369.6 & 56.2 \\
\hline 1475 & 10 & 349.7 & 31.9 \\
\hline 1475 & 16 & 354.2 & 35.9 \\
\hline 1475 & 22 & 384 & 32.1 \\
\hline 1475 & 28 & 402.7 & 31.9 \\
\hline 1475 & 34 & 425.5 & 41.7 \\
\hline 1485 & 10 & 401.3 & 58.7 \\
\hline 1495 & 10 & 431 & 62.7 \\
\hline
\end{tabular}


CHAPTER 4 RESULTS AND DISCUSSIONS -92-

\subsubsection{Apparent Density Measurements}

The apparent density measurements utilizing water displacement method (ASTM B311, 2002) with respect to furnace temperature and residence time is shown in Figure 4.36 and Table 4.X.

Apparent density values were used for the evaluation of the following material properties:

i. D egree of metallization (Lankford, et al. 1985)

ii. Porosity

iii. Slag separation

It was observed that as the furnace temperature increases and/ or residence time increases the degree of metallization increases, the porosity decreases, and metal to slag ratio decreases as indicated by an increase in apparent density. Error bars drawn in Figure 4.36 indicate the standard deviation from 4 apparent density measurements.

For D RI, since the slag and the metallized portion were not separated, measurements represent the apparent density of the slag and metal $(\alpha-\mathrm{Fe})$ mixture. The ratio of slag to metal mixture is lower for TD RI. 
The actual densities of the DRI, TD RI, and pig iron nuggets were not determined because they were porous and pores were not continuous. No measurements were performed to determine the percent porosity; however, it was generally observed microstructurally that porosity did decrease with increasing furnace temperature and residence time. This allowed apparent densities and real densities to be more comparable. The apparent density results were compared with the real density values obtained from the literature (Table 4.XI).

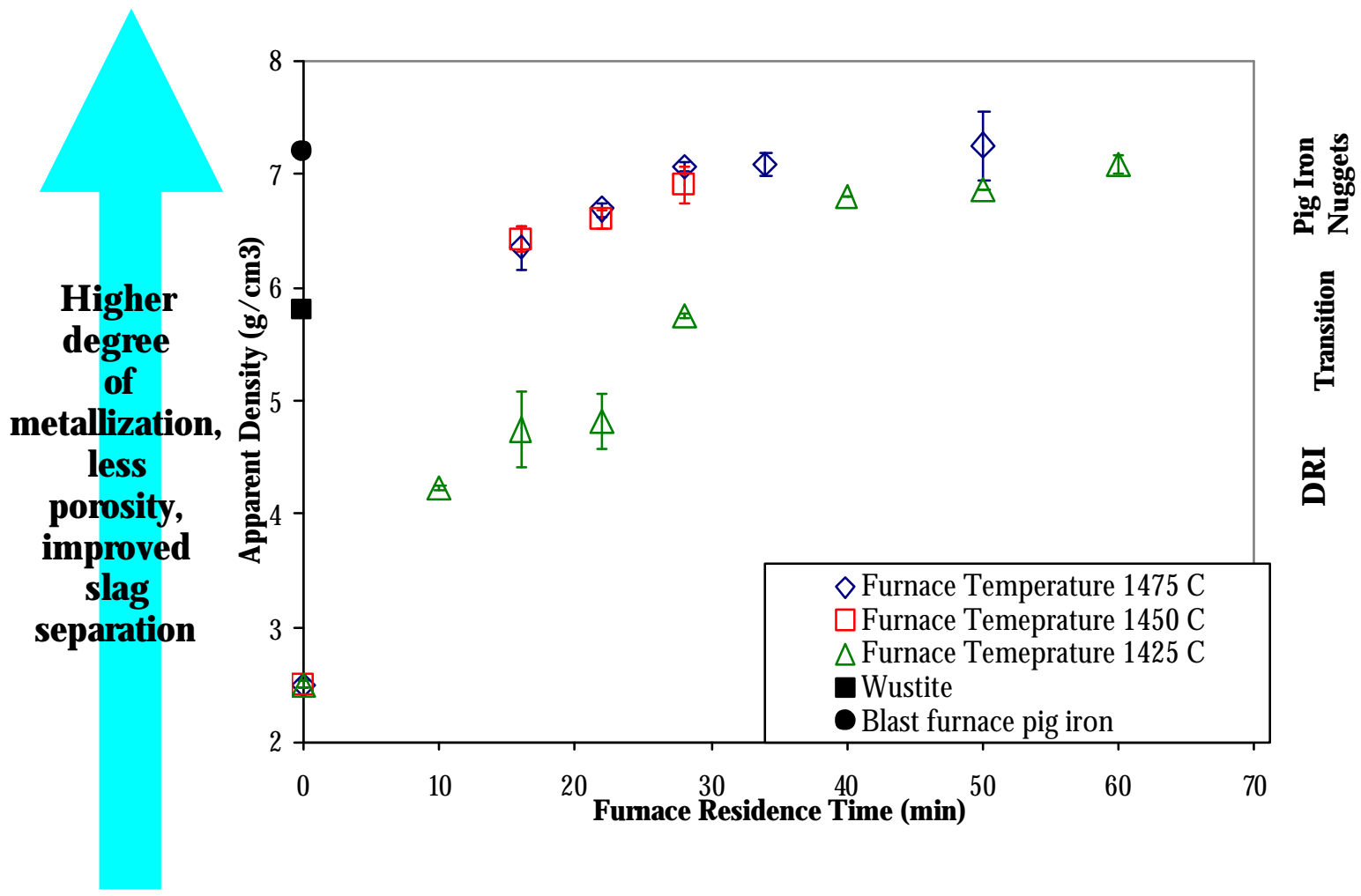

Figure 4.36 Apparent density values of the D RI, TD RI, and pig iron nuggets produced plotted against furnace residence time. E rror bars indicate the standard deviation of 4 measurements. The initial dried green ball density before firing was $2.5 \mathrm{~g} / \mathrm{cm}^{3}$ (The density of the green balls was calculated by measuring the green ball diameter and mass). 
It can be seen from Figure 4.36 and Table 4.IX that the apparent densities of the direct reduced iron (DRI) made at lower temperatures and lower residence times are lower than wustite $(\mathrm{FeO})$. This is due to intimate mixture of the low density slag (approximate slag density $2.5-3 \mathrm{~g} / \mathrm{cm}^{3}$ ) and iron (density $7.87 \mathrm{~g} / \mathrm{cm}^{3}$ ). The apparent densities of the TD RI produced are higher than DRI, and comparable to wustite. This is due to partial slag separation, higher degree of metallization and reduced amount of pores. The apparent densities of the pig iron nuggets are higher than TD RI, and comparable to pig iron. This is due to complete slag separation, higher degree of metallization, and reduced amount of pores.

\subsubsection{Pig Iron Nugget Production Furnace Temperature and Residence Time Predictions}

According to the microstructural, apparent density and microhardeness changes the furnace residence time required for pig iron nugget production at certain furnace temperatures have been determined and summarized on Table 4.XIII . In addition, these furnace residence times and temperatures (shown in Table 4.XII) were utilized in obtaining the Arrhenius plot shown in Figure 4.37(D avis and D avis, 2003). 
CHAPTER 4 RESULTS AND DISCUSSIONS -95-

Table 4.X Apparent density values of the D RI, TD RI and pig iron nuggets made at varying furnace temperatures and residence times.

\begin{tabular}{|c|c|c|c|}
\hline $\begin{array}{l}\text { Fumace Temperature } \\
\qquad\left({ }^{\circ} \mathrm{C}\right)\end{array}$ & $\begin{array}{c}\text { Fumace Residence } \\
\text { Time (min) }\end{array}$ & $\begin{array}{l}\text { Apparent Density } \\
\left(\mathbf{g} / \mathrm{cm}^{3}\right)\end{array}$ & $\begin{array}{l}\text { Standard } \\
\text { Deviation }\end{array}$ \\
\hline 0 & 0 & 2.5 & 0.025 \\
\hline 1425 & 10 & 4.2 & 0.0096 \\
\hline 1425 & 16 & 4.7 & 0.3302 \\
\hline 1425 & 22 & 4.8 & 0.2438 \\
\hline 1425 & 28 & 5.7 & 0.0182 \\
\hline 1425 & 40 & 6.8 & 0.0792 \\
\hline 1425 & $\overline{50}$ & 6.9 & 0.1274 \\
\hline 1425 & 60 & 7.1 & 0.0956 \\
\hline 1450 & 16 & 6.4 & 0.1126 \\
\hline 1450 & 22 & 6.6 & 0.0748 \\
\hline 1450 & 28 & 6.9 & 0.1559 \\
\hline 1475 & 16 & 6.4 & 0.1911 \\
\hline 1475 & 22 & 6.7 & 0.0582 \\
\hline 1475 & 28 & 7.1 & 0.0388 \\
\hline 1475 & 34 & 7.1 & 0.1023 \\
\hline 1475 & 50 & 7.2 & 0.3006 \\
\hline
\end{tabular}


CHAPTER 4 RESULTS AND DISCUSSIONS - -96-

Table 4.XI The density values of selected ferrous iron based materials

\begin{tabular}{|c|c|c|}
\hline Material & Density $\left(\mathrm{g} / \mathrm{cm}^{3}\right)$ & Reference \\
\hline Magnetite & $4.9-5.2$ & (Weiss, 1985) \\
\hline Wustite & 6.00 & (Lide, 2001) \\
\hline Pig Iron & 7.2 & (Weiss, 1985) \\
\hline Low C-White Cast Iron & 7.6-7.8 & (Shackelford, et al., 1994) \\
\hline Steel & 7.8 & (Ashby and Jones, 1986) \\
\hline Iron & 7.87 & (Lide, 2001) \\
\hline Iron Carbide $\left(\mathrm{Fe}_{3} \mathrm{C}\right)$ & 7.7 & (Lide, 2001) \\
\hline Grernnerite $\left(\mathrm{FeSiO} 0_{3}\right)$ & 3.5 & (Lide, 2001) \\
\hline Fayalite $\left(\mathrm{Fe}_{2} \mathrm{SiO}_{4}\right)$ & 4.34 & (Lide, 2001) \\
\hline
\end{tabular}

Table 4. XII The furnace temperature and residence time threshold values for pig iron nugget production.

\begin{tabular}{|c|c|}
\hline Furnace Temperature ( $\left.{ }^{\circ} \mathbf{C}\right)$ & Furnace Residence Time (min) \\
\hline 1400 & 60 \\
\hline 1425 & 38 \\
\hline 1450 & 19 \\
\hline 1475 & 8 \\
\hline
\end{tabular}


CHAPTER 4 RESULTS AND DISCUSSIONS - -97-

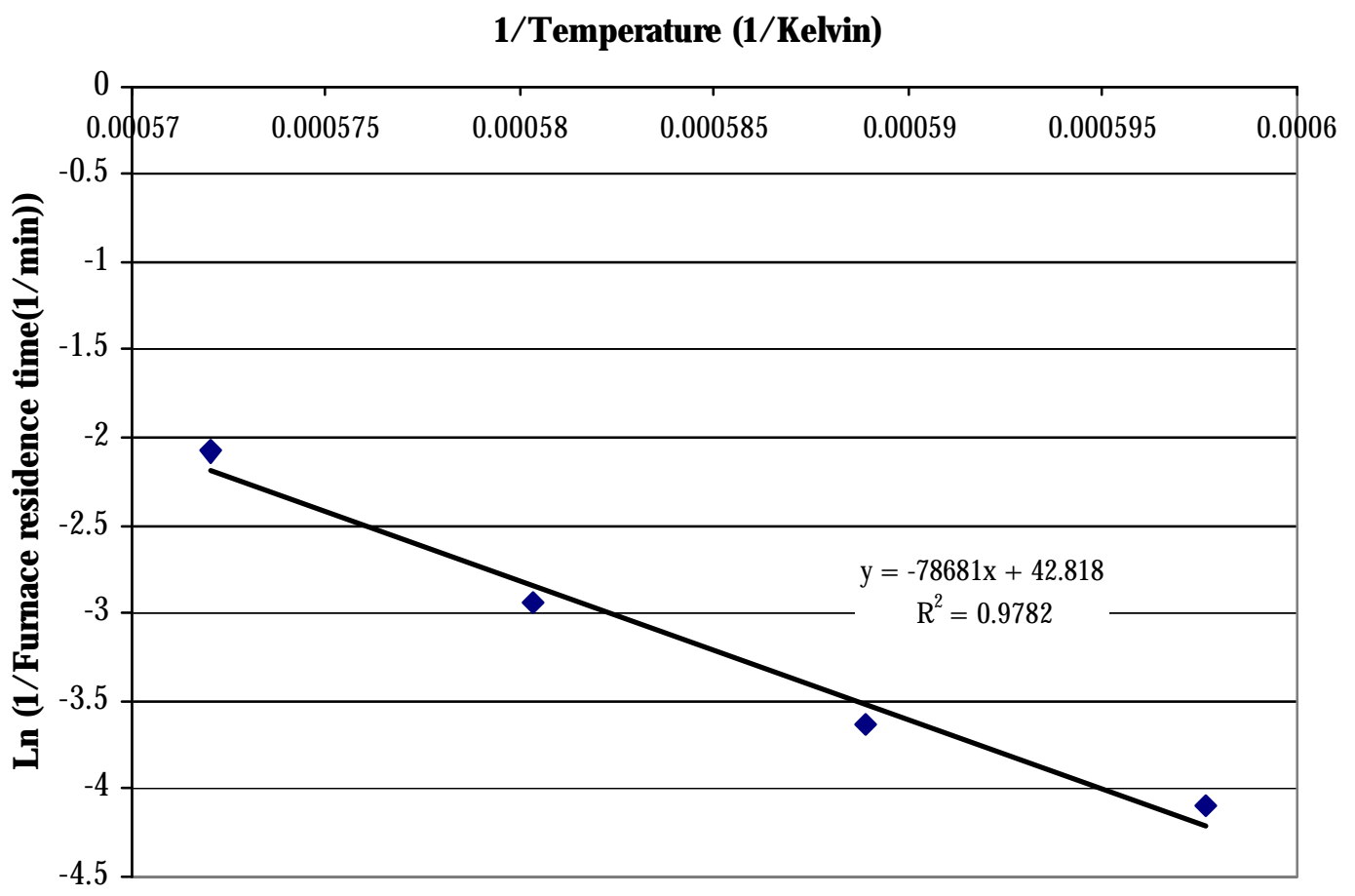

Figure 4.37 The natural logarithm of the 1 / furnace residence time required for pig iron nugget production versus the required furnace temperatures.

According to the Arrhenius equation (Eqaution 4.1) the slope of Figure 4.37 indicates the activation energy of the system divided by the gas constant and the intercept of the graph indicates the pre exponential constant A.

$$
\mathrm{k}=\mathrm{A} \exp (-\mathrm{E} / \mathrm{RT}) \quad \text { Equation } 4.1
$$

where, $\mathrm{k}$ is the rate expression (in this study the $1 /$ furnace residence time required for the pig iron nugget production), $\mathrm{A}$ is the pre-exponential factor which does not depend appreciably on the temperature, $\mathrm{E}$ is the activation energy, $\mathrm{R}$ is the gas constant and $\mathrm{T}$ is the temperature. 
It can be seen from Figure 4.37 that, the furnace residence time and temperature threshold values for pig iron nugget production can be defined by the following equation

$$
\operatorname{Ln}(\mathrm{Y})=-78681(\mathrm{X})+42.818 \quad \text { Equation } 4.2
$$

where, $\mathrm{Y}$ is the 1 / furnace residence time required for pig iron nugget production (1/ $\mathrm{min})$, and $\mathrm{X}$ is the 1 / furnace temperature required for pig iron nugget production (1/ Kelvin).

The compatibility of the calculated furnace residence time and temperature threshold values with the experimental pig iron nugget production furnace temperatures and residence times is shown in Figure 4.38.

The Equation 4.2 assumes that same sequence of chemical reactions take place at every operating temperature and only the kinetics of these reactions are affected by the temperature change. This equation does not take the thermodynamic constraints on the system into consideration. 


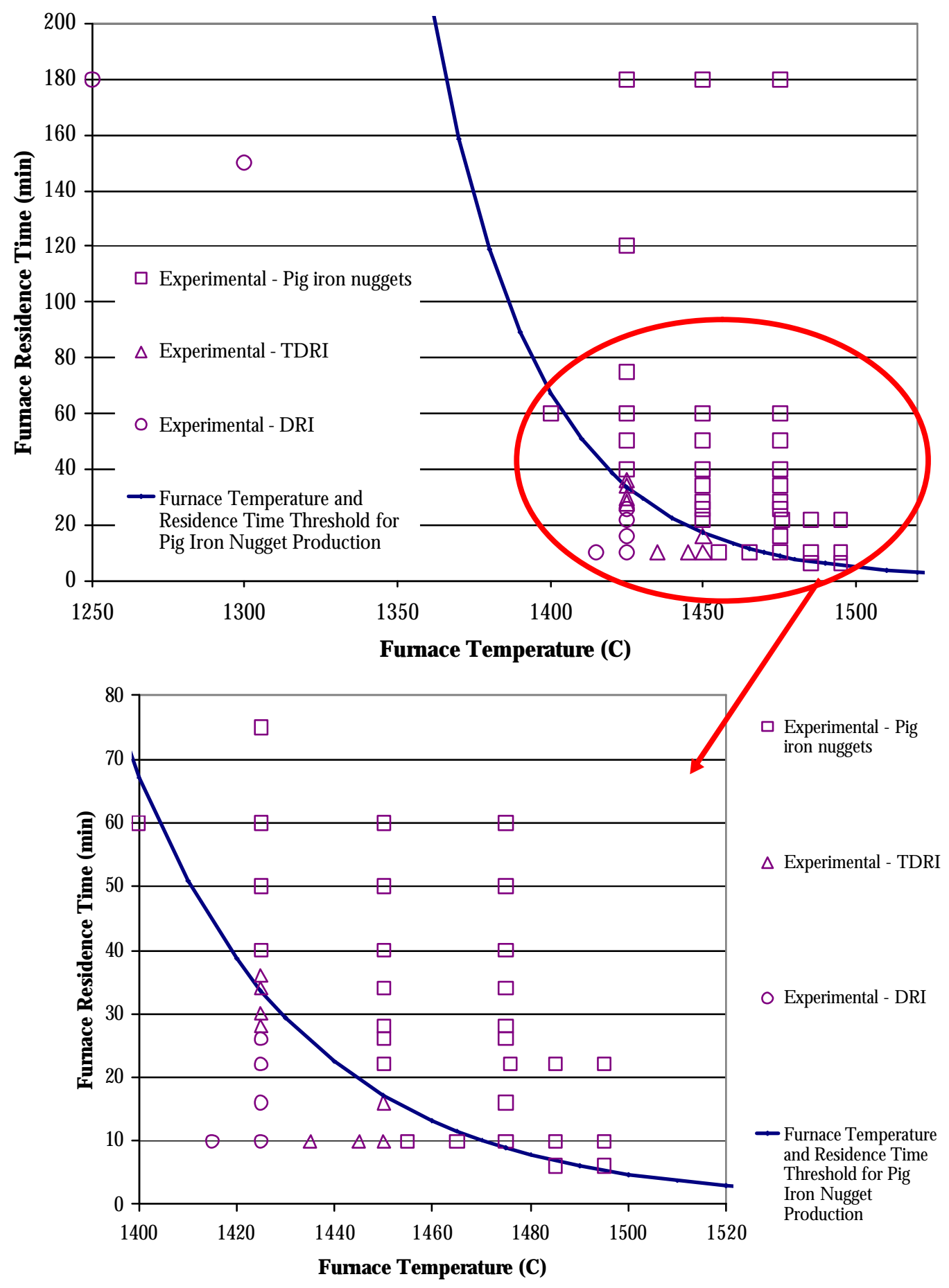

Figure 4.38 The compatibility theoretical of the furnace residence time and temperature threshold values calculated with the equation 4.2 and the experimental data. 
The furnace residence times required for pig iron nugget production at $1200^{\circ} \mathrm{C}$ and $1350^{\circ} \mathrm{C}$ furnace temperatures were calculated to be approximately 663.6 hours and 4.8 hours respectively. For the experimental set up utilized in this study these furnace residence times are unachievable, since after 3 hours of residence time the crucible starts to melt and sticks to the furnace hearth. Therefore, the lowest furnace temperature which can be utilized in this study for pig iron nugget production was calculated to be $1370{ }^{\circ} \mathrm{C}$ (2.6 hours residence time); and the lowest furnace residence time which can be utilized for pig iron nugget production in this study was calculated to be $5 \mathrm{~min}\left(1495^{\circ} \mathrm{C}\right.$ furnace temperature) (The highest temperature that laboratory scale resistance box furnace utilized in the experiments could operate was $1500^{\circ} \mathrm{C}$ )

For a large scale operation the economics of the process can be adjusted by operating at different regions of the threshold curve. For example at regions where furnace fuel is cheap and widely available the process can be operated at high furnace temperatures and short residence times. On the other hand, at regions where furnace fuel is not cheap and widely available the process can be operated at lower furnace temperatures and longer residence times. O ne draw back for operating at lower furnace temperatures and longer residence times could be increased sulfur content of the pig iron nuggets produced. Since with increasing furnace residence time amount of sulfur dissolving in pig iron nuggets increases. To prevent this low sulfur coals instead of high sulfur coals should be utilized as reducing, carburizing agents. 
CHAPTER 4 RESULTS AND DISCUSSIONS -101-

The percent error of the curve fitting was calculated to be $16.3 \%$ by utilizing Equation 4.3 and the values shown in Table 4.X III.

$\%$ error $=\left((\text { Sum of squared error/ D egrees of freedom })^{\wedge}(1 / 2)\right) /($ Mean of experimental values) $* 100$

Equation 4.3

Table 4. XIII The comparison of the furnace residence times calculated by utilizing equation 4.2 and experimental results

\begin{tabular}{|c|c|c|}
\hline $\begin{array}{c}\text { Fumace Temperature } \\
\left({ }^{\circ} \mathbf{C}\right)\end{array}$ & $\begin{array}{c}\text { Furnace Residence Time } \\
(\mathbf{m i n}) \\
\text { Calculated utilizing } \\
\text { Equation } \mathbf{4 . 2}\end{array}$ & $\begin{array}{c}\text { Fumace Residence Time } \\
(\mathbf{m i n}) \\
\text { Expenimental }\end{array}$ \\
\hline 1400 & 67.2 & 60 \\
\hline 1425 & 33.7 & 38 \\
\hline 1450 & 17.2 & 19 \\
\hline 1475 & 9 & 8 \\
\hline
\end{tabular}

The factors affecting on this percent error of curve fitting can be summarized as follows:

(i) Due to the limitations of the experimental equipment the results were only obtained for a short temperature range. They were utilized in prediction of lot larger temperature range. 
CHAPTER 4 RESULTS AND DISCUSSIONS -102-

(ii) At lower temperatures the sequences of the chemical reactions change due to thermodynamic constraints. (The sequence of chemical reactions was assumed to be independent of temperature through out the calculations)

(iii) The rate expression was assumed to the $1 /$ the furnace residence time required for pig iron nugget production. This rate expression is diffusion and reaction dependent. At the beginning the nugget formation the system was diffusion limited since the carbon diffusion in to solid iron was slow. However after sufficient carbon diffusion and melt formation the system becomes reaction limited (diffusion of carbon in to molten iron is faster). Thus, the rate expression changes with respect to changing character of the system were not taken into consideration through out the calculations. 
CHAPTER 4 RESULTS AND DISCUSSIONS -103-

\subsubsection{Summary of the Experimental Results}

Three chemically and physically different products were produced after the reduction of magnetite to iron, as a function of furnace temperature and/ or residence time. These products were:

- D irect Reduced Iron (D RI)

Solid state product with no slag separation

- Transition D irect Reduced Iron (TD RI)

Liquid and solid state product with partial slag separation

- $\quad$ Pig Iron N uggets (PIN)

Liquid state products with complete slag separation, high iron yield

Comparison of the some important properties of the direct reduced iron, transition direct reduced iron and pig iron nuggets produced is shown in Table 4.XIV . The transition between production of direct reduced iron to transition direct reduced iron to pig iron was accomplished by increasing the operational furnace temperature and/ or residence time. This was due to increasing carbon diffusion to metal producing melt formation with increasing furnace temperature and/ or residence time. 


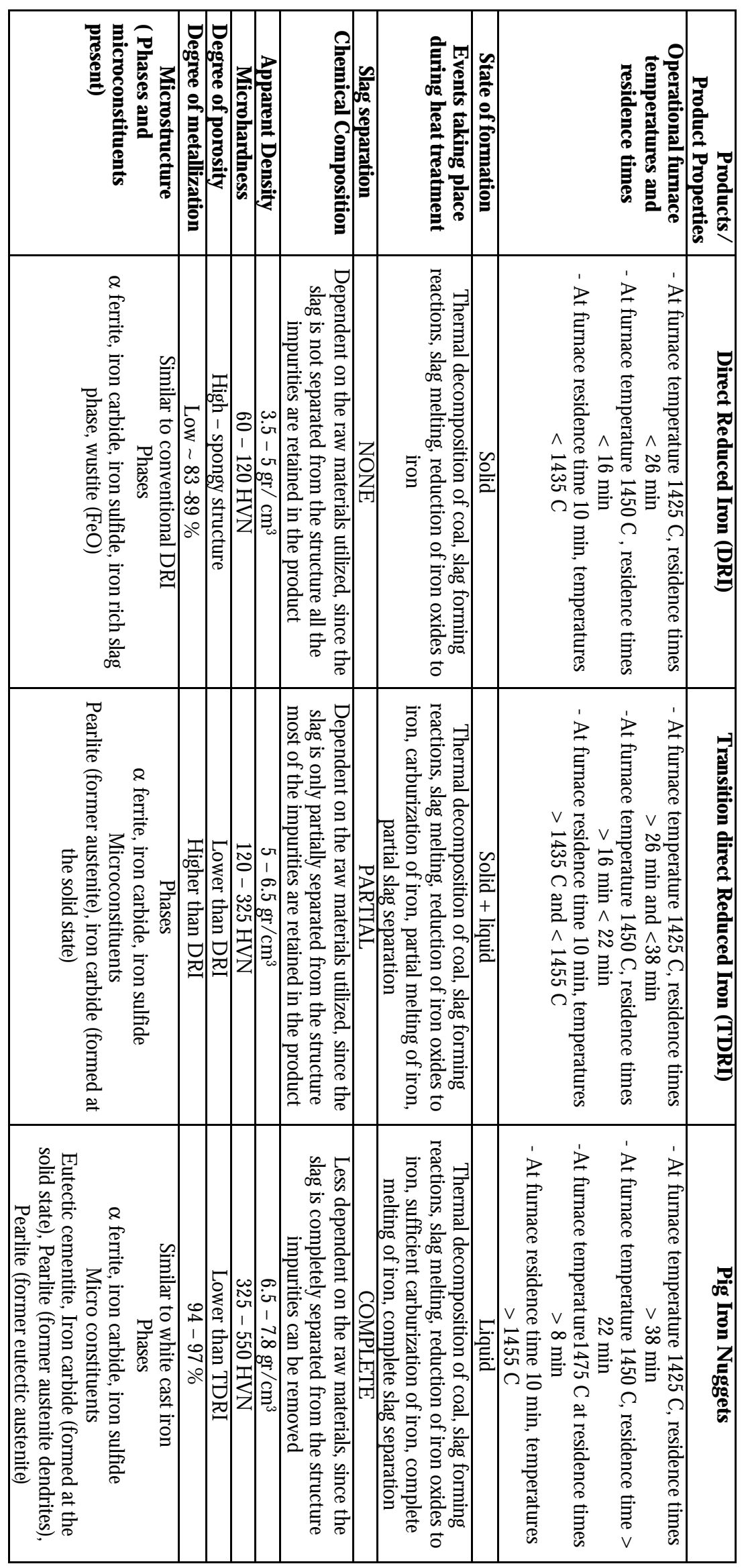

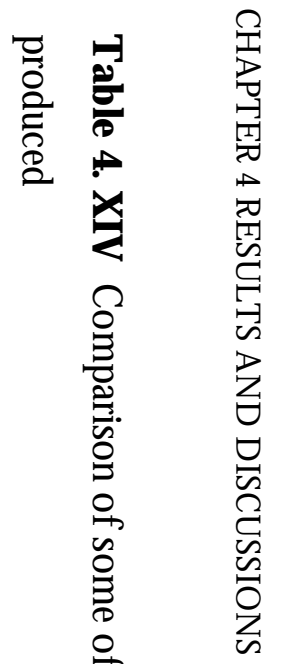

宫

思 客

趸

$\circ$

응

䨖

8

홍

范

咢.

ㄹ.ᅲ.

零

ఠี

통.

苇

으.

옹

䓌 


\section{Chapter 5 Conclusions}

This research investigated the technical feasibility of producing pig iron nuggets which have similar chemical and physical properties with blast furnace pig iron. These pig iron nuggets were produced from dried green balls containing magnetite, limestone, coal, and bentonite by a single step process. Their production was dependent on the furnace operational temperatures and residence times, since the furnace operational temperatures and residence times dictated the melt formation which results in slag separation.

Solid, high density, slag free, pig iron nuggets were produced in a laboratory scale resistance box furnace at varying furnace temperatures and residence times. The pig iron nugget produced had similar physical and chemical properties to blast furnace pig iron. The furnace temperature and residence time threshold for pig iron nugget production is shown in Figure 5.1. 


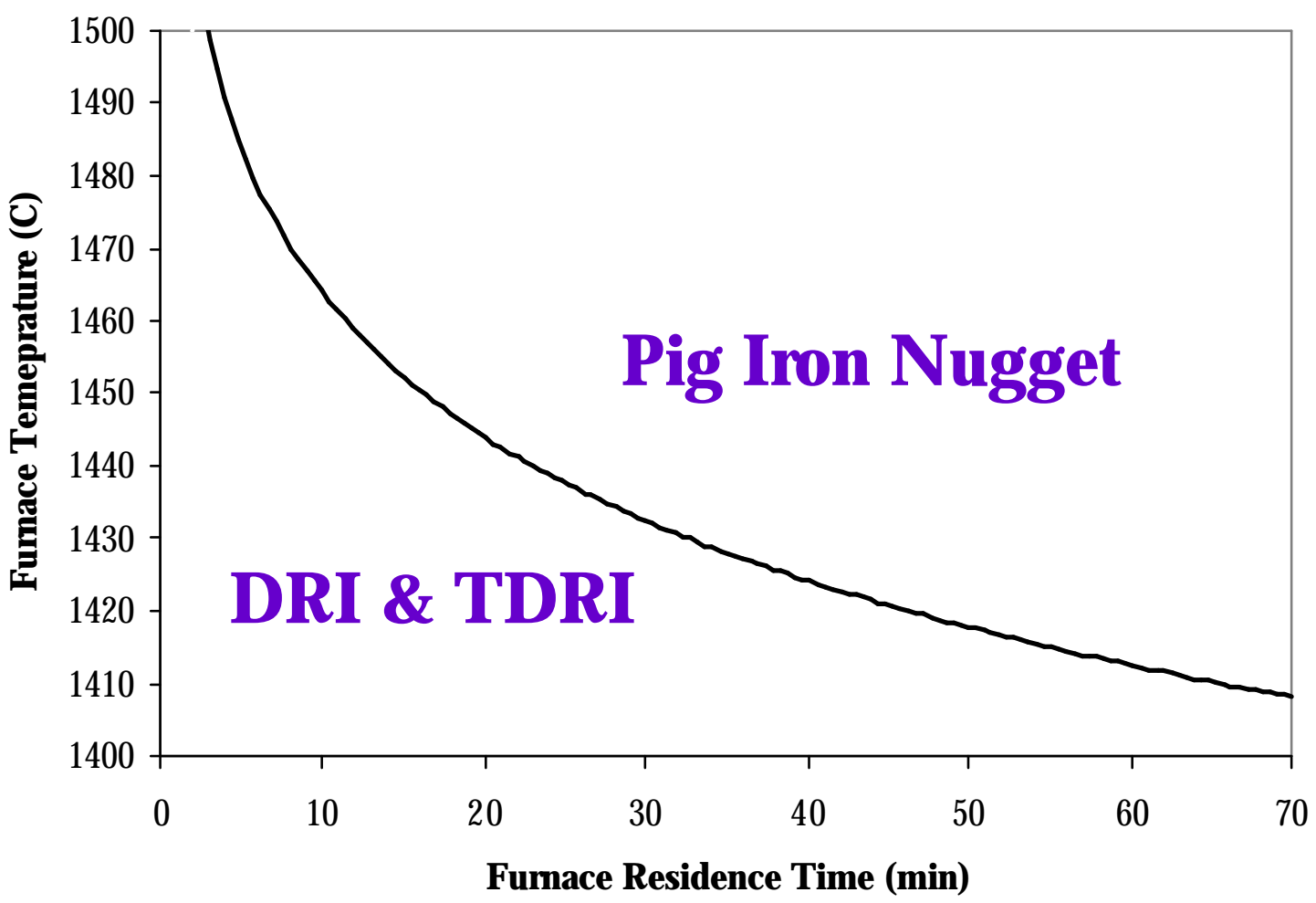

Figure 5.1 The plot representing the formation and production regions of DRI, TDRI and pig iron nuggets.

D uring pig iron nugget production as the furnace temperature and residence time increased, (i) the degree of metallization was increased, (ii) porosity was reduced, (iii) amount of bulk carbon dissolved in the metal was increased. The increased degree of metallization and reduced porosity was indicated by increased apparent density. The increased amount of carbon dissolved was indicated by increased Microhardness values. 


\section{References}

1) Anameric B. and Kawatra S.K., 2004, A Laboratory Study Relating to the Production and Properties of Pig Iron Nuggets, 2004 A nnual SME M eeting, Metallurgical Process Fundamentals: Pyrometallurgical Processing Session (Preprint number 04-98)

2) Anameric B., Kawatra S.K. and Rundman K.B., 2005, Carburization Effects on the Pig Iron Nugget Production, 2005 A nnual SME M eeting, Metallurgical Process Fundamentals: Pyrometallurgical Processing Session

3) Abraham M.C. and Gosh A., Kinetics of Reduction of Iron Oxide by Carbon, Ironmaking and Steølmaking, 6, pp 14-23, 1979

4) Agrawal B.B., Prasad K.K., Sarkar S.B., Ray H.S., 2000, Cold Bonded Ore- Coal Composite Pellets for Sponge Iron Making Part 1 Laboratory Scale D evelopment, Ironmaking \& Steelmaking, Vol 27, part 6, pp 421-425

5) ASTM B 311-93, 2002, D ensity D etermination for Power Metallurgy (P/ M) Materials Containing Less Than Two Percent Porosity, Annual Book of ASTM Standards, Volume 02.05 (N onferrous M etal Products, Metallic and Inorganic Coatings, Metal Powders, Sintered P/ M Structural Parts), pp. 86-89 
- 108 -

6) ASTM E 3, 2001, Standard Guide for Preparation Of Metallographic Specimens, Annual Book of ASTM Standards, Volume 03.01 (M etals Test M ethods and A nalytical Prooedures, Metals, Mechanical testing, elevated and Low-temperature Tests, Metallograhpy), pp. 1-11

7) ASTM E 92-82, 1997, Standard Test Method for Vickers Hardness of Metallic Materials, Annual Book of ASTM Standards, Volume 03.01 (M etals T est M ethods and A nalytical Procedures, Metals, Mechanical testing, elevated and Low-temperature Tests, Metallograhpy), pp. 229-237

8) ASTM E 384, 1999, Standard Test Method for Microindentation Hardness of Materials, Annual Book of ASTM Standards, Volume 03.01 (M etals T est M ethods and A nalytical Procedures, Metals, Mechanical testing, elevated and Low-temperature Tests, Metallograhpy), pp. $418-427$

9) ASTM E 407 ,1999, Standard Practice for Microetching Metals and Alloys, Annual Book of ASTM Standards, Volume 03.01 (M etals T est Methods and A nalytical Procedures, Metals, Mechanical testing, elevated and Low-temperature Tests, Metallograhpy), pp. 474-493

10) ASTM E 794 ,2001, Standard Test Method for Melting and Crystallization Temperatures by Thermal Analysis, Annual Book of ASTM Standards, Volume 14.02 (G eneral M ethods and Instrumentation, General Test Methods; Forensic Sciences; Terminology; Conformity Assessment; Statistical Methods), pp. 262-265 
-109 -

11) ASTM E 1131 ,1998, Standard Test Method for Compositional Analysis by Thermogravimetry, Annual Book of ASTM Standards, Volume 14.02 (G eneral M ethods and Instrumentation, G eneral Test Methods; Forensic Sciences; Terminology; Conformity Assessment; Statistical Methods), pp. 304-308

12) Ashby M.F. and Jones D.R., 1986, E ngineering M aterials 2 , An Introduction to Microstructures, Processing and D esign, Pergamon Press, pp. 10

13) Basu P., Syamaprasad U., Jouhari A.K. and Ray H.S., 1995, Smelting Reduction Technologies for Direct Ironmaking, Mineral Procssing and E x tractive M etallurgy R eview, Vol 12, p. 223 - 255

14) Blomgren S. and Tholander E., 1986, Influence of the O re Smelting Course on the Slag Microstructures at Early Ironmaking, Usable as Identification Basis for the Furnace Process Employed, Scandinavian Journal of M etallurgy, 15,pp.151-160

15) Brown M.E., Dollimore D. and Galwey A.K., 1980, Reactions in the Solid State, Comprehensive C hemical Kinetics, Vol.22, Elsevier, Amsterdam

16) Callister W.D ., 1997, Materials Science and Engineering, An Introduction, $4^{\text {th }}$ edition, John Wiley and Sons, Inc.

17) Chatterjee A., 1994, Beyond the Blast Furnace, CRC Press 
-110 -

18) D avis J.R. ,1990, M etals H andbook, Properties and Selection: Irons, Steels, and High Performance Alloys, ASTM International, $10^{\text {th }}$ edition, Volume 1, pp. 93

19) D avis C.G., McFarlin J.F., Pratt H.R., Direct Reduction Technology and Economics, Ironmaking and Stelmaking, Vol 9, No 3

20) Fruehan R.J., The Rate of Reductionof iron Oxides by Carbon, M etallurgical and M aterials T ransactions B, V ol 8, pp. 279-286, 1977

21) Ghosh P.C. and Tiwari S.N., Reduction of Pellets of Iron ore Plus Lignite Coke, ISIJ International, Vol 208, pp. 255-257, 1970

22) Goksel M. A., 1977, Fundamentals of Cold Bond Agglomeration Processes, Agglomeration 77. Vol. 2. AIME, New Y ork., 877-900

23) G oksel A., Coburn J., and Kohut J., 1991, Recycling Waste Oxide from Iron--Steel Plants Using the PTC Process, Ironmaking Conference Procedings. Vol. 50; Washington, D C; USA; 14-17 A pr. 1991. pp. 97112.

24) Goksel A., Scott T. A., Weiss F., and Coburn J.,1988, PTC-Cold Bond Agglomeration Process and Its Various Applications in the Iron and Steel Industry, Institute for Briquetting and A gglomeration, 20th Biennial C onference. Vol. 20; O rlando, Florida; USA; Sept. 1987. pp. 191-213. 
25) Haque R. and Ray H.S., 1995, Communication: Role of Ore/ Carbon Contact and Direct Reduction in the Reduction of Iron O xide by Carbon, M etallurgical and M aterials T ransactions. B, Process M etallurgy and Materials Processing Science., Vol 26, No 2, pp 400,

26) Heine R.W. and Barton J.E., 1977, Eutectic Solidification of White Iron and Its Effects on Malleable Iron Castings, Transactions of the American Foundarymen's Society, Vol. 85, pp. 379-388

27) Jana S. and Teoh L.L, 1985, Application of Direct Smelting Technology in Southeast Asia, South E ast A sia Iron and Steel Institute Q uarterly, Vol 14, Issue 4, p 23-38

28) Kawatra S.K. and Ripke S.J.,2001, D eveloping and Understanding the Bentonite Fiber Bonding Mechanism, Minerals E ngineering, Elsevier Press, Volume 14, No 6, pp. 647-659,

29) Kobayashi I., Tanigahi Y. and Uragami A, 2001, A New Process to produce Iron Directly From Fine Ore and Coal, Iron and Stelmaker, Vol 28, Issue 9, p 19- 22

30) Krauss G . 1990, Microstructures, Processing and Properties of Steels, M etals H andbook, Properties and Selection: Irons, Steels, and High Performance Alloys, ASTM International, $10^{\text {th }}$ edition, Volume 1, pp.126, and 127,132 
- 112 -

31) Lankford W.T., Samways N.L., Craven R.F. and McGannon H.E., 1985, The Making, Shaping and Treating of Steel, United States Steel, $10^{\text {th }}$ edition

32) Leckie A.H., Millar A. and Medley J.E., 1982, Short - and LongTerm Prospects for Energy Economy in Steel Making, Ironmaking and Steelmaking, Vol 9, No 5

33) Lide D .R., 2001-2002, $\mathrm{H}$ andbook of Chemistry and Physics, CRC Press, $82^{\text {nd }}$ edition, pp. 4-62,4-63

34) Maddin R.,1975, Early Iron Metallurgy in the Near East, Transadions of the Iron and Steel Institute of Japan, Volume 15, Number 2, pp.38-68

35) Mampaey F., 2001, Cast Iron, Div. 5 - Solidification Morphology of White Cast Iron, Transactions of the A merican F oundarymen's Society, 109, pp.1049-1059

36) Manning C.P., Fruehan R.J., 2001, Emerging Technologies for Iron and Steel Making, J0 M , 53 (10), pp 20-23

37) Mazurak R.E., A pril 2003, Ironmaking Industry Trends and Directions, Mining E ngineering, Vol. 55, N0 4, p 12-17

38) Mehl F.R., Microstructure of Cast Irons, M etals $H$ andbook, 1972, Atlas of Microstructures of Industrial Alloys, ASTM International, $8^{\text {th }}$ edition, Volume 7, pp. 95,99 
- 113 -

39) McG owan D. ,2003, The ABCs of Steel Metallurgy, W elding Journal, http:// www.aws.org/ wj/ feb03/ feature2.html

40) Mourao M.B. and Capacchi J.D.T., 1996, Rate of Reduction of Iron Oxide in Carbon-bearing Pellets, Transaction of the Institute of Mining and M etallurgy, Volume 105, C 151-204, pp. 190-196,

41) Morton G . and Wingrove J. ,1969, Constitution of Bloomery Slags: Part I: Roman, Journal of The Iron and Steel Institute, Volume 207, Part 12, pp.1556-1969

42) Morton G . and Wingrove J. 1969, Constitution of Bloomery Slags: Part II: Medieval, Journal of the Iron and Stel Institute, Volume 210, Part 7, pp.478-489

43) Moore JJ., 1982, An Example of the New Direct Smelting Processes for Iron and Steelmaking, Journal of M etals, p 39 - 48

44) Nascimento R. C., Mourao M. B. and Capocchi J.D.T.,1997, Microstructures of Self-reducing Pellets Bearing Iron Ore and Carbon, ISIJ International, Vol 37., No 11, pp. 1050-1056.

45) Nascimento R. C., Mourao M. B. and Capocchi J.D.T., 1998, Reduction-Swelling Behavior of Pellets Bearing Iron O re and Charcoal, Canadian M etallurgical Q uarterly, Volume 37, No 5, pp. 441448. 
- 114 -

46) Nascimento R. C., Mourao M. B. and Capocchi J.D.T., 1999,

Kinetics and Catastrophic Swelling D uring Reduction of Iron O re in Carbon Bearing Pellets, Ironmaking and Steelmaking Vol 26, No 3, pp. 182-186.

47) Park J.S. and Verhoeven J.D. , 1996, D irectional Solidification of White Cast Iron, M etallurgical and M aterials T ransactions A , Vol. 27A, no.8, pp. 2328-2337

48) Peacey J.G . and Davenport W.G . , 1979, The Blast Furnace Theory and Practice, Petgamon Press, $1^{\text {st }}$ edition

49) Rao Y.K., 1971, The Kinetics of Reduction of Hematite by Carbon, Metallurgical and Materials Transadions, $\mathrm{V}$ ol 2, pp. 1439-1447

50) Radzikowska J. and Voort G.V. , D ecember 1998, The Basics of Cast Iron Metallography, Modern Casting, pp. 46-48

51) Seaton C.E., Foster J.J. and Velasco J., 1983, Reduction Kinetics of Hematite and Magnetite Pellets Containing Coal Char. ISIJ International, Vol 23, pp. 490-496.

52) Smith W.F. , 1993, Structure and Properties of Engineering Alloys, McG raw-Hill Materials Science and Engineering Series, $2^{\text {nd }}$ Edition, pp. 1-41, 82-

53) Steffen R. and Lungen H-B., March 2004, State of the Art Technology of Direct and Smelting Reduction of Iron Ores, L a Revue de M etallurgie, $\mathrm{p}$ 171-182 
54) Srinivasan N.S. and Lahiri A.K., 1977, Studies in the Reduction of Hematite by Carbon, $M$ etallurgical and $M$ aterials T ransactions $B$, 8, pp 175-178.

55) Shackelford J.F, Alexander W., Park J.S., 1994, M aterials Scienœ E ngineering $\mathrm{H}$ andbook, CRC Press, $2^{\text {nd }}$ edition, pp. 46-49

56) True B.G ., July 1983, Trends in Ironmaking Technology, Steel Times, p 375-376

57) Teoh J.J., 1985, Recent D evelopments and Trends in Direct Reduction Technology, South E ast A sia Iron and Steel Institute Q uarterly, Vol 14, p 15 - 30

58) Vander Voort G.F. and Lucas G.M., 1998, Microindentation Hardness Testing, Advanced Materials and Processes Vol 154, no 3, pp. 21-26

59) Vander Voort G.F, 1984 , Metallography, Principles and Practice, McGraw-Hill Publications

60) Vander Voort G.F, 1986, Applied Metallography, New York Van Nostrand Reinhold Publications

61) Vander Voort G.F. , 1999, Metallography, Princliples and Practice, A SM International, Materials Park Oh 
- 116 -

62) Weiss N.L. , 1985, SME Mineral Processing Handbook, SME Publication, pp. 37-8

63) Weiss F. J., Goksel M. A. ,Apr. 1987, and Scott T.A., The Production of Hot Metal by the PTC (Pellet Technology Corporation) Process, T ool and A lloy Støls. Vol. 21, no. 4, pp. 105108.

64) Tsuge $O$., Kikukuchi S., and Tokuda K., 2002, Successful Iron Nugget Production at ITmk3 Pilot Plant, $61^{\text {st }}$ Ironmaking Proceedings, N ashville, T ennessee

65) Zervas T., McMullan J.T. and Williams, 1996 (a), D evelopments in Iron and Steel Making, International Journal of E nergy Research, Vol 20, p 69-91

66) Zervas T., McMullan J.T. and Williams, 1996 (b), Gas-Based Direct Reduction Processes for Iron and Steel Production, International Journal of E nergy Research, Vol 20, p 157-185

67) Zervas T., McMullan J.T. and Williams, 1996 (c), Solid-Based Processes for the Direct Reduction of Iron, International Journal of E nergy Research, Vol 20, p 255 - 278

68) Zervas T., McMullan J.T. and Williams, 1996 (d), Direct Smelting and Alternative Processes for the Production of Iron and Steel, International Journal of E nergy Research, Vol 20, p 1103-1128 